\title{
Actitud emprendedora en Instituciones de Educación Superior de Guanajuato
}

Adriana Fragoso Mora, Ma. Eugenia Sánchez Ramos, Juan Tomás Oliva Ramos, Laura Elena Zárate Negrete, Rosalba Pérez Márquez y Alba Edith Elías Chávez

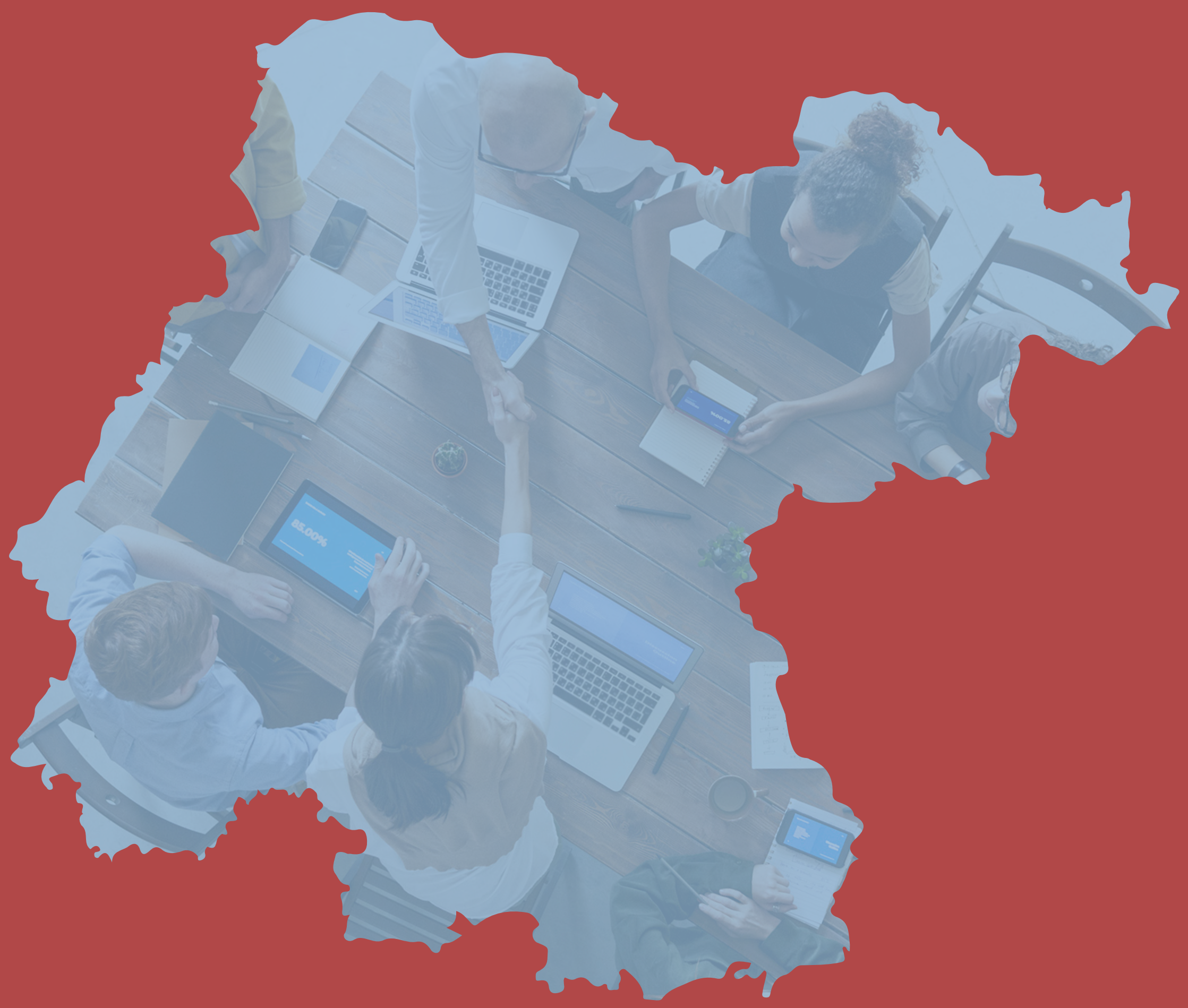

Qartuppi 


\section{(c) () ()}

Esta obra se edita bajo una Licencia Creative Commons Atribución-NoComercial-CompartirIgual 4.0 Internacional. 


\section{Actitud emprendedora en Instituciones de Educación Superior de Guanajuato}

Adriana Fragoso Mora, Ma. Eugenia Sánchez Ramos, Juan Tomás Oliva Ramos, Laura Elena Zárate Negrete, Rosalba Pérez Márquez y Alba Edith Elías Chávez

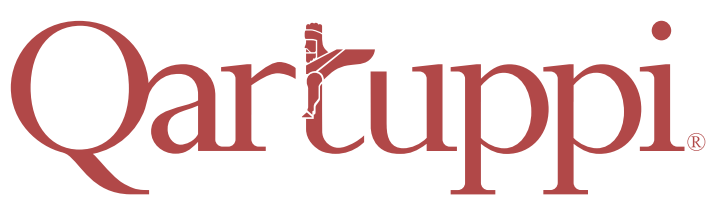




\section{Dictaminadores:}

Dr. Ernesto León Castro

Universidad Católica de la Santísima Concepción

Dr. Víctor Alfaro García

Universidad Michoacana de San Nicolás de Hidalgo

Dra. Carmen Dolores Barroso García

Universidad de Guanajuato

Mtra. Sara Eréndida Ramírez Moreno

Universidad de Guanajuato, Campus León

\section{Actitud emprendedora}

en Instituciones de Educación Superior de Guanajuato

1era. edición, mayo 2021

ISBN 978-607-8694-09-9

DOI 10.29410/QTP.21.08

D.R. (C) 2021. Qartuppi, S. de R.L. de C.V.

Villa Turca 17, Villas del Mediterráneo

Hermosillo, Son. 83220 México

http://www.qartuppi.com

Edición y Diseño: Qartuppi, S. de R.L. de C.V.

Diseño de portada: León Felipe Irigoyen Morales 
Los autores reconocen y agradecen el apoyo de las siguientes instituciones:

Tecnológico Nacional de México TecNM, Campus Purísima del Rincón (ITSPR) como caso de estudio de la presente investigación.

Secretaría de Innovación, Ciencia y Educación Superior del Estado de Guanajuato (SICES) por el financiamiento de la obra a partir de la Convocatoria Apoyo a la Producción para el Fortalecimiento de Cuerpos Académicos, 2019.

División de Ciencias Económico-Administrativas DCEA perteneciente a la Universidad de Guanajuato como caso de estudio de la presente investigación. 


\section{Tabla de contenido}

Prólogo

Eduardo Topete Gómez

Capítulo 1

Emprendimiento en México

Alba Edith Elías Chávez y Rosalba Pérez Márquez

Capítulo 2

Actitudes y factores determinantes para el emprendimiento en estudiantes de Educación Superior Tecnológica

Adriana Fragoso Mora y Juan Tomás Oliva Ramos

Capítulo 3

Perfil emprendedor en estudiantes universitarios

Laura Elena Zárate Negrete, Ma. Eugenia Sánchez Ramos

y Lizeth Alejandra Contreras Lemus

Acerca de los autores 


\section{Prólogo}

Este libro llega en el momento preciso, cuando México y el mundo se enfrentan a retos únicos, en donde se abren las oportunidades de emprender con nuevas tecnologías, por las necesidades presentadas a raíz de una pandemia y qué mejor que contar con esta obra dirigida a estudiantes universitarios y a personas con espíritu emprendedor, ya que tendrán una guía que los lleve a crear o innovar productos que satisfagan las necesidades actuales.

Se ha despertado un interés incluyente en el ámbito del emprendimiento que lleva no solo a desarrollar y presentar proyectos, sino también a buscar medios económicos para llevar a cabo dichos proyectos, aprovechando las oportunidades en diferentes sectores económicos que faciliten los recursos, con el objetivo de que haya un desarrollo importante en el crecimiento del país.

El libro se divide en tres capítulos, el primero es Emprendimiento en México, en donde se explica su concepto, sus antecedentes históricos en el mundo y en nuestro país. Después, se describen los apoyos que existen para los emprendedores, concursos nacionales e internacionales, incubadoras, crowdfunding, aceleradoras de empresas, capital de riesgo y toda una serie de fuentes de financiamientos tanto públicos como privados, de los que se dispone en la actualidad. Por último, se muestra una guía de los requisitos legales que deben cumplir los emprendedores para iniciar su empresa desde cero. 
Posteriormente, en el segundo capítulo Actitudes y factores determinantes para el emprendimiento en estudiantes de Educación Superior Tecnológica y en el tercero titulado Perfil emprendedor en estudiantes universitarios, se presentan los resultados de dos casos de estudio para identificar y evaluar las actitudes orientadas hacia el emprendimiento entre los estudiantes del Instituto Tecnológico Superior de Purísima del Rincón y de la Universidad de Guanajuato, respectivamente. Para llegar a estos resultados se aplicó el Modelo Montufar (2018), el cual considera aspectos cognitivos, afectivos, emocionales y conductuales de los emprendedores.

En ambos capítulos, se analizan variables como Autoeficiencia Percibida, Autonomía, Innovación, Propensión al Riesgo y Actitud hacia el Emprendimiento, sustentadas con las encuestas aplicadas a estudiantes de diferentes programas educativos en ambas Instituciones de Educación Superior (IES), resultados que resaltan la importancia de formar emprendedores, hacer las gestiones para nuevos proyectos y despertar en el estudiante esta visión desde su formación académica.

La propuesta del nuevo Modelo Educativo va enfocada hacia las profesiones del futuro y la formación de un egresado como agente de cambio, avalado en las declaraciones de la UNESCO y de la nueva Revolución Industrial, con un eje académico que lo caracteriza por atender necesidades del estudiante para cumplir con sus objetivos educacionales.

Es pertinente resaltar la cooperación académica entre ambas IES enfocadas al sector productivo regional y al desarrollo del conocimiento, habilidades y actitudes de los estudiantes universitarios. Mi reconocimiento al cuerpo docente que participó en este libro y que se ocupa en investigar todo aquello que abona al perfil emprendedor.

Finalmente, me congratulo decir que el propósito de esta obra es despertar el interés tanto en estudiantes, docentes, empresas e instituciones, en crear o innovar nuevos proyectos con una visión sostenible dentro de un entorno con cambios estructurales profundos para nuestra sociedad.

M. A. Eduardo Topete Gómez Jefe de División de Ingeniería en Gestión Empresarial Instituto Tecnológico Superior de Purísima del Rincón 


\title{
Capítulo 1
}

\author{
Emprendimiento en México
}

Alba Edith Elías Chávez y Rosalba Pérez Márquez 


\section{Capítulo 1}

\section{Emprendimiento en México}

Alba Edith Elías Chávez y Rosalba Pérez Márquez

El espíritu emprendedor es una de las características que determina el crecimiento, la transformación y el desarrollo de un nuevo sector económico en una región o país. El emprendimiento adquiere gran relevancia pues constituye un factor que impulsa la economía, el progreso y el nivel de bienestar de la sociedad, a través de la creación de oportunidades de trabajo, el fomento de la innovación, la estimulación de la competitividad, entre otros factores.

El principal detonante de la actividad emprendedora suele estar relacionado con un estado de alerta, a partir del cual se genera una idea de negocio para dar respuesta a una necesidad (Torres, 2016); en la mayoría de los países, surge cuando hay una crisis económica. Sin embargo, esta actividad emprendedora se ve condicionada tanto por las características de las personas como por su contexto.

Para enfrentar los desafíos actuales, se requiere la cooperación de diferentes participantes de la sociedad. El apoyo del gobierno y las instituciones privadas será crucial para el desarrollo de emprendimientos conjuntos, ya que a través de esto se pueden generar nuevas ideas, dando como resultado grandes empresas.

Dada la importancia del tema, en el presente capítulo se tienen como objetivo realizar un estudio documental histórico interpretativo del concepto emprendedor median- 
te una revisión semántica, así como sus antecedentes históricos. Se busca, además, (a) comprender la realidad y el fenómeno emprendedor en México, (b) conocer los tipos de financiamiento para el emprendimiento y los servicios de acompañamiento a emprendedores, y (c) proporcionar una guía de requisitos legales básicos que deben cumplir los emprendedores al iniciar su negocio.

\section{Definición de emprendimiento}

La palabra emprendimiento proviene del francés entrepreneur, que significa pionero, y se refiere a la persona que tiene la capacidad y las habilidades para hacer esfuerzos adicionales para lograr un objetivo establecido (Gutiérrez, 2015); también puede significar que esa persona está dispuesta a ejercer su decisión. Por lo tanto, se considera que el emprendimiento es la capacidad de diseñar una idea y, con base en ella, implementar un proyecto a través de la identificación de oportunidades.

$\mathrm{Al}$ respecto, de acuerdo con Jean Baptise Say, un emprendedor es todo aquel individuo que toma riesgos y tiene habilidades para evaluar proyectos y movilizar recursos para lograr una meta. Por su parte, Schumpeter afirmó que un emprendedor es una persona dinámica, que promueve nuevas opciones o innovaciones y que tiene como características la visión, el liderazgo, y la iniciativa. Por lo tanto, considera que el emprendimiento es el motor que impulsa la innovación y, promueve el desarrollo económico (Rivera, 2011).

La innovación y el emprendimiento son motores esenciales de la competitividad y del crecimiento de la economía; se ha observado una correlación positiva entre su fomento y los resultados económicos de los países, en términos de la creación de empleo, incremento de productividad, y avances tecnológicos. Por ello, hay un interés generalizado en su estudio y en mejorar las capacidades de emprendimiento de los ciudadanos, lo cual supone el desarrollo de actitudes y habilidades, pero también el aprendizaje de una serie de conocimientos (Cavero \& Ruiz, 2017).

En este sentido, el emprendimiento es considerado un mecanismo de transferencia de conocimiento porque las ideas se plasman en la creación de empresas (Martínez-Climent et al., 2020). Las universidades tienen un papel importante tanto en la generación como en la transferencia de conocimiento para el fomento de nuevas iniciativas empresariales. Por lo tanto, de manera coherente, se ha implementado una amplia gama de políticas para fomentar su formación con la esperanza de estimular la innovación y el desarrollo económico local (Civera et al., 2018). 


\section{Antecedentes históricos del emprendimiento en el mundo}

El emprendimiento ha estado presente desde el comienzo de la historia, el hombre siempre está tratando de encontrar mejores formas de llevar a cabo las actividades cotidianas y mejorar la calidad de vida.

La actividad emprendedora ha sido considerada desde siempre un mecanismo importante para el desarrollo económico (Schumpeter, 1934; Landes,1998). Este vínculo se observa cuando los emprendedores crean nuevos negocios, los nuevos negocios requieren generar empleos, se intensifica la competencia, e incluso aumenta la productividad a través de cambios tecnológicos (Acs y Amorós, 2008). (Cancino et al., 2012, p.19)

Este mecanismo se basa tanto en actividades económicas como sociales realizadas por individuos organizados, los cuales pueden o no, llamarse emprendedores. Esta posibilidad está relacionada con la complejidad, y el término cambia según su evolución histórica.

El término emprendimiento fue introducido por Richard Cantillón en 1755, quien conceptualizó el término emprendedor como aquel agente que compra los medios de producción con la intención de obtener nuevos productos (Duarte \& Ruiz, 2009). Este autor fue el primer teórico que resaltó la importancia del emprendimiento en la economía, relacionando los aspectos de oferta y demanda (Cherukara \& Manlel, 2011). Posteriormente, en 1803, Jean Baptiste Say (citado en Terán-Yepez \& Guerrero-Mora, 2020) definió al emprendedor como aquel que asume riesgos, evalúa y moviliza recursos hacia una alta productividad; además, es capaz de coordinar, combinar los factores de producción y realizar actividades gerenciales. La concepción de ambos autores permite comprender la importancia del emprendedor en la economía.

En relación con la definición histórica del emprendedor, Oliva (2018) comenta que:

Usualmente, el término designa a individuos dispuestos a enfrentar riesgos económicos e incertidumbre financiera con el firme propósito de materializar sus ideas en productos innovadores o negocios exitosos. Aún más, tanto el concepto de emprendedor, así como la práctica del emprendimiento, se legitiman continuamente gracias a las numerosas historias acerca de personas sumamente creativas que logran monetizar sus ideas y, de esta manera, alcanzan 
el éxito monetario y personal. De hecho, el emprendedor ha sido considerado un agente clave del desarrollo económico desde inicios del siglo pasado, cuando Schumpeter (1883-1950) lo caracterizaba como un individuo cuyas habilidades y capacidades lo diferenciaban radicalmente de otros actores sociales (Nafziger, 2006). (p.448)

Acs y Amorós (2008 citados en Cancino et al., 2012) perciben al emprendedor como impulsor del desarrollo económico de una región, a través de la creación de nuevos negocios, e intensificando la competencia y la productividad por medio la aplicación de tecnología. En este sentido definen al emprendedor como la criatura compleja de múltiples dimensiones de acuerdo con el tamaño de la organización en la que colaboran:

1. Intra-emprendedores o emprendedores corporativos dentro de grandes empresas.

2. Emprendedores de autoempleo, co-creando empresas pequeñas o empresas habituales.

3. Emprendedores por sucesión en empresas o cambio de la titularidad o gestión de la sucesión.

Esta concepción del emprendedor como agente clave del desarrollo económico, ya había sido considerada por Schumpeter (citado en Oliva, 2018) al afirmar que se caracterizaba por ser un ente innovador en las organizaciones, que hace posible el crecimiento y el consumo masivo.

A esta corriente eminentemente económica se suma Nafziger (2006), quien inserta la concepción del emprendedor centrada en el individuo como factor clave, capaz de tener una idea innovadora y llevarla a cabo. Coincidiendo de esta forma con la visión inicial emitida por Schumpeter, sobre los tipos de emprendedores:

1. Emprendedores investigadores. Aquellos capaces de transformar una nueva invención en un cambio tecnológico comercializable a partir de ideas o descubrimientos tecnológicos originales.

2. Emprendedores imitadores. Actores capaces de imitar tecnología desarrollada en otro lugar, respecto a un producto existente.

Ambos tipos de emprendedores, facilitadores iniciales y esenciales del proceso de crecimiento económico (Acs et al., 2004; Schumpeter, 1934 citados en Arroyo, 2016). 
Otras áreas del conocimiento como la administración y las ciencias políticas también hicieron aportaciones significativas en la conceptualización y teoría del emprendimiento, así como en la relación con la innovación de estos términos. Petuškienė y Glinskienė (2017) combinan la ciencia política y la administración, al proponer que los recursos del estado se enfoquen en obras de emprendimiento para brindar estabilidad social. Asimismo, distinguen entre la creación de una empresa y la orientación de una estrategia empresarial basada en crecimiento e innovación.

Por su parte, el fenómeno emprendedor fue explicado por Stevenson y Jaramillo (1990, citados en Terán-Yépez \& Guerrero-Mora, 2020) analizando las siguientes tres preguntas de investigación: qué sucede cuando los emprendedores actúan, por qué, y cómo actúan. A partir de este planteamiento, se consideró que hay cuatroáreas principales de investigación en el emprendimiento: la psicología, la sociología, la economía y la gestión empresarial, permitiendo que la investigación de la teoría sobre emprendimiento se pueda realizar a través de uno o más de ellos (Chu, 1998 citado en Terán-Yépez \& Guerrero-Mora, 2020).

Respecto al espíritu emprendedor, es relevante subrayar su estudio desde el ámbito de la psicología, ciencia que permite comprender, evaluar y transformar el comportamiento humano hacia desempeños sobresalientes, incluso relacionados con el aprendizaje y sus resultados en distintos contextos geográficos, generacionales o socio-globales del comportamiento humano.

El proceso de enseñanza-aprendizaje de los emprendedores en las universidades y nuevas empresas es una prioridad para impulsar el desarrollo económico y social de un país, por lo que es necesario reforzar el estado del arte del emprendimiento con investigaciones de autores contemporáneos y de vanguardia.

Dentro de los autores contemporáneos en el tema de emprendimiento, podemos encontrar a: (a) Etzkowitz y Leydesdorff (2000), quienes identificaron la dinámica de innovación en Modelos de Triple Hélice, en la relación universidad-industria-gobierno como impulsores del emprendimiento; (b) Acs et al. (2004) quienes definieron el emprendimiento como la base del desempeño económico de un país; (c) Baker y Nelson (2005), quienes exploraron el comportamiento de las pequeñas empresas, capaces de crear algo desde cero, explotando insumos físicos, sociales o institucionales que otras empresas rechazaron; (d) Doherty et al. (2014), quienes identificaron la hibridez, la creación del emprendimiento desde la búsqueda de la doble misión de sostenibilidad financiera y propósito social. Evalúan el impacto de la hibridación en la gestión de la misión social empresarial, la adquisición de recursos financieros y la movilización de recursos humanos, 
y presentan un marco para comprender las tensiones y compensaciones resultantes de la hibridación.

Dentro de los autores con enfoques novedosos y emergentes sobre el tema de emprendimiento se identifican autores como: (a) Ratten y Jones (2018), quienes exponen el concepto de emprendimiento transformacional, y cómo a través del uso de prácticas comerciales novedosas se reduce la desigualdad en el mercado y cómo se transforma la sociedad a través de soluciones creativas; (b) Kraus et al. (2017), quienes desarrollaron una escala de medición para el emprendimiento social; (c) Urbano et al. (2019), quienes proporcionan información sobre el campo del espíritu empresarial, la innovación y la gestión estratégica; (d) Audretsch y Moog (2020), quienes sugieren que el espíritu empresarial está indisolublemente ligado a un valor fundamental común entre las economías desarrollas occidentales, la democracia.

Como se puede observar, el emprendimiento es un tema de gran relevancia en la actualidad, porloqueexisten esfuerzosanivelglobalparadarleimpulso,sobretodo,atravésdel conjunto denominado "Triple hélice de desarrollo", que "consiste en la relación universidadgobierno-empresa. Esta relación impulsa las acciones encaminadas a la transformación de ideas-negocio a empresas reales a través de la educación, el soporte económicofinanciero y el apoyo de la experiencia empresarial" (Zacarías \& Olmos, 2010, p.101).

\section{El emprendimiento en México}

En México, las micro, pequeñas y medianas empresas (MIPYMES) son organizaciones medulares para el crecimiento económico del país, no solo por ser la principal fuente de ingreso, sino por la flexibilidad de adaptarse a los cambios tecnológicos y su gran potencial de generación de empleo. Por lo que se reconoce su importancia en el desarrollo regional y local (Coepes, 2015).

Según datos estadísticos del Instituto Nacional de Estadística y Geografía (INEGI) y la Secretaría de Economía, en colaboración con la Asociación Mexicana de Secretarios de Desarrollo Económico (AMSDE), en México en 2018:

[...] había un total de 4 millones 057 mil 719 Microempresas, con una participación de mercado equivalente al 97.3 por ciento.

- Además, había un total de 111 mil 958 Pequeñas y Medianas empresas (PYMES), con una participación de 2.7 por ciento en el mercado. 
- En total, [...] 4 millones 169 mil 677 Micro, Pequeñas y Medianas Empresas (MIPYMES), clasificadas en los sectores de manufacturas, comercio, e-comerse y servicios privados no financieros. (Martínez, 2019, párr.3)

Por su parte, Velázquez (2019) señala que:

la actividad emprendedora vive una etapa de esplendor, pues [en 2019] cada mes se abrieron unas 35,000 empresas. Además, tres de cada 10 emprendedores que abrieron un negocio lo hicieron por necesidad, mientras que el resto lo hizo con el fin de mejorar su estilo de vida y de profesionalizarse. (párr.2)

A pesar de que las MIPYMES son consideradas como uno de los motores de la economía, su desarrollo se ha visto obstaculizado por diversas problemáticas y retos (Ramos, 2018), entre ellos:

- Falta de financiamiento. De acuerdo con Reyes (2019), uno de los problemas que enfrentan estas empresas es la gestión y acceso al crédito, pues se les presentan una serie de barreras como, por ejemplo, procesos que requieren de estados financieros que no saben presentar adecuadamente, tasas de interés que disuaden la contratación de créditos y procesos lentos. Por otra parte, las instituciones financieras no se han podido adaptar a las necesidades de financiamiento de estas empresas.

- Bajo nivel de profesionalización. En ocasiones estas empresas son consideradas como un empleo precario, sin que exista una cultura empresarial, presentando bajos niveles de productividad (Naciones Unidas, 2015). Estas empresas tienen retos que afrontar, sin embargo, pueden implementar nuevas tecnologías, mejorar procesos, capacitarse y contar con una organización bien estructurada.

- Poca vinculación. Son muy pocas las empresas que se preocupan por generar relaciones con otras empresas, o que buscan la vinculación con instituciones que les ayuden a mejorar sus procesos, e innovar.

Sin embargo, en el país se siguen dando esfuerzos por apoyar a los emprendedores a través de diferentes instancias de gobierno y particulares dispuestos a invertir, sobre todo, en empresas que incursionan en la innovación (aunque aún es poco lo que se ha logrado para que se de una consolidación en ese aspecto). Prueba de este esfuerzo puede observarse en algunas instituciones de educación superior (IES) que han fomentado el 
apoyo a los emprendedores con incubadoras de negocios o parques de emprendimiento (tabla 1).

\section{Tabla 1}

Universidades públicas y privadas que impulsan el emprendimiento

\begin{tabular}{lll}
\multicolumn{1}{c}{ Universidad } & \multicolumn{1}{c}{ Apoyo al emprendimiento } \\
\cline { 2 - 3 } Públicas & Instituto Politécnico Nacional & $\bullet$ Incubación de empresas con base tecnológica \\
\cline { 2 - 3 } & Universidad Nacional Autónoma de México & $\bullet$ Programa de emprendimiento \\
& - Incubadora \\
\cline { 2 - 3 } Privadas & Universidad Anáhuac & $\bullet$ Modelo de emprendimiento atrayente \\
\cline { 2 - 3 } & Instituto Tecnológico de Monterrey & $\bullet$ Incubadora \\
& & $\bullet$ Aceleradora \\
\hline
\end{tabular}

Nota: Elaboración propia.

Considerando que se cuenta con estas opciones, los emprendimientos deberían ser cada vez más; sin embargo, el emprendimiento puede ser un proceso complejo, en el que se presentan riesgos y obstáculos, los cuales las personas no siempre están dispuestas a afrontar. Por lo cual, es conveniente que el gobierno implemente programas que incentiven a las personas a emprender y se diseñe una red de acompañamiento, capacitación y apoyo en el proceso de desarrollo de sus modelos de negocio.

\section{Apoyo para el emprendimiento}

"North (1990) explica que las instituciones gubernamentales son el agente de cambio en el proceso económico al proporcionar respaldo legal y estructuras públicas que beneficien la creación de empresas" (García-Macías et al., 2018, s.p.). Estos apoyos empresariales deben beneficiar al sector, contribuyendo directamente a mejorar el nivel de vida de la población al tener una fuente de empleo y ser parte del segmento de emprendedores que tienen la capacidad de incrementar sus ingresos de forma exponencial. Sin embargo, estos recursos implican cumplir una serie de requisitos y documentos que respalden el proyecto, convirtiéndose en un trabajo administrativo y financiero obligatorio para el emprendedor, y en muchas de las ocasiones, el tiempo dedicado a formular reportes técnicos para las instituciones gubernamentales son el costo por haber recibido financiamiento gubernamental, por eso sería importante poner en una balanza el tiempo destinado a cumplir con los formatos y documentos versus el beneficio económico. 


\section{Financiamiento a emprendedores}

Es de suma importancia mencionar que para emprender o llevar a cabo una idea de negocio no se requieren grandes cantidades de dinero, lo más importante es que el producto o servicio sea algo que el mercado desea o requiera, es decir, que cubra una necesidad, deseo o solucione un problema.

Existen distintos tipos de apoyos a los cuales se puede tener acceso a través del gobierno, sin embargo, hay que eliminar la idea de que, si no hay ayuda con bienes de capital o dinero, entonces, no se puede emprender. Lo importante es tener una idea clara del negocio.

Uno de los factores de mayor relevancia en la determinación del éxito o fracaso de un emprendimiento es el financiamiento. Los emprendedores recurren a apoyos financieros de diversas fuentes a lo largo de su proceso de gestación y maduración de su negocio (Cortés \& Echecopar, 2008 citados en García-Macías et al., 2018).

No solo es importante ser una persona innovadora y capaz de detectar problemas y necesidades en la sociedad para crear algún producto o servicio, sino que es un cúmulo de habilidades que además permitan ser un gran vendedor de ideas y negociador ante inversionistas, y la falta de alguna de estas habilidades dejará incompleto el proceso de emprendimiento. En este sentido García-Macías et al. (2018) afirman que "la fuente de financiamiento bancaria, en algunas ocasiones no es considerada como la opción más viable para la nueva empresa" (s.p).

Los emprendedores requieren dinero en la mayoría de los casos para echar a andar la idea de negocio, y con las múltiples fuentes de financiamiento necesitan analizar qué opción es la más adecuada de acuerdo con la etapa en la que se encuentra el proyecto. En una etapa muy temprana, el tener un acercamiento a una institución bancaria no es la fuente más viable de financiamiento, ya que estos tienen varios candados, los cuales están diseñados para negocios con algunos años en el mercado y que requieren de capital para acelerar el crecimiento de la empresa donde ya hay un producto probado.

Los emprendedores que van comenzando tienen la incertidumbre de si funcionará su negocio o no. Uno de los temores cuando se comienza a emprender es saber si la idea o proyecto de emprendimiento será rentable y si se podrá pagar un crédito bancario; pero en una etapa de arranque es difícil conocer lo que podrá generar a corto, mediano o largo 
plazo, por esta razón las instituciones financieras no tienen la certeza de que el emprendedor solvente el crédito, debido a la alta incertidumbre.

Por este motivo, un alto número de nuevos negocios recurren al autofinanciamiento a través de ahorros personales, así como al financiamiento de accionistas informales como lo pueden ser: individuos interesados, amigos, proveedores, clientes, prestamistas e incluso la propia familia. (Bosma, Van Praag \& De Wit, 2000; Bygrave y Hunt, 2004 citados en García-Macías et al., 2018)

Para que las personas confíen en el emprendedor, es importante que este tenga capacidades de liderazgo, comunicación, y negociación, además de ser una persona congruente con sus ideales, pero siempre buscando mejorar con el apoyo y asesoría de personas que dominan ciertos temas; es decir, un emprendedor que es proactivo tiene mayor credibilidad ante otras personas acerca del buen funcionamiento que tendrá su emprendimiento. Por lo cual, la actitud del emprendedor ante los retos y obstáculos será determinante para que las personas le confían su dinero para invertir en su proyecto.

En este contexto, existen distintos concursos y programas de emprendimiento en donde diferentes instituciones no gubernamentales o empresas apoyan a los emprendedores con ideas innovadoras que den soluciones a las diversas necesidades de la comunidad, en donde algunos dan mentoría e invierten en startups o ponen en contacto a los emprendedores con potenciales inversionistas de su proyecto. Es una solución de financiamiento muy interesante, ya que no solo se obtiene el recurso económico que se necesita para emprender, sino que se crea un ecosistema en donde el emprendedor hace comunidad con otros emprendedores, posibles socios, mentores de áreas especializadas e inversionistas y se vuelve más enriquecedor el proyecto, por el proceso de retroalimentación al que está expuesto constantemente, haciendo que baje el riesgo de fracaso.

\section{Financiamiento de iniciativa pública}

En los últimos años, México ha impulsado una política para el apoyo a la innovación tecnológica por medio de programas específicos para empresas y las destacan como actores esenciales para la competitividad y el desarrollo económico (Corona et al., 2013).

En la década de los noventa, los programas de apoyo se orientaron a regiones y necesidades específicas (Casas, 2001). Gracias a esto, la tendencia se fue fortaleciendo en los años posteriores a través de los programas de ciencia y tecnología. 
Por mencionar algunas convocatorias del Consejo Nacional de Ciencia y Tecnología (Conacyt, 2020) se encuentran:

1. PROINNOVA. Apuntala a la inversión científica, desarrollo tecnológico e innovación de empresas que participen en redes y alianzas estratégicas con empresas y centros académicos de investigación, completando y no sustituyendo con recursos públicos el monto que estas destinan a campos precursores del conocimiento.

2. INNOVAPYME. Incentiva a la inversión en investigación y desarrollo de más MIPYMES del sector productivo del país, mediante el otorgamiento de estímulos económicos a las empresas que fehacientemente realicen actividades relacionadas a la investigación y desarrollo tecnológico, con la finalidad de incrementar su competitividad, creación de nuevos empleos e impulsar el crecimiento económico del país.

3. INNOVATEC. Estimula el desarrollo de proyectos tecnológicos que impulsen la competitividad de las empresas, así como también obtener un mejor balance entre los recursos aplicados para estas actividades.

Actualmente este tipo de financiamiento va encaminado a las empresas que ya están establecidas, y requieren innovar procesos o productos para fortalecer la competitividad en un mercado global y entrar en la categoría de país, estado o región innovadora con capacidad de creación y mejora, y no solo ser un país que se adapta a comprar la tecnología de otros países, ya que la manera de ser punta de lanza en cualquier sector a nivel mundial es siendo el primero en innovar, desarrollar o implementar soluciones que resuelvan una necesidad que nadie ha resuelto. La importancia del apoyo por medio de la iniciativa pública trae consigo mejorar no solo una empresa, sino mejorar una región, impulsar la economía y mejorar la calidad de vida de las personas.

\section{Apoyos gubernamentales}

Las empresas innovadoras en México representan casi el 25\% del total de las empresas, y de ese porcentaje al menos dos tercios crean productos nuevos o mejorados (Alarcón \& Díaz, 2014). Los apoyos gubernamentales en su mayoría están destinados a mejorar productos y procesos para incrementar el poder de innovación del sector privado.

Estos apoyos se ofrecen a través de las distintas secretarías o dependencias como la Secretaría de Economía, Secretaría de Desarrollo Social, Secretaría de Innovación Ciencia y Tecnología, entre otras. Las cuales, normalmente, ofrecen créditos con tasas de interés bajas y apoyos a fondo perdido subsidiados por el gobierno. Pueden ser de diferentes tipos como: 
1. Fondo PYME. Esta herramienta está diseñada para apoyar a las empresas, especialmente a las pequeñas empresas y a emprendedores, brindando soporte temporal para programas y proyectos de desarrollo, creación y viabilidad (Secretaría de Economía, 2020a).

2. Programa Nacional de Financiamiento al Microempresario (PRONAFIM). El punto principal es aumentar la productividad de las empresas y mejorar sus condiciones de vida mediante la prestación de servicios integrales de microfinanzas, alentando así a los pequeños empresarios a iniciar negocios, desarrollar y consolidar a los mismos (Secretaría de Economía, 2020b).

3. Nacional financiera (NAFIN). En sus diferentes modalidades facilita el acceso al crédito para las micro, pequeñas y medianas empresas del país (Nacional Financiera, 2020).

Puede existir muchos otros, debido a que cada sexenio las administraciones en el gobierno crean nuevos programas o dan un nuevo enfoque a los existentes. Asimismo, han desaparecido algunos otros programas, sin embargo, quien quiere emprender o mejorar su negocio se moverá para buscar los recursos necesarios con apoyo o sin apoyo del gobierno, ya que este no es la única opción para obtener financiamiento.

\section{Friends, Family and Fools}

“Las 'tres efes', más conocidas como Friends, Family and Fools, es un término anglosajón que designa la fuente más cercana y accesible a la hora de buscar financiación para emprender un negocio" (Rubio, 2020). Esta es una de las fuentes de financiación más comunes debido a la accesibilidad con la que se encuentra a estas personas, sobre todo, amigos y familia. Por eso es importante tomar en cuenta los términos en los que ellos pondrán dinero de su bolsa, ya que puede convertirse en un socio con voto o sin voto para la toma de decisiones, e incluso puede haber intervención operativa y administrativa en el emprendimiento de acuerdo con el tipo de términos que se hayan incluido en la parte legal del acuerdo, o su aportación puede ser considerada solo como un préstamo.

Es fundamental abrir el panorama a los aportadores de capital acerca de cuáles son los riesgos a los que se enfrenta su dinero, en el caso de entrar como socio capitalista, ya que al ser un proyecto emprendedor que se encuentra en fases tempranas, el riesgo es muy alto, no obstante, también es importante reconocer las recompensas que habrá, si todo marcha con un buen panorama para el emprendedor. Por esta razón mantener 
informados a los socios respecto a cómo va el negocio, se volverá una labor más que deberá llevar el líder de la futura organización.

\section{Crowdfunding}

El crowdfunding es una manera interesante de validar un proyecto de emprendimiento, ya que se puede subir a las distintas plataformas que existen en la actualidad y determinar el interés de las personas por la idea de negocio que se tiene; mientras más personas quieran ser parte del emprendimiento, indicará que hay una o muchas personas que creen que hay un problema qué solucionar y les hará sentido invertir o aportar a su proyecto por el grado de solución.

Según González (2014 citado en Jiménez-Cercado \& Acosta-Véliz, 2018), entre los modelos de crowdfunding existen cuatro tipos muy conocidos:

1. "Crowdfunding de donaciones, que consiste en no recibir ningún beneficio a cambio de lo aportado y se utiliza en organizaciones sin fines de lucro" (p.3). Su característica principal es otorgar un beneficio económico sin esperar algo a cambio y comúnmente las campañas que se suben a las plataformas de crowdfunding de donaciones son fundaciones en pro de los más necesitados, así como personas que están pasando por una situación compleja como enfermedades, accidentes, desastres, etc., requiriendo el apoyo económico para salir adelante. Y quien tiene empatía por alguna de estas causas puede acudir a dichas plataformas para ayudar con dinero.

2. "Crowdfunding de inversión, en el que los donantes forman parte del proyecto como socios" (p.3). Este tipo de crowdfunding atrae a socios inversionistas para que sean parte del emprendimiento, y de acuerdo cómo se establezca podrían ser parte o no de la toma de decisiones y las reuniones de asamblea que tengan en la empresa. Hay que tener en cuenta los pros y contras de tener una cantidad significativa de socios, ya que se les tiene que rendir cuentas cada cierto periodo para dar a conocer qué se está haciendo con su inversión y en qué momento la recuperarán.

3. "Crowdfunding de préstamos o crowdlending, que consiste en devolver paulatinamente el préstamo con su respectivo interés" (p.3). Este tipo de fondeos tiene la característica de regresar el dinero en los periodos de tiempo seleccionado con un interés, por lo tanto, es una manera fácil de adquirir dinero sin la necesidad de recurrir a un banco y hacer todo el proceso que solicita. Es una buena idea recurrir a este tipo de préstamos si el emprendedor confía plenamente en su proyecto y ha bajado el riesgo validando y vendiendo su producto anteriormente; este tipo de 
financiamiento es más económico, y no se requiere un socio capitalista —al cual se tendría que rendir cuentas-. Por otro lado, si el negocio falla, el único responsable del pago del préstamo con sus intereses sería el emprendedor, por lo tanto, este tipo de crowdfunding es más conveniente cuando no hay tanta incertidumbre en el emprendimiento.

4. "Crowdfunding de recompensas, en el que se reciben recompensas a cambio de las donaciones (p.3). Este modelo de fondeo se caracteriza por ofrecer un producto o servicio a cambio de la aportación económica. Una de las cosas más importantes es que el emprendedor pueda ofrecer algo que aporte valor a la persona que dará dinero para que funcione como recompensa, puede ser, por ejemplo, publicidad a cambio o algún producto o servicio que el propio emprendimiento ofrezca.

\section{Inversionistas ángeles}

Un inversionista ángel "es una persona que invierte dinero propio en startups, empresas con alto potencial de crecimiento" (Milich, 2019, párr.1). En muchas ocasiones, este tipo de inversionistas son personas con experiencia en la creación de empresas, conocen el mundo del emprendimiento, y han logrado concentrar una serie de contactos durante su carrera empresarial; por esta razón, creen que la manera más rápida de potenciar una startup es a través de la inyección de capital, para llevar a cabo la estrategia de crecimiento y desarrollo de nueva tecnología, pero en combinación con un equipo de emprendedores talentosos que no le tengan miedo al trabajo y que prioricen el emprendimiento sobre cualquier actividad extra que no aporte a la estrategia de crecimiento.

Estos inversionistas actúan como catalizadores de startups; entran en las primeras etapas del emprendimiento a cambio de un pequeño porcentaje de la empresa, pero su papel va más allá de solo inyectar capital, pues su experiencia y conocimiento les permite involucrarse, asesorar al emprendedor y utilizar sus contactos en beneficio de la empresa.

Muchos de los inversionistas ángeles crean sus propios grupos, para ser parte de eventos de inversión, donde conocen proyectos de emprendedores y tienen la posibilidad de hacer conexiones con aquellos que tengan potencial de crecimiento. Una de las maneras de acceder a los eventos de inversionistas es tener contacto con incubadoras de negocio, ya que generalmente forman parte de los invitados. Otra de las formas es estar activo en la comunidad de emprendedores a través de networking, eventos de emprendimiento, coworking, y contacto con otros empresarios. 
En definitiva, no importa el medio que se elija para financiar una idea de negocio, lo importante es la constancia y la disciplina del emprendedor, y un arduo trabajo para materializarla.

\section{Servicios de apoyo y acompañamiento a emprendedores Incubadora de negocios}

El camino menos turbulento a la hora de iniciar un negocio es a través de asesoría especializada y conocer cómo otros emprendedores tuvieron éxito; tener apoyo y acompañamiento impulsa a los emprendedores a operar basados en casos de éxito nacionales e internacionales; por ello, acercarse a incubadoras de negocios es una buena opción.

Las incubadoras de negocios son entidades que apoyan a los emprendedores a desarrollar su proyecto los primeros años de vida (Dutta, 2018; Peña, 2004); es una gran herramienta para los emprendedores que tienen una idea de negocio y requieren conocer todas las implicaciones que conlleva, pues les permite tener asesoría de personas expertas en cada área y hacer contacto con otros emprendedores. Con estos recursos, un nuevo emprendimiento tiene más posibilidades de sobrevivir una vez que haya finalizado el acompañamiento, ya que el emprendedor tiene mayor conocimiento de las áreas de la empresa y del entorno.

El proceso de incubación de un emprendimiento puede iniciar en etapas muy tempranas. Desde que el emprendedor tiene una idea de negocio, la incubadora dará acompañamiento para realizar una investigación de mercado — que ayude a pulir su idea y entender las necesidades del consumidor- y el plan de negocios. Además, dará asesoría especializada enfocada en áreas fundamentales de la empresa como finanzas, marketing, organización, planificación del proyecto, entre otras. Para ese momento, el emprendedor contará con un prototipo que puede seguir mejorando hasta que su idea de negocio esté materializada y pueda salir al mercado. Después del lanzamiento, la incubadora dará seguimiento al emprendimiento y su relación con el mercado, para que el emprendedor siga aprendiendo y, de ser necesario, pueda corregir su camino; de tal manera que se impulse el crecimiento de la empresa y su profesionalización.

Una parte valiosa de las incubadoras de negocios es que se logra crear una comunidad de emprendedores, en la cual se comparten experiencias, se realizan nuevas convocatorias de emprendimiento, e incluso algunos emprendedores se asocian, uniendo fuerzas y capacidades con equipos multidisciplinarios. Sin duda alguna, la asesoría de una 
incubadora de negocios ayudará sustancialmente al emprendedor para que su proyecto tenga menos posibilidades de fracaso.

\section{Guía de requisitos legales básicos que deben cumplir los emprendedores}

Para crear una empresa se requiere cumplir con una serie de requisitos legales, relacionados con licencias, permisos, registros y obligaciones administrativas. Además, se debe cumplir con lo establecido en el Artículo 31 de la Constitución Política de los Estados Unidos Mexicanos, "contribuir para los gastos públicos, así de la Federación, como de los Estados, de la Ciudad de México y del Municipio en que residan, de la manera proporcional y equitativa que dispongan las leyes" (fracc. IV). Y, así pagar los impuestos correspondientes.

También se deberá considerar y cuidar la actividad legal con cada uno de los proveedores y clientes, así como lo relacionado con las leyes existentes respecto a la protección de datos personales.

Por lo tanto, crear un negocio en México — al igual que en otros países-implica cumplir varios aspectos como, por ejemplo:

- Marca y logotipo (creación y registro)

- Nombre de la empresa

- Registro Federal de Contribuyentes (RFC) como persona física o persona moral

- Obtención de e.firma

- Registro Público de la Propiedad y Comercio

- Registro ante el IMSS e INFONAVIT

- Licencia de uso de suelo

- Licencia de funcionamiento

- Licencia de uso nominativo

\section{Marca y logotipo (creación y registro)}

De acuerdo con la Real Academia Española (RAE, 2020), un logotipo es un símbolo gráfico peculiar para identificar una empresa, marca o producto. Según Yirda (2020), un logotipo debe poseer el nombre con el que se conocerá a la empresa, además debe ser lo suficientemente claro y legible para que el consumidor o cliente pueda reconocerlo con facilidad. Considerando lo anterior, se puede decir que un logotipo es la imagen gráfica de un nombre o conjunto de letras que identifican a una empresa. Por ello, es de suma importancia que las empresas registren su marca y logotipo, para evitar que pueda ser usada por terceros. 
En el entorno económico actual, la marca se ha convertido en una herramienta estratégica, pues no solo vende productos o servicios sino sensaciones, por lo que se relaciona emocionalmente con los consumidores a través de atributos intangibles, lo cual genera valor para la empresa (Muñiz, 2020).

En México, el órgano designado para proteger la propiedad industrial, marcas y patentes, es el Instituto Mexicano de la Propiedad Industrial (IMPI), que brinda protección a individuos y empresas en términos de invenciones, marcas, diseños, logotipos, fórmulas, aromas, sonidos, entre otros.

Para registrar una marca, primero es necesario asegurarse de que nadie más la haya registrado. Para ello, debe usarse la herramienta MARCANET, que el IMPI pone a disposición de los usuarios, donde deberá ingresar el nombre de la marca para consultar la disponibilidad.

Hasta hace unos meses, lo único que se podía registrar en el IMPI eran marcas comerciales, anuncios comerciales (comúnmente conocidos como lemas), nombres comerciales e incluso obtener una denominación de origen (como en el caso del tequila, el mezcal, o el queso manchego); ahora también se pueden agregar hologramas, sonidos, olores o una combinación de los anteriores como parte de las marcas comerciales.

El registro se puede hacer en línea o en las oficinas del IMPI. Si realiza el proceso en línea, necesita su firma electrónica (anteriormente FIEL) y registrarse como usuario en la plataforma del IMPI; si decide realizar el trámite directamente en las oficinas, deberá considerar la ubicación de la sede regional que le corresponda. Si el procedimiento lo realiza una entidad legal, se deberá agregar la documentación correspondiente (estatutos y poder notarial para acciones administrativas). Dependiendo de lo que desee proteger, deberá completar una solicitud para proteger los signos distintivos de Tipo A (marcas, marcas colectivas, marcas de certificación, aviso o nombre comerciales) o de tipo B (marca holográfica, marca sonora, marca olfativa, imagen comercial o la combinación de los anteriores).

Es importante considerar que la solicitud de registro de marca no siempre tiene una respuesta positiva por parte del IMPI; pero en caso de que así sea, la vigencia de la protección de la marca es de 10 años, renovables por periodos de la misma duración. Esta protección tiene efecto en el país; si la empresa planea operar en el extranjero, deberá seguir los procedimientos de propiedad intelectual del país o región correspondiente. 


\section{Nombre de la empresa}

Para determinar el nombre de la empresa se deberá tener múltiples opciones, porque para constituir una sociedad se verificará que no haya un nombre igual ya registrado. Se debe decidir qué opción es la que más agrada, y a partir de esto, clasificar las demás opciones en orden de importancia (Ruiz, s.f.).

El nombre comercial es la denominación de una empresa, comercio o establecimiento y se puede solicitar su publicación a través del IMPI. Este nombre y el derecho a su uso exclusivo están protegidos sin necesidad de registro, pero se requiere solicitar su publicación para establecer la presunción de buena fe en su adopción y uso frente a terceros, y acreditar el uso del nombre comercial aplicado a un giro determinado (IMPI, 2012). Esta publicación tendrá efecto durante 10 años que pueden renovarse en periodos iguales.

Antes de iniciar el trámite de publicación deberá asegurarse que el nombre comercial sea único; además, deberá considerar que de acuerdo con la Ley Federal de protección a la Propiedad Industrial no se publicarán aquellos que carezcan de elementos que hagan distinguir a la empresa o establecimiento de que se trate de otros de su género (Art. 210).

Por lo tanto, de acuerdo con Ruiz (s.f.), el nombre de una empresa o negocio debe contar al menos con las siguientes características:

- Ser corto

- Ser representativo de nuestra actividad o producto

- Ser fácil de pronunciar y recordar

- Ser único y original (para evitar similitudes con otros existentes)

\section{Registro Federal de Contribuyentes como persona física o persona moral}

Una de las primeras dificultades a las que se enfrenta un emprendedor al iniciar un negocio de cualquier índole es que deberá elegir cómo registrarse, es decir, como una persona física o como una persona moral, porque cada uno de estos planes satisface diferentes necesidades y tiene diferentes leyes e impuestos por cumplir.

$\mathrm{Al}$ optar por registrarse como persona física solo habrá que elegir, ante el Servicio de Administración Tributaria (SAT), el tipo de régimen que más convenga al empresario. La figura 1 muestra los distintos tipos de regímenes que existen en México y sus obligaciones.

En el caso de elegir registrarse como persona moral, primero tendrá que constituirse; para ello, el primer paso será presentar una solicitud ante la Secretaría de Relaciones Exteriores (SRE) para elegir el tipo de denominación social que mejor se adapte a la em- 


\section{Figura 1}

Tipos de regímenes en México

\begin{tabular}{|c|c|c|c|c|c|}
\hline & \multicolumn{5}{|c|}{ Régimen } \\
\hline Obligaciones & Asalariados & $\begin{array}{l}\text { Honorarios } \\
\text { (servicios } \\
\text { profesionales) }\end{array}$ & $\begin{array}{c}\text { Arrendamiento } \\
\text { de inmuebles }\end{array}$ & $\begin{array}{l}\text { Actividades } \\
\text { empresariales }\end{array}$ & $\begin{array}{l}\text { Incorporación } \\
\text { fiscal }\end{array}$ \\
\hline Definición & $\theta$ & $\theta$ & $\theta$ & $\varnothing$ & $\theta$ \\
\hline Inscripción & $\varnothing$ & $\varnothing$ & $\theta$ & $\theta$ & $\theta$ \\
\hline RFC actualizado & $\varnothing$ & $\varnothing$ & $\theta$ & $\theta$ & $\theta$ \\
\hline Facturación electrónica & $\boldsymbol{\otimes}$ & $\varnothing$ & $\theta$ & $\theta$ & $\theta$ \\
\hline Contabilidad & $\otimes$ & $\varnothing$ & $\otimes$ & $\theta$ & $\theta$ \\
\hline Declaración & Anual & $\begin{array}{c}\text { Mensual, } \\
\text { Anual, } \\
\text { Informativa y } \\
\text { DIM* }^{*}\end{array}$ & $\begin{array}{l}\text { Mensual, } \\
\text { Anual, } \\
\text { Informativa }\end{array}$ & $\begin{array}{c}\text { Mensual, } \\
\text { Anual, } \\
\text { Informativa y } \\
\text { DIM* }^{*}\end{array}$ & Bimestral \\
\hline Otras obligaciones & $\varnothing$ & $\theta$ & $\theta$ & $\theta$ & $\theta$ \\
\hline
\end{tabular}

Nota: * Declaración Informativa Múltiple. Adaptado de Bermejo (2019).

presa; con lo cual se asegura que el nombre no esté registrado constitutivamente en el país o en el extranjero con la misma razón social.

Para este trámite se puede consultar a un notario público, con el cual se deberá acudir para la creación y protocolización del acta constitutiva de la empresa, en la cual se estipulan los aspectos generales de esta, que de acuerdo con la Ley General de Sociedades Mercantiles son los siguientes:

I. Los nombres, nacionalidad y domicilio de las personas físicas o morales que constituyan la sociedad;

II. El objeto de la sociedad;

III. Su razón social o denominación;

IV. Su duración;

V. El importe del capital social;

VI. La expresión de lo que cada socio aporte en dinero o en otros bienes; el valor atribuido a éstos y el criterio seguido para su valorización [...];

VII. El domicilio de la sociedad; 
VIII. La manera conforme a la cual haya de administrarse la sociedad y las facultades de los administradores;

IX. El nombramiento de los administradores y la designación de los que han de llevar la firma social;

X. La manera de hacer la distribución de las utilidades y pérdidas entre los miembros de la sociedad;

XI. El importe del fondo de reserva;

XII. Los casos en que la sociedad haya de disolverse anticipadamente, y

XIII. Las bases para practicar la liquidación de la sociedad y el modo de proceder a la elección de los liquidadores, cuando no hayan sido designados anticipadamente. (Art. 6)

Una vez que el acta constitutiva esté legalizada, será necesario inscribir a la empresa ante el SAT, en el Registro Federal de Contribuyentes (RFC) para obtener la cédula fiscal.

El RFC es una clave única e intransferible de registro que sirve para identificar a las personas que realiza una actividad económica, las cuales deben contribuir con el gasto público de la nación. Este procedimiento se aplica tanto a las personas físicas como morales. Este trámite lo puede realizar directamente el interesado o a través de un contador, en las instalaciones del SAT del municipio o delegación que corresponda.

\section{Obtención de e.firma}

En México, como en el mundo, las firmas electrónicas se utilizan cada vez más, no solo en asuntos fiscales, sino también en asuntos mercantiles o comerciales.

La e.firma (antes Firma Electrónica) es "el conjunto de datos y caracteres que te identifica al realizar trámites y servicios por internet" (SAT, 2020). La e.firma es única, es un archivo seguro y cifrado, que tiene la validez de una firma autógrafa, y por sus características, es segura y garantiza la identidad.

Por sus características, la e.firma brinda garantía a las actividades electrónicas de los contribuyentes que emiten Comprobantes Fiscales Digitales por Internet (CFDI) a través de algún sistema de facturación electrónica; con su uso se puede identificar al generador del mensaje y verificar que no haya sido modificado, falsificado o alterado en sus valores.

Para obtener la e.firma (SAT, 2020), se debe realizar el trámite de forma presencial, programando una cita en la oficina del SAT que corresponda. Al acudir a la cita se registrarán los datos biométricos del solicitante (huellas dactilares, fotografía de frente, 
fotografía del iris) y se firmaran y digitalizaran los documentos originales. Los requisitos para el trámite pueden ser consultados en la página de la dependencia, entre los que se incluyen:

- Original de la identificación oficial vigente

- Contar con Clave Única de Registro de Población (CURP)

- En caso de personas morales, el responsable legal debe contar con e.firma activa y presentar el poder general para actos de dominio o de administración, así como el acta constitutiva de la empresa.

\section{Registro Público de la Propiedad y Comercio}

En el caso de las personas morales, una vez protocolizada el acta constitutiva y que se tenga la inscripción ante el SAT, se deberá realizar la solicitud de inscripción en el Registro Público de la Propiedad y el Comercio, en él se inscribirá la empresa y los bienes inmuebles que la conforman.

\section{Registro ante el IMSS e INFONAVIT}

En caso de que se tenga planeado la contratación de trabajadores, se deberá solicitar el registro como patrón ante el Instituto Mexicano del Seguro Social (IMSS) y el Instituto del Fondo Nacional de la Vivienda para los Trabajadores (Infonavit), obteniendo el número de identificación patronal; este trámite se puede realizar en ventanilla en la Subdelegación IMSS que corresponda o puede realizarse por internet. Los requisitos necesarios para las diferentes modalidades pueden ser consultados en su página web (IMSS, 2020).

\section{Licencia de uso de suelo}

Esta licencia puede ser solicitada por una persona física o moral, en el caso que se requiera el permiso para utilizar un predio con un determinado uso de suelo, ya sea habitacional, de servicios, comercial o industrial (Gobierno de México, 2020). Entre los requisitos se encuentran los siguientes:

- Acta constitutiva (en caso de ser persona moral)

- Identificación oficial vigente (INE o Pasaporte)

- Título profesional

- Comprobante de domicilio (no mayor a tres meses; puede ser de luz o agua)

- Croquis de ubicación del predio 
- Escrituras del predio (para demostrar que es un terreno regular y pueda tener acceso a los servicios básicos)

- Plano tipográfico, que permita conocer la zona de manera completa y los relieves del terreno

- Último pago predial vigente

- Escrito libre de solicitud de la licencia de uso de suelo

- Oficio de solicitud (proporcionado en la dependencia de cada municipio)

- Plano georreferenciado con coordenadas universal transversal (UTM)

Todos estos documentos deben presentarse en originales y copias; el costo del trámite se puede consultar en la ley de ingresos de cada delegación o municipio del estado. Pues varían cada año, según el tipo de solicitud (comercial, habitacional o industrial).

\section{Licencia de funcionamiento}

Una licencia de funcionamiento es aquel documento oficial con vigencia anual que emite un municipio, en el que se autoriza a una persona física o moral el funcionamiento de establecimientos comerciales, industriales o de servicio (Mayorga, 2020).

La licencia comercial de una empresa es un certificado emitido por el ayuntamiento, con respecto a la ubicación del establecimiento, y mediante el cual autoriza iniciar actividades en dichas instalaciones.

El uso final del permiso de operación es verificar que los proyectos e instalaciones utilizados para llevar a cabo las actividades comerciales se hayan construido y ejecutado de acuerdo con el proyecto y las características técnicas descritas.

\section{Licencia de anuncio nominativo}

Esta licencia permite a una persona física o moral instalar un anuncio que contenga el nombre comercial de su negocio, así como su logotipo, emblema o eslogan, por medio de los cuales se pueda identificar el local comercial donde desarrollará sus actividades (Gobierno de la Ciudad de México, 2020). El trámite se realiza de manera presencial, y en algunos casos, en línea, según lo indique cada municipio. Algunos de los requisitos que se requieren para el trámite son:

- Formato de solicitud

- Identificación del solicitante 
- Levantamiento de la fachada o sitio donde se colocará el letrero (plano a escala y croquis de localización)

- Fotos de la fachada del inmueble

- Diseño detallado del anuncio (indicando dimensiones, colores, materiales, tipografía y demás elementos que contribuyan a definir las características del mensaje publicitario, así como el sistema de fijación propuesto).

- Licencia de uso de suelo

- El proyecto de publicidad a color

Los requisitos para la solicitud de esta licencia deberán ser consultados en la página de la dependencia que corresponda.

\section{Conclusiones}

El capital emprendedor es un factor activo del crecimiento económico de México. Las actividades de emprendimiento contribuyen a la disminución de la pobreza, a través del empleo, la generación de ingresos y la elevación del nivel económico, lo cual repercute en el bienestar de la comunidad.

Hay que tener en cuenta que el financiamiento del capital emprendedor ha sido un potenciador para el surgimiento de las empresas más innovadoras durante los últimos 30 años; un ejemplo de esto, son empresas internacionales como Microsoft, Apple, Facebook, Airbnb y Google.

En México, por primera vez en el sistema emprendedor, startups han conseguido levantar rondas de inversión serie A, es decir, significativamente mayor al capital básico que se requiere para operar. Algunas de estas primeras empresas fueron: Kueski, Clip, Konfío, Cornershop y Gaia, que en conjunto levantaron 62.2 millones de dólares, reafirmando que el monto financiado se refleja en el tamaño exponencial que puede lograr una empresa (López, 2016).

Para lograr que el sueño del emprendedor se eche a andar, se requiere de aptitudes y actitudes que hagan sinergia con el ecosistema. Entre ellas: (1) la capacidad de esforzarse intensamente en la búsqueda de alcanzar sus objetivos, (2) la integridad, como factor para construir una buena reputación, (3) la capacidad de liderazgo para hacer equipos de trabajo y rodearse con las personas adecuadas que tengan habilidades multidisciplinarias que fortalezcan todas la áreas de la empresa, (4) la atención al cliente para que siempre busque estar mejorando la experiencia del usuario y con esto desarrollar procedimien- 
tos que tengan estándares de calidad para poder competir en un mercado global, (5) la trayectoria que tenga recorrida con base en historias de fracaso y éxito que ayude a implementar todo lo aprendido,(6) el conocimiento de la industria, que le ayude a tomar las decisiones adecuadas porque conoce a su segmento o nicho de mercado y cómo funciona el sector, y (7) el deseo de hacer dinero, ya que es una de las razones más importantes para hacer crecer una empresa.

Las aptitudes y actitudes del emprendedor junto con los instrumentos de apoyo al emprendimiento promueven y potencializan su desarrollo a través del uso efectivo de prácticas de formalización, búsqueda de crecimiento y gestión empresarial, basadas en el liderazgo, la planeación estratégica y la innovación. Así, se logra transformar mentalidades y fortalecer habilidades empresariales en aquellos emprendedores que tienen la capacidad de asumir riesgos para salirse de un empleo estable y comenzar un emprendimiento, que se convierta en una empresa.

De acuerdo con los objetivos planteados en el presente estudio documental histórico interpretativo del concepto emprendedor, se puede concluir que en México existen emprendedores dispuestos a innovar; sin embargo, el entorno puede dificultar la creación de nuevas empresas como, por ejemplo, las políticas gubernamentales y las deficiencias en materia de apoyo por parte de las instituciones. Por otra parte, cabe destacar que en México existe una tendencia colectiva a evitar el pago de impuestos, por lo que la mayoría de los emprendedores tardan para registrarse ante el SAT en promedio hasta 2.5 años; esto impacta negativamente al emprendedor, al no poder acceder a beneficios que el gobierno ofrece para emprender.

\section{Referencias}

Acs, Z. J., Audretsch, D. B., Braunerhjelm, P., \& Carlsson, B. (2004). The missing link: The knowledge filter and entrepreneurship in endogenous growth. CEPR Discussion paper $n^{\circ} 4783$.

Alarcón, M., \& Díaz, C. (2014). The technology based sectors in Mexico: An analysis for the firm size and the production scale. Economic Review of Galicia, 23(4), 49-60.

Arroyo, M. (2016). Emprendimiento y universidad emprendedora: Conceptualización, propuesta metodológica y caracterización de la universidad politécnica de Valencia (Tesis doctoral). Universidad Politécnica de Valencia, España.

Audretsch, D. B., \& Moog, P. (2020). Democracy and Entrepreneurship. Entrepreneurship Theory and Practice. https://doi.org/10.1177/1042258720943307 
Baker, T., \& Nelson, R. E. (2005). Crear algo de la nada: construcción de recursos a través del bricolaje empresarial. Ciencias administrativas trimestrales, 50(3), 329-366.

Bermejo, G. (2019). ¿Qué es un régimen fiscal? Guillermo Bermejo [Blog]. http://www. gbermejo.com/2019/11/que-es-un-regimen-fiscal.html

Cancino, C. A., Coronado, F., \& Farias, A. (2012). Antecedentes y resultados de emprendimientos dinámicos en Chile: cinco casos de éxito. INNOVAR, 22, 19-32.

Casas, R. (2001). La formación de redes de conocimiento: una perspectiva desde México. Anthropos/UNAM-Instituto de Investigaciones Sociales.

Cavero, J. M., \& Ruiz, D. (2017). Educación para la innovación y el emprendimiento: Una educación para el futuro. Recomendaciones para su impulso. Real Academia de Ingeniería.

Cherukara, J., \& Manalel, J. (2011). Evolution of Entrepreneurship theories through different schools of though. The Ninth Biennial Conference on Entrepreneurship at EDI, Ahmedabad.

Civera, A., Donina, D., Meoli, M., \& Vismara, S. (2018). The Creation of Academic Spinoffs: Does the International Mobility of the Academic Leader Matter? Academy of Management Proceedings, (1).

Comisión Estatal para la planeación de la educación superior (Coepes).(2015).Importancia de las Pymes en México. http://www.noticiascoepesgto.mx/articulos/255pymesroque

Consejo Nacional de Ciencia y Tecnología (Conacyt). (2020). Programa de Estímulos a la Innovación. https://www.conacyt.gob.mx/index.php/fondos-y-apoyos/programade-estimulos-a-la-innovacion

Corona, J., Dutrenit, G., Puchet, M., \& Santiago, F. (2013). La Co-evolución de las políticas de CTI, el sistema de innovación y el entorno institucional en México. En G. Dutrénit, \& P. Zúñiga, Políticas de ciencia, tecnología e innovación para el desarrollo. La experiencia latinoamericana (pp. 22-49). Foro Consultivo y Tecnológico.

Constitución Política de los Estados Unidos Mexicanos (1917). Última reforma. Diario Oficial de la Federación, DOF 08-05-20.

Corominas, J. (1981). Breve diccionario etimológico de la lengua castellana. Gredos.

Doherty, B., Haugh, H., \& Lyon, F. (2014). Social enterprises as hybrid organizations: A review and research agenda. International journal of management reviews, 16(4), 417-436. 
Duarte, T., \& Ruiz, M. (2009). Emprendimiento, una opción para el desarrollo. Scientia Et thecnica, 15(43), 326-331. https://www.redalyc.org/pdf/849/84917310058.pdf

Dutta, C. (2018). The Role of Business Incubators in Entrepreneurship Development-A Brief Review of Literatures. Research Bulletin, 44(1), 105-120.

Etzkowitz, H., \& Leydesdorff, L. (2000). La dinámica de la innovación: de los Sistemas Nacionales y el "Modo 2" a una Triple Hélice de relaciones universidad-industriagobierno. Política de investigación, 29(2), 109-123.

García-Macías, M. A., Zeron-Félix, M., Sánchez-Tovar, Y. (2018). Factores de entorno determinantes del emprendimiento en México. Entramado, 14(1). https://www. redalyc.org/jatsRepo/2654/265457559007/html/index.html

Gobierno de la Ciudad de México (2020). Licencia de Anuncio Denominativo. https:// tramites.cdmx.gob.mx/inicio/ts/281/0

Gobierno de México. (2020). Licencia de uso de suelo. https://www.gob.mx/tramites/ ficha/licencia-de-uso-de-suelo/Entidades7315

Gutiérrez, S. (2015). Emprendimiento en las empresas familiares. RICEA, 4(7).

Instituto Mexicano de la Propiedad Industrial (IMPI). (2012). ¿Cómo publicar un nombre comercial?

Instituto Mexicano del Seguro Social (IMSS). (2020). Trámites para Alta Patronal en sus diferentes modalidades. http://www.imss.gob.mx/tramites/alta-patronal

Jiménez-Cercado, M. E., \& Acosta-Véliz, M. (2018). El crowdfunding como alternativa para el emprendedor del siglo XXI. Forum Empresarial, 23(2).

Kraus, S., Niemand, T., Halberstadt, J., Shaw, E. \& Syrjä, P. (2017). Social entrepreneurship orientation: development of a measurement scale. International Journal of Entrepreneurial Behaviour and Research, 23(6): 977-997.

Ley Federal de protección a la Propiedad Industrial (2020). Nueva Ley. Diario Oficial de la Federación, DOF 01-07-2020.

Ley General de Sociedades Mercantiles (2009). Última reforma. Diario Oficial de la Federación, DOF 02-06-2009.

López, J. (2016). Las 5 startups más exitosas de México. El Financiero. https://www. elfinanciero.com.mx/empresas/las-startups-mas-exitosas-de-mexico

Martínez, L. (2019). Presenta INEGI radiografía de MiPyMES en México. Líder empresarial. https://www.liderempresarial.com/presenta-inegi-radiografia-de-mipymes-enmexico/ 
Martínez-Climent, C., Mastrangelo, L., \& Ribeiro-Soriano, D. (2020). The knowledge spillover effect of crowdfunding. Knowledge Management Research \& Practice, 1-11. http://dx.doi.org/10.1080/14778238.2020.1768168

Mayorga, M. I. (2020). Licencias de funcionamiento municipal. https:// gobiernodesolidaridad.gob.mx/licencias-funcionamiento

Milich, G. (2019). ¿Qué es un inversionista ángel y cómo atraerlo a tu negocio? Rockconten [Blog]. https://rockcontent.com/es/blog/inversionista-angel/

Muñiz, R. (2020). Marketing en el Siglo XXI. https://www.marketing-xxi.com/Marketingsiglo-xxi.html

Nacional Financiera (NAFIN). (2020). Acciones para apoyar la economía. https://www. nafin.com/portalnf/content/acciones-para-apoyar-la-economia/

Naciones Unidas (2015). Espacios de diálogo y cooperación productiva: el rol de las pymes. Naciones Unidas/CEPAL. https://www.cepal.org/es/publicaciones/38233espacios-dialogo-cooperacion-productiva-rol-pymes

Nafziger, W. (2006). Economic Development. Cambridge University Press.

North, D.C. (1990). A Transaction Cost Theory of Politics. Journal of Theorical Politics. https://doi.org/10.1177/0951692890002004001

Oliva, J. E. (2018). Factores, condiciones y contexto del emprendimiento cultural. Nova scientia, 10(20), 442-464. https://doi.org/10.21640/ns.v10i20.1081

Petuškienè, E., \& Glinskienè, R. (2017). Promoting Lithuania's Competitiveness through Entrepreneurship: the Results of Expert Assessment. Social Research, 39(1), 13-26. https://doi.org/10.21277/sc.v1i39.72

Ramos, L. (2018). La importancia y retos de las pymes en México y Latinoamérica. https:// blog.agendize.com/es-mx/la-importancia-y-retos-de-las-pyme-en-mexico-ylatinoamerica

Real Academia Española (RAE). (2020). Diccionario de la lengua española [en línea].

Reyes, P. (2019). Los retos de las Pymes y el crecimiento. El universal. https://www. eluniversal.com.mx/opinion/pavel-reyes-mercado/los-retos-de-las-pymes-y-elcrecimiento

Rivera, C. (2011). ¿De qué hablamos cuando hablamos de entrepreneurship? Cuadernos Unimetanos, 11-17.

Rubio, F. (2017). Financiación: cómo conseguirla para tu negocio. Francisco Rubio. Consultor de negocios online [Blog]. https://www.franciscorubio.es/conseguir-financiacionnegocio/ 
Ruiz, J. P. (s.f.). Descubre cuáles son los requisitos para poner un negocio. Factura-e. https://www.factura-e.mx/blog/documentos-que-requieres-tramitar-al-ponerun-negocio/

Schumpeter, J. A. (1934). The Theory of Economic Development: An Inquiry into Profits, Capital, Credit, Interest and the Business Cycle. Transaction Publishers.

Secretaría de Economía (SE). (2020a). Fondo de Apoyo para la Micro, Pequeña y Mediana Empresa (FONDO PYME). http://www.fondopyme.gob.mx/

Secretaría de Economía (SE). (2020b). Programa Nacional de Financiamiento al Microempresario (PRONAFIM). https://www.gob.mx/pronafim/que-hacemos

Servicios de Administración Tributaria (SAT). Obtén tu certificado de e.firma (antes Firma Electrónica). https://www.sat.gob.mx/tramites/16703/obten-tu-certificado-de-e. firma-(antes-firma-electronica)\#

Terán-Yépez, E. F., \& Guerrero-Mora, A. M. (2020). Teorías de emprendimiento: revisión crítica de la literatura y sugerencias para futuras investigaciones. Revista espacios, 14(7). https://www.revistaespacios.com/a20v41n07/a20v41n07p07.pdf

Velázquez, F. (2019). Emprender en México después del cierre del Inadem. Entrepreneur. https://www.entrepreneur.com/article/337435

Yirda, A. (2020). Definición de Logotipo. Concepto Definición. https://conceptodefinicion. de/logotipo/

Zacarías, H. M. M., \& Olmos, R. E. (2010). Análisis de las características del emprendimiento y liderazgo en los países de Asia y Latinoamérica. Portes, revista mexicana de estudios sobre la Cuenca del Pacífico, 4(8), 101-122. 


\section{Capítulo 2}

Actitudes y factores determinantes para el emprendimiento en estudiantes de Educación Superior Tecnológica

Adriana Fragoso Mora y Juan Tomás Oliva Ramos 


\section{Capítulo 2}

\section{Actitudes y factores determinantes para el emprendimiento en estudiantes de Educación Superior Tecnológica}

Adriana Fragoso Mora y Juan Tomás Oliva Ramos

En la actualidad, el conocimiento y la aplicación de tecnología, así como el desarrollo de habilidades científico-tecnológicas, en innovación y emprendimiento son temas de gran relevancia para todos los gobiernos, al considerarse agentes de transformación en los entornos industriales, políticos, económicos y sociales. Por lo tanto, se han fortalecido políticas para estimular la ampliación de oportunidades para la población, mediante las instituciones de educación superior tecnológica (Tecnológico Nacional de México [TecNM], 2017).

En México, en el entorno de educación superior tecnológica, el TecNM es "pieza fundamental en la formación de profesionistas e investigadores, así como en la generación de conocimiento, investigación, desarrollo tecnológico e innovación" (2017, p.13); a través de su Modelo Educativo para el Siglo XXI contribuye a la formación de profesionales que impulsen la actividad económica en el país, la investigación científica, la innovación tecnológica, la creatividad y el emprendimiento, que permitan el desarrollo social, económico, cultural y humano. Para ello, se diseñan estrategias didácticas para asegurar el desarrollo de competencias genéricas y específicas señaladas en el perfil profesional, así como actitudes deseables como el emprendimiento (Dirección General de Educación Superior Tecnológica [DGEST], 2012). 
En los distintos programas educativos del TecNM, específicamente en el Instituto Tecnológico Superior de Purísima del Rincón (ITSPR), en el Estado de Guanajuato, se realizan esfuerzos coordinados para evaluar el emprendimiento, contemplando dos elementos esenciales: 1) comportamiento emprendedor traducido en las actitudes de los estudiantes y 2) contexto del ecosistema local como impulsor del emprendimiento.

En este capítulo se presentan los resultados de la investigación desarrollada en el ITSPR para identificar y evaluar las actitudes orientadas hacia el emprendimiento entre los estudiantes pertenecientes a las carreras de Ingeniería: Bioquímica, Informática, Industrial, Electromecánica, Gestión Empresarial y Sistemas Automotrices; aplicando los trabajos en orientación emprendedora de diferentes autores (Covin \& Slevin, 1989; Cromie, 2000; Filion, 2003; Vecchio, 2003) y los rasgos comunes que aparecen en estas investigaciones, podemos decir que los principales rasgos de la personalidad emprendedora son: Locus de Control, Autoeficacia, Riesgo y Proactividad.

Los resultados permiten identificar cuáles son las actitudes preponderantes que poseen los estudiantes hacia el emprendimiento y las áreas de oportunidad en su formación integral para algunas de las dimensiones evaluadas, a medida que avanzan en los planes de estudio correspondientes. Se detectan estrategias para el mayor impacto de la orientación emprendedora profesional, así como el desarrollo de competencias transversales que favorecen un cambio de mentalidad y desarrollo de comportamiento empresarial. De forma institucional se replantea la vinculación pertinente con plataformas en línea y ecosistemas impulsores del emprendimiento dentro del Sistema Tecnológico Nacional y del Estado de Guanajuato.

\section{Emprendimiento}

Ser emprendedor implica afrontar algunos desafíos ligados a la estructura formal de su iniciativa de emprendimiento, es decir, a la integración de variables novedosas que la distingan y marquen la diferencia frente a otras existentes en el mercado al que busca llegar; asimismo, es trascendente reconocer el trabajo continuo del emprendedor para buscar y descubrir diferentes formas para que su iniciativa logre posicionarse en el mercado de manera estratégica y confiable; este escenario lleva al emprendedor a conformar de manera contundente una opción viable de su modelo de negocio para que opere de manera sólida, dinámica y confiable, permitiendo que la iniciativa genere los ingresos mínimos esperados durante la vida útil de la iniciativa. 
Una iniciativa de emprendimiento debe fincarse en dar solución a una necesidad, ya sea de tipo social o técnico, esto implica implementar de forma dinámica acciones para crear un modelo de negocio idóneo para satisfacerla; por otro lado, es primordial integrar a este modelo, elementos diferenciadores y potenciales, garantizando que estos puedan satisfacer las necesidades identificadas.

En la actividad emprendedora, definir un producto o servicio es imprescindible para que un proyecto sea viable; a través de un modelo de negocio es posible aportar valor a la idea; sin embargo, en ocasiones, los emprendedores no aciertan en esta definición y se olvidan de que detrás de la idea de producto debe encontrarse la resolución de una necesidad real y no aquello que el emprendedor cree que puede funcionar.

La idea de negocio es la parte central de la que parten todos los proyectos; si esta idea logra satisfacer un mercado podrá surgir la posibilidad de un beneficio económico, para ello se requiere tener claro el modelo de negocio (figura 1), pues la sola definición de un producto o servicio no asegura conseguir un negocio viable.

\section{Figura 1}

Creación del Modelo de Negocio

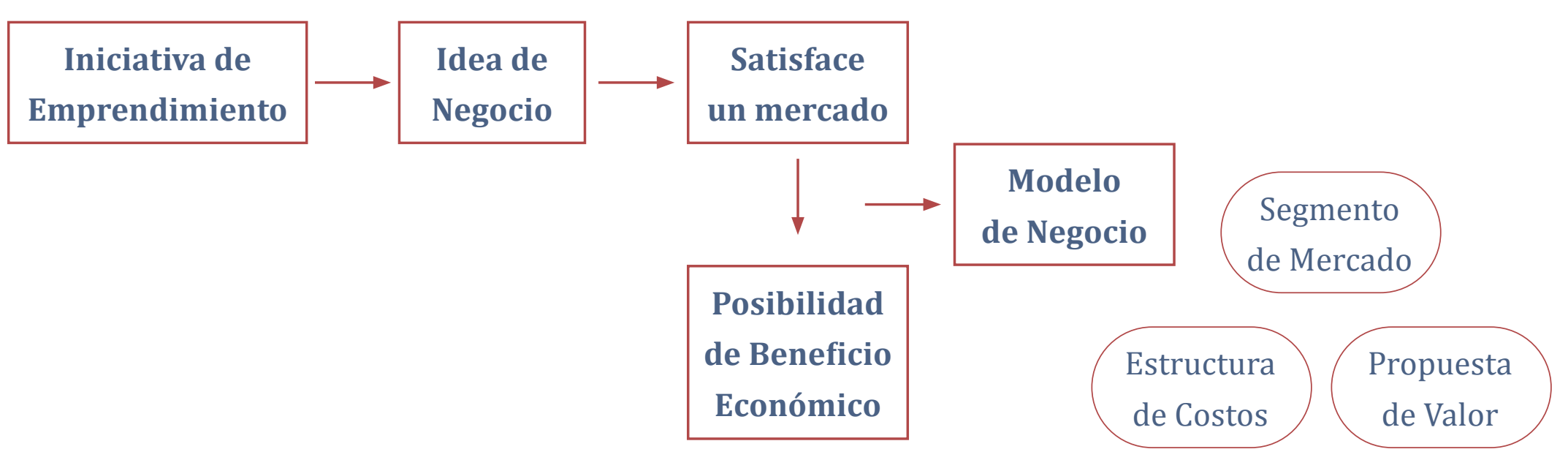

Nota: Elaboración propia.

Una alternativa idónea que permite fortalecer la idea de negocio es la estructura de modelo de negocio que propone Osterwalder (2009) que comprende estos elementos:

- Propuesta de valor. Creada para los clientes y usuarios mediante lo que se ofertará.

- Segmento de mercado. Clientes y usuarios reales.

- Cadena de valor. Actividades clave, alianzas, tareas, recursos clave, activos y tecnología.

- Estructura de costos y fuente de ingresos. 
Chesbrough y Rosenbloom (citados en Llorens, 2010) destacan que las funciones primordiales de un modelo de negocio se basan en: 1) articular la propuesta de valor (toda actividad que se desarrolla desde la compra de material hasta el consumidor final), 2) identificar el segmento de mercado, 3) definir la estructura de la cadena de valor, 4) especificar el mecanismo de generación de ventas, 5) describir la posición de la empresa dentro de la red de valor, y 6) formular la estrategia competitiva.

Diversos autores (Afuah \& Tucci, 2002; Margreta, 2002; Zott \& Amit, 2009) han brindado su postura en torno a la importancia de un modelo de negocios, en este contexto es trascendente contemplar que una característica particular de estas posturas se basa en que los modelos de negocios se construyen con la intención de establecer la manera como una empresa puede obtener ingresos.

El modelo de negocios es una herramienta de gran valor para fortalecer las iniciativas de negocio; permite al emprendedor integrar diversas mejoras de carácter técnico a su propuesta.

\section{Ecosistema de emprendimiento informal y su impacto en el desarrollo de la innovación frugal}

En el lenguaje cotidiano, el término emprendimiento es utilizado cada vez con mayor frecuencia por diversos actores de la sociedad como académicos, políticos y por los mismos emprendedores. El proceso emprendedor está dividido en tres fases: 1) el reconocimiento de la oportunidad, 2) el desarrollo de la oportunidad y 3) la creación de valor.

Un enfoque alternativo que debemos tener en cuenta es el modelo de emprendimiento del Netherlands Institute for Knowledge-intensive Entrepreneurship (NIKOS, 2004), el cual considera su desarrollo a través de cuatro actividades: investigación, enseñanza, apoyo al desarrollo de empresas, formación y consultoría.

Ante la situación actual, el emprendimiento puede ser concebido como un detonador de desarrollo económico, en un entorno global hiperconectado, con alta incertidumbre y desequilibrio económico ocasionado ante los nuevos escenarios provocados a partir de la pandemia COVID-19.

En México, el Instituto Nacional de Estadística y Geografía (INEGI), en su papel de organismo rector para la generación de estadísticas oportunas y debido a la coyuntura por la pandemia, presenta los resultados de la Encuesta sobre el Impacto Generado por COVID-19 en las Empresas (ECOVID-IE): 
- De los 4.9 millones de establecimientos del sector privado y paraestatal registrados en los Censos Económicos 2019, 99.8\% pertenecen al conjunto de establecimientos micro, pequeños y medianos.

- A 17 meses de concluido el levantamiento censal, el Estudio sobre Demografía de los Negocios 2020 estima que, de los 4.9 millones de establecimientos micro, pequeños y medianos sobrevivieron 3.9 millones (79.19\%), poco más de un millón (20.81\%) cerraron sus puertas definitivamente y nacieron 619 mil 443 establecimientos que representan $12.75 \%$ de la población de negocios del país. (INEGI, 2020, párr.1)

En el contexto actual, renace la visión emprendedora como elemento impulsor de la innovación y la generación de crecimiento económico. Según la Organización de las Naciones Unidas para la Educación, la Ciencia y la Cultura (UNESCO, 2017), con la creación de nuevos escenarios de competitividad global, a partir de la innovación generada por perfiles de personas consideradas nómadas digitales en aumento, se estima que más de tres mil billones de personas se formarán y trabajarán desde cualquier parte del mundo, a partir de capacidades multidisciplinares hacia 2030 con libertad financiera, lograda bajo el apoyo de combinaciones rentables en tecnologías y herramientas virtuales con impacto sustancial a su calidad de vida y bajo condiciones de sostenibilidad ambiental.

Por lo tanto, evaluar tanto el ecosistema empresarial (EE) como el papel de los entornos institucionales y la innovación frugal desde la perspectiva del emprendimiento como práctica, se convierte en un elemento esencial de análisis para el entorno económico actual.

El ecosistema empresarial comprende los componentes interactivos de los sistemas empresariales con características locales y regionales particulares (Mason \& Brown, 2014), que están conformados por diversos elementos — dominios, atributos o componentes - y un conjunto de actores, cuyas acciones y relaciones pueden influir en: a) la intención de emprender (Motoyama \& Knowlton, 2016), b) el proceso de emprendimiento (Shane \& Venkataraman, 2000), c) el tipo de emprendimiento (Blank \& Dorf, 2003), y d) el crecimiento y desarrollo de startups (Olutuase, Brijlal, Yan, \& Ologundudu, 2018).

La Organización para la Cooperación y el Desarrollo Económicos (OCDE, 2016) revela que el entorno para la innovación ha cambiado y, por lo tanto, ha aumentado la importancia de las empresas nuevas y pequeñas en el proceso de innovación.

A este nuevo proceso de innovación se le ha denominado frugal, y se explica en el ámbito de aquellas innovaciones realizadas por pequeñas empresas que producen más 
nuevos productos que las grandes, en contraste con los hallazgos que parecen favorecer a las grandes empresas. Esto debido a la capacidad flexible de las pequeñas empresas para generar cambios en la propuesta de valor traducida hacia sus clientes en productos, servicios y tiempo oportuno, ya que ofrecen originalmente a sus clientes accesibilidad, precio, condiciones de uso, tecnología o incluso personalización, en periodos más cortos a partir de procesos optimizados, orilladas por la escasez de algún tipo de recurso, sea este económico, tecnológico, de inversión o relacionados con la atracción del talento idóneo hacia el interior de su estructura empresarial; por lo tanto, emerge al mercado global como una capacidad distintiva empresarial en ágil respuesta de su adaptación al entorno para continuar subsistiendo o para el logro de rentabilidad real.

La innovación frugal representa un nuevo estado de ánimo, uno que ve las limitaciones de recursos como una oportunidad y que favorece la agilidad sobre la eficiencia (Radjou \& Prabhu, 2014). El marco institucional que prevalece en las economías en desarrollo es fundamental para dar forma a la orientación empresarial, la creación de nuevas empresas y, en última instancia, el crecimiento (Williams \& Vorley, 2015).

La ventaja basada en la frugalidad de los ingresos se deriva de la construcción de una estrategia que resuelve las limitaciones en la capacidad de los consumidores para comprar y usar productos.

Las economías emergentes tienen una mayor proporción de su población con ingresos muy bajos; estos grandes segmentos tienden a ser ignorados por empresas de economías avanzadas que asumen que los consumidores no pueden pagar por productos innovadores (Prahalad \& Hammond, 2002).

Es posible entender la innovación frugal como la plataforma de lanzamiento para el emprendimiento informal actual, el cual satisface al cliente por el valor creado en productos y servicios que han sido transformados a partir de escucharlo ágil y de forma pertinente; a partir de la escasez de recursos estructurales o de inversión en la pequeña empresa, con acceso al mercado de manera mayormente eficaz al proceso de lanzamiento de nuevos productos con respecto al despliegue realizado por empresas globales, que transforman su propuesta de valor a partir de los ciclos de planeación y desarrollo de vida a largo alcance, con montos de inversión cuantiosos para su puesta en marcha. Para explicar mejor lo anterior, se comparan tres ejemplos:

- Mercado Libre vs Amazon: plataformas e-commerce para venta de productos o servicios similares con propuestas de valor diferenciadas. 
- Trivago vs Cadena Hotelera RIU: plataformas para reservaciones de alojamiento con opciones de actividades adicionales como ecoturismo, pueblos mágicos, playas vírgenes y destinos históricos.

- Hyundai vs Toyota: marcas de autos compactos; la primera, firma coreana de reciente introducción al mercado mexicano e identificada por vehículos de precios bajos; la segunda, firma japonesa altamente posicionada por su estatus y precios altos orientada a perfiles de cliente con poder adquisitivo elevado, los cuales pueden representar algunas barreras económicas, sociales y culturales.

Los ejemplos anteriores ofrecen productos y servicios sustitutos con propuestas de valor equivalentes, con atributos como garantías, precio, accesibilidad, rapidez, confort, diseño, status y costos, entre otros, ampliamente diferenciados entre empresas de reciente introducción versus empresas de extendida permanencia en el mercado; las primeras atienden participaciones de mercado para consumidores de bajos ingresos, aglutinados en mercados denominados masivos, en contraposición con las empresas globales caracterizadas por posicionamiento de marca, las cuales sugieren precios elevados. Al respecto, la figura 2 ejemplifica la innovación frugal y su impacto en el ecosistema de emprendimiento informal a partir de los resultados: conocimiento efectivo, intercambio de información, redes: compartir recursos.

\section{Figura 2}

Ecosistema de innovación frugal y emprendimiento informal

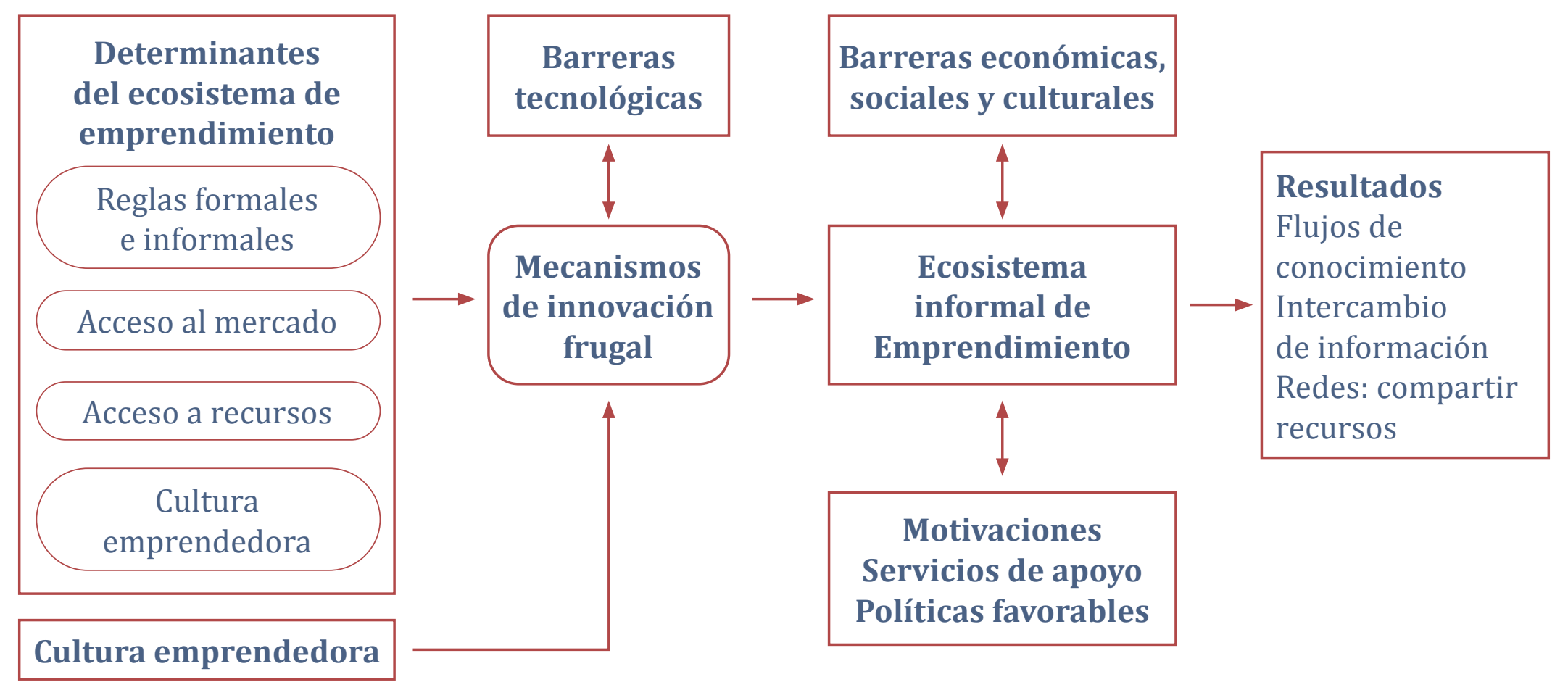

Nota: Tomado de Igwe, Odunukan, Rahman, Rugara, \& Ochinanwata (2020). Traducción libre. 


\section{Caso de estudio}

El Tecnológico Nacional de México como órgano desconcentrado de la Secretaría de Educación Pública de México tiene adscrito 266 institutos en todo el país y atiende una matrícula de 556270 estudiantes, y busca ofrecer una educación superior de buena calidad, orientada a satisfacer las necesidades del desarrollo social, científico, tecnológico, económico, cultural y humano de México.

Dentro del Estado de Guanajuato, el Instituto Tecnológico de Purísima del Rincón (ITSPR) cuenta con seis programas educativos:

1. Ingeniería en Gestión Empresarial

2. Ingeniería Industrial

3. Ingeniería Informática

4. Ingeniería Bioquímica

5. Ingeniería Electromecánica

6. Ingeniería en Sistemas Automotrices

Los programas de estudio antes mencionados son objeto de la presente investigación; tienen una población estudiantil aproximada de 1524 alumnos durante los períodos 2019-2020, para los planes vigentes 2009-201. Los planes fueron realizados en 2009 y revisados en 2016 para la implementación del enfoque de competencias, lo que garantiza su pertinencia.

La estructura y decreto de creación del ITSPR como organismo público descentralizado de la administración pública del estado de Guanajuato obedece a normativa académica desarrollada de forma colegiada dentro del TecNM. Además, la institución se asegura de que los procedimientos del Sistema de Gestión Integral estén alineados a la normativa académica y de operación.

El ITSPR se rige por el Modelo de Educación por Competencias Siglo XXI: Formación y desarrollo de competencias profesionales (DGEST, 2012), conformado por tres dimensiones (figura 3):

En la Dimensión filosófica se sostiene la concepción de que el ser humano y su desarrollo integral constituyen el eje central del proceso educativo-formativo, razón por la cual se profundiza en las directrices de transformación, autogestión y autorregulación como estadios significativos para la autorrealización y la creación de posibilidades para transformar su realidad. 
[...] en la Dimensión académica se adopta el concepto de aprendizaje constructivista, con un enfoque centrado en la formación y el desarrollo de competencias profesionales que resignifica el proceso de evaluación, la relación didáctica entre estudiante y docente, las condiciones idóneas para el diseño de estrategias de aprendizaje y el papel de las academias; también se asume la formación de capital humano apto para desarrollar investigación aplicada, crear tecnología y favorecer la innovación.

La Dimensión organizacional mantiene la gestión por procesos y la gestión educativa para el alto desempeño, con énfasis en el liderazgo transformacional, así como la coordinación y organización de la institución —que regula su operación-, para impulsar el trabajo colaborativo, comprometido y satisfactorio para la persona y la comunidad tecnológica- en favor de la misión y la visión del Sistema. (p.85)

\section{Figura 3}

Dimensionamiento del Modelo Educativo Siglo XXI:

Formación y desarrollo de competencias profesionales

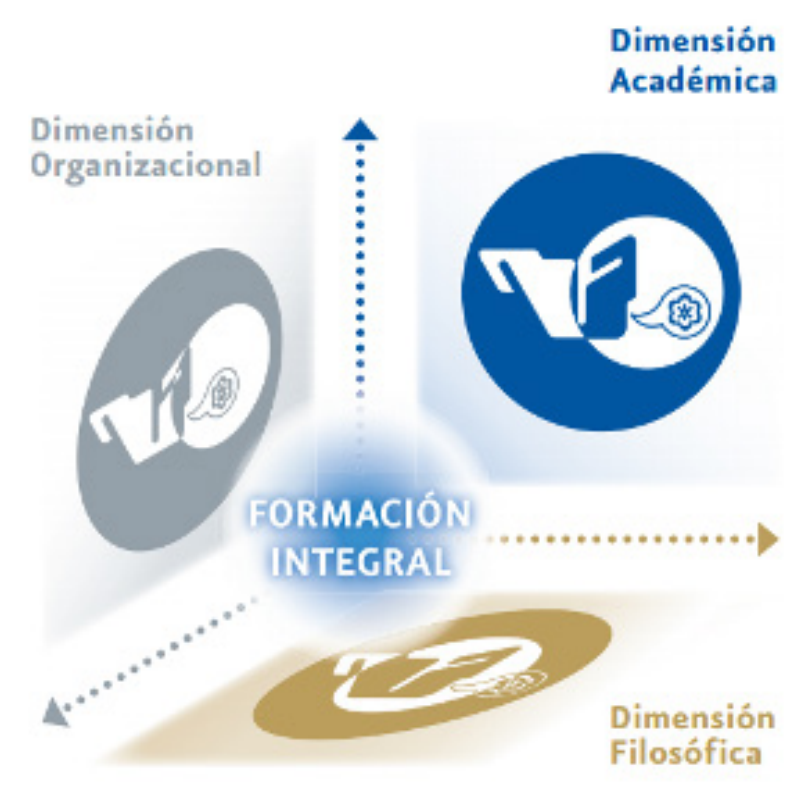

Fuente: DGEST (2012).

El Modelo Educativo Siglo XXI (DGEST, 2012) impulsa el aprovechamiento del potencial del ser humano de manera armónica, propone su integración al conocimiento mundial y su participación en una sociedad más justa y equitativa.

De acuerdo con los resultados institucionales en el estudio de factibilidad (ITSPR, 2019), se puede estimar que la Ingeniería en Gestión Empresarial es considerada una de 
las carreras más pobladas y con mayor oportunidad para integrarse al sector productivo, por la amplitud de su campo laboral.

En la zona de influencia del ITSPR, la Ingeniería en Gestión Empresarial puede identificarse como uno de los campos de aplicación en los sectores productivo y social de tipo público y privado y a la actividad económica principal de la región.

En relación con los perfiles prioritarios demandados en el estado de Guanajuato, sobresale el perfil de ingenierías y, en particular, el de Ingeniería en Gestión Empresarial, por la demanda de un perfil afín para puestos de calidad, manufactura, mantenimiento, procesos, producción y logística, en sectores tales como agroalimenticio, automotriz, calzado, transformación, plástico, metalmecánico y servicios (ITSPR, 2019).

En alineación a la mística institucional, en el ITSPR la formación del estudiante obedece a la creación de una formación integral, basada en competencias profesionales tecnológicas dependiendo de su área multidisciplinar de ingeniería, así como una formación que fomente las vocaciones emprendedoras de su perfil para el desarrollo de capacidades científicas y de innovación que le permitan impactar su entorno a través de soluciones tecnológicas aplicables; por tanto, el Modelo Educativo está fundamentado en el Modelo del Talento Emprendedor (MTE) desarrollado por el Tecnológico Nacional de México (TecNM, 2014).

la misión del MTE es la de fortalecer el desarrollo del espíritu emprendedor en los jóvenes estudiantes del TecNM desarrollando sus aptitudes, valores, responsabilidad social y liderazgo, mejorando con esto el nivel de calidad educativa en nuestro país, coadyuvando a mejorar las condiciones de empleo y la creación de empresas de base tecnológica con alto nivel de innovación. (López, Ortiz, \& Torres, 2018, pp.2-3)

Lo anterior, a partir de los tres perfiles siguientes: Intra-emprendedor, Líder Social y Empresario (figura 4).

Según el Tecnológico Nacional de México (2014) el propósito del MTE si bien es fomentar la innovación tecnológica, como se puede apreciar en la figura [4], su enfoque permite desarrollar integralmente los aspectos humanos de los estudiantes partiendo desde la propia sensibilización del mismo con el objetivo de inspirarlo para llevarlo a través de un proceso de autoconocimiento 
y su relación con el entorno, desarrollando durante el proceso su capacidad creativa y de generar relaciones humanas que le permitan vincularse con el ecosistema emprendedor y salir avante en el proceso de maduración de su ideas rumbo a generar un modelo negocio. (López et al., 2018, p.2)

\section{Figura 4}

Fases del Modelo Talento Emprendedor del TecNM

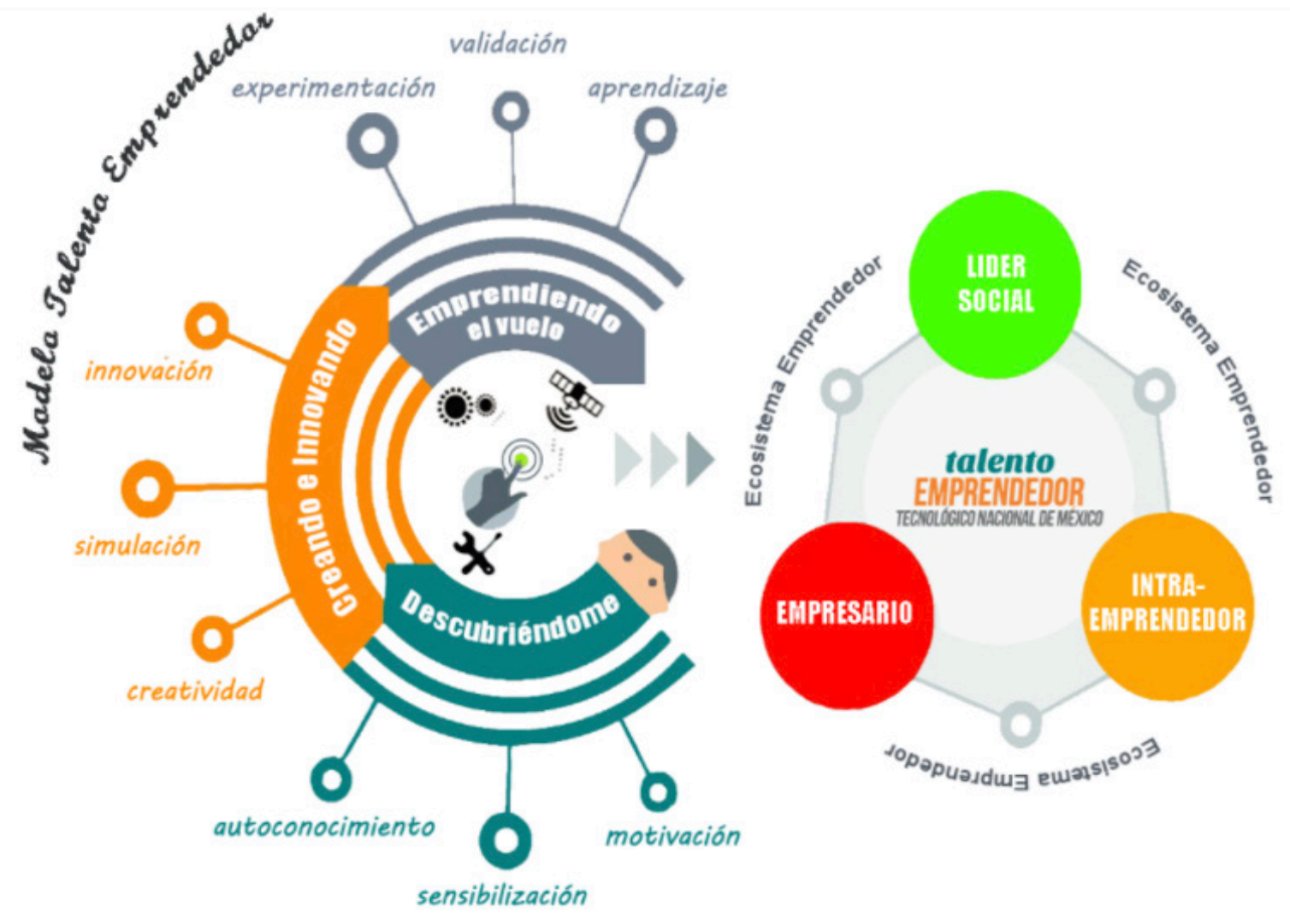

Nota: Tomado de TecNM (s.f.).

\section{Metodología}

Se realizó una investigación con alcance exploratorio, descriptivo y correlacional con enfoque cuantitativo en la búsqueda de la relación de las variables: Autoeficacia percibida, Autonomía, Innovación, Propensión al riesgo y Actitud hacia el emprendimiento, en las seis carreras de Ingeniería del Instituto Tecnológico Superior de Purísima del Rincón. Para lo cual, se diseñó un instrumento de acuerdo con el Modelo Montufar (2018), el cual considera aspectos cognitivos, afectivos, emocionales y conductuales para evaluar las variables mencionadas.

Para la obtención de los datos, se diseñaron y aplicaron 506 encuestas a los estudiantes del ITSPR de los seis programas educativos de ingeniería: Bioquímica, Electromecánica, Industrial, Informática, Gestión Empresarial, y Sistemas Automotrices. La muestra 
fue del 30\% de la población estudiantil de forma representativa a juicio y conveniencia de la presente investigación, como porcentaje mínimo para la realización de investigaciones.

A continuación, se da a conocer el muestreo representativo realizado para cada una de las Ingenierías del ITSPR. En la última columna de la derecha se muestra el número total de estudiantes encuestados. La carrera de Ingeniería en Gestión Empresarial y la de Ingeniería Industrial son las que tienen el mayor número de encuestados, debido a que son las dos más numerosas de la Institución (tabla 1).

\section{Tabla 1}

Distribución del muestreo representativo para cada Ingeniería

\begin{tabular}{lcccccc}
\multicolumn{1}{c}{ Ingeniería } & $\mathbf{2}$ & $\mathbf{4}$ & $\mathbf{6}$ & $\mathbf{8}$ & $\mathbf{1 0}$ & Total \\
\hline Bioquímica & 34 & 16 & 10 & 9 & 6 & $\mathbf{7 5}$ \\
\hline Electromecánica & 33 & 2 & 17 & 18 & 1 & $\mathbf{7 1}$ \\
\hline Industrial & 10 & 0 & 25 & 42 & 8 & $\mathbf{8 5}$ \\
\hline Informática & 10 & 21 & 19 & 16 & 6 & $\mathbf{7 2}$ \\
\hline Gestión Empresarial & 27 & 28 & 49 & 39 & 6 & $\mathbf{1 4 9}$ \\
\hline Sistemas Automotrices & 11 & 5 & 16 & 22 & 0 & $\mathbf{5 4}$ \\
\hline Total & $\mathbf{1 2 5}$ & $\mathbf{7 2}$ & $\mathbf{1 3 6}$ & $\mathbf{1 4 6}$ & $\mathbf{2 7}$ & $\mathbf{5 0 6}$ \\
\hline
\end{tabular}

Nota: Elaboración propia con base en el 30\% del total de alumnos por carrera.

\section{Resultados}

\section{Factores determinantes (variables) considerados para realizar la encuesta}

La muestra se realizó de forma representativa aleatoria a juicio y conveniencia del equipo de investigadores, considerando las características de la población estudiantil a través del análisis de las variables: Autoeficacia percibida, Autonomía, Innovación, Propensión al riesgo y Actitud hacia el emprendimiento.

\section{Autoeficacia percibida}

La autoeficacia percibida establece ser una conducta con la cual produces resultados, pues se trata de ser capaces de ejecutar acciones. Según Bandura (1997), la autoeficacia ha mostrado consistentemente ser un factor de gran importancia, y debe ser conceptualizada de manera específica. La autoeficacia percibida se acota como un alto sentido de 
eficacia y facilita el procesamiento de información y el desempeño cognitivo en distintos contextos, incluyendo la toma de decisiones y el logro académico.

Esta variable es definida también como un rasgo o una característica que posee un sujeto, ya que, al realizar ciertas acciones, este puede tener un juicio o una valoración ante las circunstancias. Se considera a una persona con autoeficacia cuando es eficaz en la ejecución de tareas específicas.

\section{Autonomía}

La autonomía puede ser apreciada como una actitud, y se refiere a la independencia en la toma de decisiones a nivel personal, pero también empresarial; es considerada como la libertad que posee cada individuo para actuar. Se refiere como autonomía a la capacidad y el derecho de poder efectuar los propios juicios morales, ya que es vital su reconocimiento por parte de los individuos (Schneewind, 1998).

El emprendedor desarrolla la capacidad de establecer por cuenta propia los retos que está dispuesto a enfrentar y las decisiones que asumirá, identificar cuál será el camino que puede seguir para culminar sus objetivos, equilibrar los riesgos que asumirá respecto a los resultados que es posible que obtenga y asumir con madurez las consecuencias de las decisiones. La autonomía puede llegar a convertirse en uno de los principales motivos para que un emprendedor logre culminar los retos que afronte conforme avanza en su propuesta de emprendimiento.

\section{Innovación}

Una de las variables decisivas que permite lograr un desarrollo contundente es el conocimiento, este debe plasmarse de manera tangible y convertirse en innovación. La norma mexicana NMX-GT-001-IMNC-2007 considera a la innovación como el: "Proceso [...] dirigido a un mercado bajo un enfoque de negocio que detecta oportunidades y capacidades organizacionales [...] para generar productos, procesos [...] y servicios novedosos aceptados por los consumidores" (Álvarez \& López, 2010, p.5).

De acuerdo con Dussauge (2013), la innovación es una idea nueva hecha realidad o llevada a la práctica e implica invenciones y descubrimientos, aplicados al perfeccionamiento o surgimiento de soluciones a problemas humanos o a propuestas de la sociedad. En nuestros días, la variable innovación desde la perspectiva del emprendimiento está ligada directamente a construir un proceso continuo de conocimientos, que podrá llevar a una serie de acciones novedosas para obtener una mejora significativa o bien, una invención que deberá ser explotada para llegar a un mercado potencial. 
La innovación se centra en una idea nueva, buscando ser explotada de manera exitosa. Piatier (1987) define la innovación como una idea transformada en algo vendido o usado, mientras que Gee (1981) la define como un proceso que parte de una idea, invención o reconocimiento de una necesidad, para desarrollar un producto, técnica o servicio útil hasta que sea comercialmente aceptado.

La actitud de innovación puede fincarse en dos variables detonantes, la invención y el descubrimiento. La invención se relaciona con todas aquellas creaciones que aún no se conocen, mientras que un descubrimiento es aquello que ya existe y, en determinado momento, puede llegar a compartirse con la sociedad para que lo identifique como algo que ignoraba.

\section{Propensión al riesgo}

La toma de riesgos puede considerarse de manera subjetiva y objetiva. Esta actitud se liga a la intención de que un emprendedor tenga la capacidad de afrontar riesgos, aceptarlos y asumir las responsabilidades que se deriven. En ciertos escenarios, cuando el emprendedor posee la capacidad y la preparación para desarrollar su propuesta de proyecto, esta variable se vuelve más flexible de asumir.

El nivel de propensión al riego que un emprendedor puede asumir depende de: 1) el conocimiento y la experiencia adoptada en situaciones o escenarios que el emprendedor llevo a cabo; y 2) los recursos con los que el emprendedor asume la responsabilidad para desarrollar un nuevo proyecto.

\section{Actitud hacia el emprendimiento}

Esta actitud se orienta a emprender; sin duda, es una de las variables con mayor importancia dentro de la propuesta de este análisis, ya que a partir de las actitudes emprendedoras, el perfil del emprendedor se construye paulatinamente durante el desarrollo profesional; esta variable tiene por consecuencia la innovación, que las personas suelen tener para cambiar la forma de hacer las cosas, por algo sumamente nuevo y diferente, a través de una perspectiva diferente a la forma de cubrir las necesidades diarias.

Algunas directrices que fomentan la actitud hacia el emprendimiento durante las primeras etapas de un emprendedor son: 1) la incorporación de nuevos programas en la etapa universitaria que fortifiquen el desarrollo de los estudiantes; y 2) el impulso en la creación de empresas de base tecnológica a través de programas de capacitación. 


\section{Resumen general de resultados de cada uno de los factores determinantes}

En la tabla 2 se muestran los resultados de cada una de las variables, considerando los factores determinantes.

\section{Tabla 2}

Resumen general de los resultados considerando todos los factores determinantes

\begin{tabular}{lccccc} 
& $\begin{array}{c}\text { Autoeficacia } \\
\text { percibida }\end{array}$ & Autonomía & Innovación & $\begin{array}{c}\text { Propensión } \\
\text { al riesgo }\end{array}$ & $\begin{array}{c}\text { Actitud hacia el } \\
\text { emprendimiento }\end{array}$ \\
$\begin{array}{l}\text { Completamente } \\
\text { en desacuerdo }\end{array}$ & $5.1 \%$ & $12.4 \%$ & $3.5 \%$ & $4.0 \%$ & $6.2 \%$ \\
\hline En desacuerdo & $17.4 \%$ & $30.1 \%$ & $14.9 \%$ & $20.8 \%$ & $18.5 \%$ \\
\hline De acuerdo & $41.6 \%$ & $38.5 \%$ & $49.1 \%$ & $50.5 \%$ & $41.6 \%$ \\
\hline Muy de acuerdo & $35.9 \%$ & $19.0 \%$ & $32.5 \%$ & $24.7 \%$ & $33.7 \%$ \\
\hline
\end{tabular}

Nota: Elaboración propia.

De acuerdo con los resultados de la tabla 2 y con apoyo de las variables definidas en la encuesta es pertinente resaltar lo siguiente:

- Considerando la variable de Autoeficacia percibida, el 41.6\% de los estudiantes encuestados está de acuerdo en poseer una conducta que les permite producir resultados.

- De acuerdo con la variable de Autonomía, el 38.5\% de la población encuestada señala que está de acuerdo en poseer una actitud relacionada a la independencia en la toma de decisión.

- Considerando la variable de Innovación, el 49.1\% de los estudiantes encuestados señala que está de acuerdo en poseer atributos de innovación, es decir, buscan nuevas ideas para generar soluciones a diversas necesidades.

- De acuerdo con la variable Propensión al riesgo, el 50.5\% de los estudiantes encuestados está de acuerdo en tomar o asumir riesgos en su vida.

- Considerando la variable de Actitud hacia el emprendimiento, el $41.6 \%$ de la población encuestada está de acuerdo en poseer una actitud emprendedora.

Uno de los aspectos trascendentes que es importante considerar se refiere a las cualidades preponderantes en los estudiantes encuestados, y en ese sentido es pertinente 
señalar que las cualidades de eficacia percibida, innovación y actitud hacia el emprendimiento son las que se presentan un porcentaje más alto, aunque el resto de las cualidades también juegan un rol relevante dentro del perfil emprendedor. Las cualidades evaluadas son un aspecto medular, que de alguna forma pueden definir el perfil de los estudiantes de cada una de las ingenierías, consideradas desde el momento de su ingreso, la permanencia y su egreso.

Además, el perfil de un emprendedor puede apoyarse en las siguientes competencias transversales:

- Apertura a nuevas ideas.

- Confianza en sí mismo.

- Proactividad en la generación de ideas y enfoque en la planeación de la empresa.

- Visión del negocio en el largo plazo.

- Conciencia de las implicaciones que conlleva ser emprendedor.

- Satisfacción por ser emprendedor.

Un rasgo que puede caracterizar a la población estudiantil encuestada es que buscan nuevas ideas para generar soluciones a diversas necesidades, es decir, son innovadores y les motiva generar resultados, al mismo tiempo que buscan aventurarse muy a pesar del factor fracaso. Asimismo, es pertinente destacar que en general la comunidad estudiantil está dispuesta a asumir riesgos.

\section{Resultados por Licenciatura}

A continuación, se muestran los resultados correspondientes al objetivo específico 1: "Diagnosticar los factores determinantes de autoeficacia percibida, autonomía, innovación, propensión al riesgo y actitud hacia el emprendimiento durante la formación profesional de los estudiantes de Ingeniería del Tecnológico Superior de Purísima del Rincón ubicado en el Estado de Guanajuato, México". Los resultados se presentan por licenciatura, considerando la edad de los encuestados.

\section{Ingeniería Bioquímica}

En la tabla 3 se muestran los resultados de los factores determinantes en los encuestados del área de Ingeniería Bioquímica, en el rango de 17 a 22 años. Mientras que en la tabla 4 , los del rango de 23 a 27 años. 


\section{Tabla 3}

Factores determinantes en los encuestados de Ingeniería Bioquímica (17 a 22 años)

\begin{tabular}{lccccc} 
& $\begin{array}{c}\text { Autoeficacia } \\
\text { percibida }\end{array}$ & Autonomía & Innovación & $\begin{array}{c}\text { Propensión } \\
\text { al riesgo }\end{array}$ & $\begin{array}{c}\text { Actitud hacia el } \\
\text { emprendimiento }\end{array}$ \\
$\begin{array}{l}\text { Completamente } \\
\text { en desacuerdo }\end{array}$ & $3.8 \%$ & $9.9 \%$ & $2.6 \%$ & $2.6 \%$ & $4.4 \%$ \\
\hline En desacuerdo & $16.6 \%$ & $28.7 \%$ & $13.7 \%$ & $14.8 \%$ & $17.7 \%$ \\
\hline De acuerdo & $43.7 \%$ & $41.1 \%$ & $52.7 \%$ & $50.3 \%$ & $44.0 \%$ \\
\hline Muy de acuerdo & $35.9 \%$ & $20.3 \%$ & $31.0 \%$ & $32.3 \%$ & $33.9 \%$ \\
\hline
\end{tabular}

Nota: Elaboración propia.

\section{Tabla 4}

Factores determinantes en los encuestados de Ingeniería Bioquímica (23 a 27 años)

\begin{tabular}{lccccc} 
& $\begin{array}{c}\text { Autoeficacia } \\
\text { percibida }\end{array}$ & Autonomía & Innovación & $\begin{array}{c}\text { Propensión } \\
\text { al riesgo }\end{array}$ & $\begin{array}{c}\text { Actitud hacia el } \\
\text { emprendimiento }\end{array}$ \\
$\begin{array}{l}\text { Completamente } \\
\text { en desacuerdo }\end{array}$ & $9.4 \%$ & $15.6 \%$ & $3.9 \%$ & $3.9 \%$ & $7.2 \%$ \\
\hline En desacuerdo & $15.6 \%$ & $31.1 \%$ & $9.4 \%$ & $14.4 \%$ & $15.0 \%$ \\
\hline De acuerdo & $40.0 \%$ & $36.7 \%$ & $49.4 \%$ & $44.4 \%$ & $45.6 \%$ \\
\hline Muy de acuerdo & $35.0 \%$ & $16.7 \%$ & $37.2 \%$ & $37.2 \%$ & $32.2 \%$ \\
\hline
\end{tabular}

Nota: Elaboración propia.

De acuerdo con el análisis generado, los estudiantes más jóvenes poseen en mayor medida una cualidad de innovación, sin embargo, en cuanto a la cualidad de autoeficacia percibida no son tan fuertes, además, están dispuestos a asumir riesgos y tienen orientación al emprendimiento. En relación con los estudiantes de mayor edad, la actitud hacia el emprendimiento predomina más, sin embargo, disminuye su cualidad para asumir riesgos, pero son más colaborativos conforme van creciendo.

\section{Ingeniería Electromecánica}

En la tabla 5 se muestran los resultados de los factores determinantes en los encuestados del área de Ingeniería Electromecánica, en el rango de 17 a 22 años. Mientras que en la tabla 6, los del rango de 23 a 27 años. 


\section{Tabla 5}

Factores determinantes en los encuestados de Ingeniería Electromecánica (17 a 22 años)

\begin{tabular}{lccccc} 
& $\begin{array}{c}\text { Autoeficacia } \\
\text { percibida }\end{array}$ & Autonomía & Innovación & $\begin{array}{c}\text { Propensión } \\
\text { al riesgo }\end{array}$ & $\begin{array}{c}\text { Actitud hacia el } \\
\text { emprendimiento }\end{array}$ \\
\hline $\begin{array}{l}\text { Completamente } \\
\text { en desacuerdo }\end{array}$ & $4.0 \%$ & $11.2 \%$ & $2.7 \%$ & $2.5 \%$ & $6.2 \%$ \\
\hline En desacuerdo & $17.5 \%$ & $26.5 \%$ & $15.6 \%$ & $15.6 \%$ & $16.8 \%$ \\
\hline De acuerdo & $43.7 \%$ & $43.0 \%$ & $47.9 \%$ & $47.4 \%$ & $42.7 \%$ \\
\hline Muy de acuerdo & $34.8 \%$ & $19.3 \%$ & $33.8 \%$ & $34.5 \%$ & $34.3 \%$ \\
\hline
\end{tabular}

Nota: Elaboración propia.

\section{Tabla 6}

Factores determinantes en los encuestados de Ingeniería Electromecánica (23 a 27 años)

\begin{tabular}{lccccc} 
& $\begin{array}{c}\text { Autoeficacia } \\
\text { percibida }\end{array}$ & Autonomía & Innovación & $\begin{array}{c}\text { Propensión } \\
\text { al riesgo }\end{array}$ & $\begin{array}{c}\text { Actitud hacia el } \\
\text { emprendimiento }\end{array}$ \\
$\begin{array}{l}\text { Completamente } \\
\text { en desacuerdo }\end{array}$ & $4.3 \%$ & $13.8 \%$ & $1.9 \%$ & $2.4 \%$ & $4.3 \%$ \\
\hline En desacuerdo & $16.7 \%$ & $29.5 \%$ & $9.0 \%$ & $17.6 \%$ & $13.8 \%$ \\
\hline De acuerdo & $35.2 \%$ & $30.0 \%$ & $44.3 \%$ & $47.6 \%$ & $44.8 \%$ \\
\hline Muy de acuerdo & $43.8 \%$ & $26.7 \%$ & $44.8 \%$ & $32.4 \%$ & $37.1 \%$ \\
\hline
\end{tabular}

Nota: Elaboración propia.

De acuerdo con los porcentajes que se muestran en las tablas 5 y 6 , es pertinente señalar que los estudiantes más jóvenes presentan dos cualidades en mayor porcentaje (innovación y propensión al riesgo); mientras que la autoeficacia, la autonomía y la actitud hacia el emprendimiento son cualidades que se encuentran en porcentajes similares. En relación con los estudiantes más grandes, la cualidad de propensión al riesgo se mantiene, conforme aumenta su edad, la cualidad de innovación va disminuyendo, y buscan generar más resultados, colaborar y trabajar en equipo; su actitud hacia el emprendimiento es mayor. 


\section{Ingeniería Industrial}

En la tabla 7 se muestran los resultados de los factores determinantes en los encuestados del área de Ingeniería Industrial, en el rango de 17 a 22 años. Mientras que en la tabla 8, los del rango de 23 a 27 años.

\section{Tabla 7}

Factores determinantes en los encuestados de Ingeniería Industrial (17 a 22 años)

\begin{tabular}{lccccc} 
& $\begin{array}{c}\text { Autoeficacia } \\
\text { percibida }\end{array}$ & Autonomía & Innovación & $\begin{array}{c}\text { Propensión } \\
\text { al riesgo }\end{array}$ & $\begin{array}{c}\text { Actitud hacia el } \\
\text { emprendimiento }\end{array}$ \\
\hline $\begin{array}{l}\text { Completamente } \\
\text { en desacuerdo }\end{array}$ & $4.1 \%$ & $10.5 \%$ & $2.4 \%$ & $3.5 \%$ & $6.1 \%$ \\
\hline En desacuerdo & $18.9 \%$ & $33.0 \%$ & $16.6 \%$ & $18.5 \%$ & $19.3 \%$ \\
\hline De acuerdo & $44.4 \%$ & $38.8 \%$ & $54.9 \%$ & $51.3 \%$ & $44.6 \%$ \\
\hline Muy de acuerdo & $32.6 \%$ & $17.7 \%$ & $26.1 \%$ & $26.7 \%$ & $30.1 \%$ \\
\hline
\end{tabular}

Nota: Elaboración propia.

\section{Tabla 8}

Factores determinantes en los encuestados de Ingeniería Industrial (23 a 27 años)

\begin{tabular}{lccccc} 
& $\begin{array}{c}\text { Autoeficacia } \\
\text { percibida }\end{array}$ & Autonomía & Innovación & $\begin{array}{c}\text { Propensión } \\
\text { al riesgo }\end{array}$ & $\begin{array}{c}\text { Actitud hacia el } \\
\text { emprendimiento }\end{array}$ \\
\hline $\begin{array}{l}\text { Completamente } \\
\text { en desacuerdo }\end{array}$ & $6.7 \%$ & $10.4 \%$ & $2.0 \%$ & $1.0 \%$ & $5.2 \%$ \\
\hline En desacuerdo & $19.5 \%$ & $31.9 \%$ & $14.8 \%$ & $16.0 \%$ & $19.0 \%$ \\
\hline De acuerdo & $30.1 \%$ & $34.3 \%$ & $47.7 \%$ & $48.9 \%$ & $38.0 \%$ \\
\hline Muy de acuerdo & $43.7 \%$ & $23.5 \%$ & $35.6 \%$ & $34.1 \%$ & $37.8 \%$ \\
\hline
\end{tabular}

Nota: Elaboración propia.

Considerando los resultados de la tabla 7 y 8 para los estudiantes de Ingeniería Industrial, es pertinente destacar lo siguiente: en los estudiantes más jóvenes, la cualidad de innovación se presenta con mayor fuerza, seguida de la propensión al riesgo. Mientras que la autonomía es la cualidad más débil. Respecto a los estudiantes de mayor edad, las cualidades de innovación y propensión al riesgo se mantienen como las más fuertes; la orientación emprendedora disminuye, así como la autonomía. 


\section{Ingeniería Informática}

En la tabla 9 se muestran los resultados de los factores determinantes en los encuestados del área de Ingeniería Informática, en el rango de 17 a 22 años. Mientras que en la tabla 10, los del rango de 23 a 27 años.

\section{Tabla 9}

Factores determinantes en los encuestados de Ingeniería Informática (17 a 22 años)

\begin{tabular}{lccccc} 
& $\begin{array}{c}\text { Autoeficacia } \\
\text { percibida }\end{array}$ & Autonomía & Innovación & $\begin{array}{c}\text { Propensión } \\
\text { al riesgo }\end{array}$ & $\begin{array}{c}\text { Actitud hacia el } \\
\text { emprendimiento }\end{array}$ \\
\hline $\begin{array}{l}\text { Completamente } \\
\text { en desacuerdo }\end{array}$ & $4.2 \%$ & $11.0 \%$ & $3.3 \%$ & $2.2 \%$ & $5.4 \%$ \\
\hline En desacuerdo & $18.2 \%$ & $31.3 \%$ & $14.6 \%$ & $16.7 \%$ & $21.6 \%$ \\
\hline De acuerdo & $45.1 \%$ & $40.6 \%$ & $51.6 \%$ & $50.7 \%$ & $43.4 \%$ \\
\hline Muy de acuerdo & $32.5 \%$ & $17.0 \%$ & $30.5 \%$ & $30.4 \%$ & $29.6 \%$ \\
\hline
\end{tabular}

Nota: Elaboración propia.

\section{Tabla 10}

Factores determinantes en los encuestados de Ingeniería Informática (23 a 27 años)

\begin{tabular}{lccccc} 
& $\begin{array}{c}\text { Autoeficacia } \\
\text { percibida }\end{array}$ & Autonomía & Innovación & $\begin{array}{c}\text { Propensión } \\
\text { al riesgo }\end{array}$ & $\begin{array}{c}\text { Actitud hacia el } \\
\text { emprendimiento }\end{array}$ \\
\hline $\begin{array}{l}\text { Completamente } \\
\text { en desacuerdo }\end{array}$ & $1.5 \%$ & $8.9 \%$ & $3.0 \%$ & $0 \%$ & $2.2 \%$ \\
\hline En desacuerdo & $22.2 \%$ & $34.1 \%$ & $14.8 \%$ & $18.5 \%$ & $21.5 \%$ \\
\hline De acuerdo & $48.1 \%$ & $36.3 \%$ & $34.8 \%$ & $44.4 \%$ & $45.9 \%$ \\
\hline Muy de acuerdo & $28.1 \%$ & $20.7 \%$ & $47.4 \%$ & $37.0 \%$ & $30.4 \%$ \\
\hline
\end{tabular}

Nota: Elaboración propia.

Para el caso de los estudiantes más jóvenes, es pertinente señalar que las dos cualidades que poseen en mayor porcentaje son la innovación, la propensión al riesgo y la actitud hacia el emprendimiento; la autonomía se encuentra en el menor porcentaje, es decir, son poco autónomos. 
Considerando los resultados del grupo de entre 23 a 27 años, llama la atención que la innovación cae drásticamente y la eficacia es la que los caracteriza, es decir, buscan obtener resultados. Asimismo, los resultados señalan que son menos autónomos conforme van creciendo; por su parte, la actitud hacia el emprendimiento también se mantiene.

\section{Ingeniería en Gestión Empresarial}

En la tabla 11 se muestran los resultados de los factores determinantes en los encuestados del área de Ingeniería en Gestión Empresarial en el rango de 17 a 22 años. Mientras que en la tabla 12 , los del rango de 23 a 27 años.

\section{Tabla 11}

Factores determinantes en los encuestados de Ingeniería en Gestión Empresarial (17 a 22 años)

\begin{tabular}{lccccc} 
& $\begin{array}{c}\text { Autoeficacia } \\
\text { percibida }\end{array}$ & Autonomía & Innovación & $\begin{array}{c}\text { Propensión } \\
\text { al riesgo }\end{array}$ & $\begin{array}{c}\text { Actitud hacia el } \\
\text { emprendimiento }\end{array}$ \\
\hline $\begin{array}{l}\text { Completamente } \\
\text { en desacuerdo }\end{array}$ & $5.9 \%$ & $15.3 \%$ & $4.6 \%$ & $3.2 \%$ & $8.1 \%$ \\
\hline En desacuerdo & $17.7 \%$ & $30.8 \%$ & $17.0 \%$ & $17.9 \%$ & $20.6 \%$ \\
\hline De acuerdo & $40.2 \%$ & $34.7 \%$ & $46.2 \%$ & $47.4 \%$ & $37.5 \%$ \\
\hline Muy de acuerdo & $36.1 \%$ & $19.2 \%$ & $32.2 \%$ & $31.4 \%$ & $33.8 \%$ \\
\hline
\end{tabular}

Nota: Elaboración propia.

\section{Tabla 12}

Factores determinantes en los encuestados de Ingeniería en Gestión Empresarial (23 a 27 años)

\begin{tabular}{lccccc} 
& $\begin{array}{c}\text { Autoeficacia } \\
\text { percibida }\end{array}$ & Autonomía & Innovación & $\begin{array}{c}\text { Propensión } \\
\text { al riesgo }\end{array}$ & $\begin{array}{c}\text { Actitud hacia el } \\
\text { emprendimiento }\end{array}$ \\
$\begin{array}{l}\text { Completamente } \\
\text { en desacuerdo }\end{array}$ & $8.9 \%$ & $17.0 \%$ & $10.0 \%$ & $8.1 \%$ & $10.0 \%$ \\
\hline En desacuerdo & $16.7 \%$ & $28.1 \%$ & $14.8 \%$ & $11.1 \%$ & $16.3 \%$ \\
\hline De acuerdo & $38.1 \%$ & $39.6 \%$ & $44.1 \%$ & $43.3 \%$ & $36.7 \%$ \\
\hline Muy de acuerdo & $36.3 \%$ & $15.2 \%$ & $31.1 \%$ & $37.4 \%$ & $37.0 \%$ \\
\hline
\end{tabular}

Nota: Elaboración propia. 
Los resultados obtenidos del grupo de estudiantes de 17 a 22 años indican que la cualidad más fuerte es que asumen riesgos, son innovadores y buscan ser autoeficaces; la actitud hacia el emprendimiento es la cualidad que muestran con un porcentaje más bajo.

En el caso de los estudiantes de 23 a 27 años, se mantienen con un porcentaje alto en las cualidades de innovación y propensión al riesgo, la actitud hacia el emprendimiento se mantiene, y la cualidad de autonomía se incrementa; mientras que la autoeficacia se encuentra en un porcentaje bajo relacionado con el grupo de 17 a 22 años.

\section{Ingeniería en Sistemas Automotrices}

En la tabla 13 se muestran los resultados de los factores determinantes en los encuestados del área de Ingeniería en Sistemas Automotrices en el rango de 17 a 22 años. Es pertinente señalar que el análisis para los estudiantes de 23 a 27 no se tomó en cuenta debido a que la muestra es muy pequeña.

\section{Tabla 13}

Factores determinantes en los encuestados de Ingeniería en Sistemas Automotrices (17 a 22 años)

\begin{tabular}{lccccc} 
& $\begin{array}{c}\text { Autoeficacia } \\
\text { percibida }\end{array}$ & Autonomía & Innovación & $\begin{array}{c}\text { Propensión } \\
\text { al riesgo }\end{array}$ & $\begin{array}{c}\text { Actitud hacia el } \\
\text { emprendimiento }\end{array}$ \\
\hline $\begin{array}{l}\text { Completamente } \\
\text { en desacuerdo }\end{array}$ & $5.2 \%$ & $12.2 \%$ & $3.4 \%$ & $3.90 \%$ & $5.2 \%$ \\
\hline En desacuerdo & $13.6 \%$ & $27.5 \%$ & $11.4 \%$ & $12.70 \%$ & $14.1 \%$ \\
\hline De acuerdo & $41.6 \%$ & $42.7 \%$ & $51.1 \%$ & $51.50 \%$ & $42.9 \%$ \\
\hline Muy de acuerdo & $39.6 \%$ & $17.6 \%$ & $34.1 \%$ & $31.90 \%$ & $37.8 \%$ \\
\hline
\end{tabular}

Nota: Elaboración propia.

La innovación y la propensión al riesgo son las cualidades de mayor porcentaje en este grupo, mientras que la actitud hacia el emprendimiento y la autonomía se encuentran en segundo término. Una descripción general para este grupo es que son estudiantes innovadores que asumen riesgos, y que muestran una actitud de emprendimiento de manera adecuada y donde el trabajo realizado posee un pilar de autonomía de forma significativa. 


\section{Análisis por género}

En este apartado se presentan los resultados de los encuestados de las diferentes licenciaturas, considerando el género.

\section{Ingeniería Bioquímica}

En la tabla 14 se muestran los resultados de los factores determinantes en los hombres encuestados del área de Ingeniería Bioquímica. Mientras que en la tabla 15, los resultados de las mujeres.

\section{Tabla 14}

Factores determinantes en los hombres encuestados de Ingeniería Bioquímica

\begin{tabular}{lccccc} 
& $\begin{array}{c}\text { Autoeficacia } \\
\text { percibida }\end{array}$ & Autonomía & Innovación & $\begin{array}{c}\text { Propensión } \\
\text { al riesgo }\end{array}$ & $\begin{array}{c}\text { Actitud hacia el } \\
\text { emprendimiento }\end{array}$ \\
$\begin{array}{l}\text { Completamente } \\
\text { en desacuerdo }\end{array}$ & $5.1 \%$ & $11.7 \%$ & $4.4 \%$ & $5.7 \%$ & $5.7 \%$ \\
\hline En desacuerdo & $15.6 \%$ & $28.6 \%$ & $8.6 \%$ & $11.4 \%$ & $15.9 \%$ \\
\hline De acuerdo & $40.0 \%$ & $31.7 \%$ & $48.9 \%$ & $36.8 \%$ & $35.9 \%$ \\
\hline Muy de acuerdo & $39.4 \%$ & $27.9 \%$ & $38.1 \%$ & $46.0 \%$ & $42.5 \%$ \\
\hline
\end{tabular}

Nota: Elaboración propia.

\section{Tabla 15}

Factores determinantes en las mujeres encuestadas de Ingeniería Bioquímica

\begin{tabular}{lccccc} 
& $\begin{array}{c}\text { Autoeficacia } \\
\text { percibida }\end{array}$ & Autonomía & Innovación & $\begin{array}{c}\text { Propensión } \\
\text { al riesgo }\end{array}$ & $\begin{array}{c}\text { Actitud hacia el } \\
\text { emprendimiento }\end{array}$ \\
\hline $\begin{array}{l}\text { Completamente } \\
\text { en desacuerdo }\end{array}$ & $4.6 \%$ & $10.5 \%$ & $2.2 \%$ & $1.7 \%$ & $4.6 \%$ \\
\hline En desacuerdo & $16.8 \%$ & $29.3 \%$ & $14.7 \%$ & $16.0 \%$ & $17.8 \%$ \\
\hline De acuerdo & $44.3 \%$ & $43.7 \%$ & $53.5 \%$ & $54.2 \%$ & $47.5 \%$ \\
\hline Muy de acuerdo & $34.3 \%$ & $16.5 \%$ & $29.6 \%$ & $28.0 \%$ & $30.1 \%$ \\
\hline
\end{tabular}

Nota: Elaboración propia. 
Los resultados que se muestran en la tabla 14 y 15 muestran que la innovación es la cualidad que predomina tanto para las mujeres como para los hombres. En el caso de las mujeres la segunda cualidad es la de propensión al riesgo, mientras que para los hombres es la autoeficacia.

\section{Ingeniería Electromecánica}

En la tabla 16 se muestran los resultados de los factores determinantes en los hombres encuestados del área de Ingeniería Electromecánica. Mientras que en la tabla 17, los resultados de las mujeres.

\section{Tabla 16}

Factores determinantes en los hombres encuestados de Ingeniería Electromecánica

\begin{tabular}{lccccc} 
& $\begin{array}{c}\text { Autoeficacia } \\
\text { percibida }\end{array}$ & Autonomía & Innovación & $\begin{array}{c}\text { Propensión } \\
\text { al riesgo }\end{array}$ & $\begin{array}{c}\text { Actitud hacia el } \\
\text { emprendimiento }\end{array}$ \\
\hline $\begin{array}{l}\text { Completamente } \\
\text { en desacuerdo }\end{array}$ & $3.8 \%$ & $11.80 \%$ & $2.7 \%$ & $2.4 \%$ & $5.7 \%$ \\
\hline En desacuerdo & $17.2 \%$ & $26.70 \%$ & $13.4 \%$ & $15.5 \%$ & $16.4 \%$ \\
\hline De acuerdo & $42.1 \%$ & $40.20 \%$ & $46.5 \%$ & $47.3 \%$ & $41.7 \%$ \\
\hline Muy de acuerdo & $36.9 \%$ & $21.30 \%$ & $37.4 \%$ & $34.9 \%$ & $36.1 \%$ \\
\hline
\end{tabular}

Nota: Elaboración propia.

\section{Tabla 17}

Factores determinantes en las mujeres encuestadas de Ingeniería Electromecánica

\begin{tabular}{lccccc} 
& $\begin{array}{c}\text { Autoeficacia } \\
\text { percibida }\end{array}$ & Autonomía & Innovación & $\begin{array}{c}\text { Propensión } \\
\text { al riesgo }\end{array}$ & $\begin{array}{c}\text { Actitud hacia el } \\
\text { emprendimiento }\end{array}$ \\
$\begin{array}{l}\text { Completamente } \\
\text { en desacuerdo }\end{array}$ & $6.7 \%$ & $8.9 \%$ & $1.1 \%$ & $3.3 \%$ & $5.6 \%$ \\
\hline En desacuerdo & $20.0 \%$ & $36.7 \%$ & $26.7 \%$ & $23.3 \%$ & $16.7 \%$ \\
\hline De acuerdo & $45.6 \%$ & $43.3 \%$ & $55.6 \%$ & $52.2 \%$ & $60.0 \%$ \\
\hline Muy de acuerdo & $27.8 \%$ & $11.1 \%$ & $16.7 \%$ & $21.1 \%$ & $17.8 \%$ \\
\hline
\end{tabular}

Nota: Elaboración propia. 
Los resultados obtenidos en hombres y mujeres son positivos, las cualidades más altas son la innovación, la propensión al riesgo y la actitud hacia el emprendimiento. En este sentido, las mujeres presentan los porcentajes más altos.

\section{Ingeniería Industrial}

En la tabla 18 se muestran los resultados de los factores determinantes en los hombres encuestados del área de Ingeniería Industrial. Mientras que en la tabla 19, los resultados de las mujeres.

\section{Tabla 18}

Factores determinantes en los hombres encuestados de Ingeniería Industrial

\begin{tabular}{lccccc} 
& $\begin{array}{c}\text { Autoeficacia } \\
\text { percibida }\end{array}$ & Autonomía & Innovación & $\begin{array}{c}\text { Propensión } \\
\text { al riesgo }\end{array}$ & $\begin{array}{c}\text { Actitud hacia el } \\
\text { emprendimiento }\end{array}$ \\
$\begin{array}{l}\text { Completamente } \\
\text { en desacuerdo }\end{array}$ & $3.8 \%$ & $11.60 \%$ & $2.3 \%$ & $3.3 \%$ & $6.2 \%$ \\
\hline En desacuerdo & $17.7 \%$ & $30.80 \%$ & $12.8 \%$ & $14.3 \%$ & $15.0 \%$ \\
\hline De acuerdo & $37.4 \%$ & $33.90 \%$ & $50.5 \%$ & $47.5 \%$ & $39.7 \%$ \\
\hline Muy de acuerdo & $41.0 \%$ & $23.70 \%$ & $34.5 \%$ & $34.9 \%$ & $39.0 \%$ \\
\hline
\end{tabular}

Nota: Elaboración propia.

\section{Tabla 19}

Factores determinantes en las mujeres encuestadas de Ingeniería Industrial

\begin{tabular}{lccccc} 
& $\begin{array}{c}\text { Autoeficacia } \\
\text { percibida }\end{array}$ & Autonomía & Innovación & $\begin{array}{c}\text { Propensión } \\
\text { al riesgo }\end{array}$ & $\begin{array}{c}\text { Actitud hacia el } \\
\text { emprendimiento }\end{array}$ \\
$\begin{array}{l}\text { Completamente } \\
\text { en desacuerdo }\end{array}$ & $6.8 \%$ & $9.6 \%$ & $2.50 \%$ & $2.3 \%$ & $5.1 \%$ \\
\hline En desacuerdo & $20.2 \%$ & $34.2 \%$ & $19.50 \%$ & $21.2 \%$ & $23.0 \%$ \\
\hline De acuerdo & $40.9 \%$ & $40.7 \%$ & $53.50 \%$ & $53.0 \%$ & $45.6 \%$ \\
\hline Muy de acuerdo & $32.1 \%$ & $15.4 \%$ & $24.60 \%$ & $23.5 \%$ & $26.3 \%$ \\
\hline
\end{tabular}

Nota: Elaboración propia. 
Los resultados obtenidos en hombres y mujeres son positivos, en el caso de las mujeres las cualidades de innovación, propensión al riesgo y actitud hacia el emprendimiento presentan los mayores porcentajes, mientras que en los hombres únicamente la innovación y propensión al riesgo.

\section{Ingeniería Informática}

En la tabla 20 se muestran los resultados de los factores determinantes en los hombres encuestados del área de Ingeniería Informática. Mientras que en la tabla 21, los resultados de las mujeres.

\section{Tabla 20}

Factores determinantes para los hombres encuestados de Ingeniería Informática

\begin{tabular}{lccccc} 
& $\begin{array}{c}\text { Autoeficacia } \\
\text { percibida }\end{array}$ & Autonomía & Innovación & $\begin{array}{c}\text { Propensión } \\
\text { al riesgo }\end{array}$ & $\begin{array}{c}\text { Actitud hacia el } \\
\text { emprendimiento }\end{array}$ \\
$\begin{array}{l}\text { Completamente } \\
\text { en desacuerdo }\end{array}$ & $3.7 \%$ & $11.6 \%$ & $3.3 \%$ & $2.2 \%$ & $5.3 \%$ \\
\hline En desacuerdo & $18.8 \%$ & $31.7 \%$ & $13.1 \%$ & $17.9 \%$ & $20.8 \%$ \\
\hline De acuerdo & $44.6 \%$ & $38.6 \%$ & $50.9 \%$ & $47.8 \%$ & $42.9 \%$ \\
\hline Muy de acuerdo & $32.9 \%$ & $18.1 \%$ & $32.7 \%$ & $32.0 \%$ & $31.0 \%$ \\
\hline
\end{tabular}

Nota: Elaboración propia.

\section{Tabla 21}

Factores determinantes en las mujeres encuestadas de Ingeniería Informática

\begin{tabular}{lccccc} 
& $\begin{array}{c}\text { Autoeficacia } \\
\text { percibida }\end{array}$ & Autonomía & Innovación & $\begin{array}{c}\text { Propensión } \\
\text { al riesgo }\end{array}$ & $\begin{array}{c}\text { Actitud hacia el } \\
\text { emprendimiento }\end{array}$ \\
$\begin{array}{l}\text { Completamente } \\
\text { en desacuerdo }\end{array}$ & $4.4 \%$ & $7.6 \%$ & $3.1 \%$ & $0.9 \%$ & $4.0 \%$ \\
\hline En desacuerdo & $18.2 \%$ & $31.6 \%$ & $20.4 \%$ & $13.3 \%$ & $24.4 \%$ \\
\hline De acuerdo & $48.9 \%$ & $45.8 \%$ & $44.4 \%$ & $57.8 \%$ & $46.7 \%$ \\
\hline Muy de acuerdo & $28.4 \%$ & $15.1 \%$ & $32.0 \%$ & $28.0 \%$ & $24.9 \%$ \\
\hline
\end{tabular}

Nota: Elaboración propia. 
Los resultados que se derivan de las tablas 20 y 21 muestran que la variable de propensión al riesgo es la de mayor presencia en hombres y mujeres. En el caso de los hombres, la cualidad de mayor presencia es la innovación, seguida de la propensión al riesgo, la autoeficacia y la actitud hacia el emprendimiento. En el caso de las mujeres, la cualidad con mayor porcentaje es la propensión al riesgo seguida de la autoeficacia y de la actitud hacia el emprendimiento.

\section{Ingeniería en Gestión Empresarial}

En la tabla 22 se muestran los resultados de los factores determinantes para los hombres encuestados del área de Ingeniería en Gestión Empresarial. Mientras que en la tabla 23, los resultados de las mujeres.

\section{Tabla 22}

Factores determinantes en los hombres encuestados de Ingeniería en Gestión Empresarial

\begin{tabular}{lccccc} 
& $\begin{array}{c}\text { Autoeficacia } \\
\text { percibida }\end{array}$ & Autonomía & Innovación & $\begin{array}{c}\text { Propensión } \\
\text { al riesgo }\end{array}$ & $\begin{array}{c}\text { Actitud hacia el } \\
\text { emprendimiento }\end{array}$ \\
\hline $\begin{array}{l}\text { Completamente } \\
\text { en desacuerdo }\end{array}$ & $7.6 \%$ & $14.6 \%$ & $6.0 \%$ & $5.4 \%$ & $9.8 \%$ \\
\hline En desacuerdo & $18.4 \%$ & $32.4 \%$ & $17.8 \%$ & $17.6 \%$ & $18.4 \%$ \\
\hline De acuerdo & $41.7 \%$ & $37.8 \%$ & $47.9 \%$ & $45.7 \%$ & $38.7 \%$ \\
\hline Muy de acuerdo & $32.2 \%$ & $15.2 \%$ & $28.3 \%$ & $31.3 \%$ & $33.0 \%$ \\
\hline
\end{tabular}

Nota: Elaboración propia.

\section{Tabla 23}

Factores determinantes para las mujeres encuestadas de Ingeniería en Gestión Empresarial

\begin{tabular}{lccccc} 
& $\begin{array}{c}\text { Autoeficacia } \\
\text { percibida }\end{array}$ & Autonomía & Innovación & $\begin{array}{c}\text { Propensión } \\
\text { al riesgo }\end{array}$ & $\begin{array}{c}\text { Actitud hacia el } \\
\text { emprendimiento }\end{array}$ \\
$\begin{array}{l}\text { Completamente } \\
\text { en desacuerdo }\end{array}$ & $5.8 \%$ & $15.0 \%$ & $5.0 \%$ & $3.2 \%$ & $7.7 \%$ \\
\hline En desacuerdo & $17.3 \%$ & $29.7 \%$ & $16.3 \%$ & $16.8 \%$ & $20.6 \%$ \\
\hline De acuerdo & $39.2 \%$ & $34.3 \%$ & $45.0 \%$ & $47.3 \%$ & $36.8 \%$ \\
\hline Muy de acuerdo & $37.8 \%$ & $20.1 \%$ & $33.8 \%$ & $32.7 \%$ & $34.8 \%$ \\
\hline
\end{tabular}

Nota: Elaboración propia. 
Los resultados que se muestran en las tablas 22 y 23 permiten dar a conocer los siguientes hallazgos: los hombres de Ingeniería en Gestión Empresarial poseen las cualidades de innovación y propensión al riesgo en mayor porcentaje, mientras que la actitud hacia el emprendimiento no es una cualidad muy presente. En el caso de las mujeres, la cualidad que las distingue es que asumen riesgos, son innovadoras y buscan generar resultados. La actitud hacia el emprendimiento es una cualidad aún por desarrollar en ellas.

\section{Ingeniería en Sistemas Automotrices}

En la tabla 24 se muestran los resultados de los factores determinantes para los hombres encuestados del área de Ingeniería en Sistemas Automotrices. Mientras que en la tabla 25 , los resultados de las mujeres.

\section{Tabla 24}

Factores determinantes para los hombres encuestados de Ingeniería en Sistemas Automotrices

\begin{tabular}{lccccc} 
& $\begin{array}{c}\text { Autoeficacia } \\
\text { percibida }\end{array}$ & Autonomía & Innovación & $\begin{array}{c}\text { Propensión } \\
\text { al riesgo }\end{array}$ & $\begin{array}{c}\text { Actitud hacia el } \\
\text { emprendimiento }\end{array}$ \\
$\begin{array}{l}\text { Completamente } \\
\text { en desacuerdo }\end{array}$ & $5.1 \%$ & $12.4 \%$ & $3.5 \%$ & $4.0 \%$ & $5.5 \%$ \\
\hline En desacuerdo & $14.0 \%$ & $27.6 \%$ & $11.4 \%$ & $13.1 \%$ & $14.6 \%$ \\
\hline De acuerdo & $41.8 \%$ & $42.4 \%$ & $51.3 \%$ & $50.1 \%$ & $42.7 \%$ \\
\hline Muy de acuerdo & $39.1 \%$ & $17.6 \%$ & $33.8 \%$ & $32.8 \%$ & $37.2 \%$ \\
\hline
\end{tabular}

Nota: Elaboración propia.

Los resultados que se muestran en las tablas 24 y 25 indican que los hombres de Ingeniería en Sistemas Automotrices poseen en mayor porcentaje la cualidad de innovación, seguida de propensión al riesgo, y actitud hacia el emprendimiento. En el caso de las mujeres, la cualidad de propensión al riesgo se presenta en mayor porcentaje, seguida de innovación, y actitud hacia el emprendimiento. 


\section{Tabla 25}

Factores determinantes para las mujeres encuestadas de Ingeniería en Sistemas Automotrices

\begin{tabular}{lccccc} 
& $\begin{array}{c}\text { Autoeficacia } \\
\text { percibida }\end{array}$ & Autonomía & Innovación & $\begin{array}{c}\text { Propensión } \\
\text { al riesgo }\end{array}$ & $\begin{array}{c}\text { Actitud hacia el } \\
\text { emprendimiento }\end{array}$ \\
$\begin{array}{l}\text { Completamente } \\
\text { en desacuerdo }\end{array}$ & $3.3 \%$ & $3.3 \%$ & $0 \%$ & $0 \%$ & $0 \%$ \\
\hline En desacuerdo & $13.3 \%$ & $36.7 \%$ & $23.3 \%$ & $10.0 \%$ & $16.7 \%$ \\
\hline De acuerdo & $60.0 \%$ & $50.0 \%$ & $50.0 \%$ & $83.3 \%$ & $50.0 \%$ \\
\hline Muy de acuerdo & $23.3 \%$ & $10.0 \%$ & $26.7 \%$ & $6.7 \%$ & $33.3 \%$ \\
\hline
\end{tabular}

Nota: Elaboración propia.

\section{Discusión}

Las perspectivas del estudio y su aplicación desde nuestro aprendizaje como autores responden a los objetivos planteados al inicio de la investigación. El proceso de evaluación de los factores determinante es precisamente centrarlo en las potencialidades personales y profesionales involucradas, por ejemplo, se observa la relación entre el factor determinante de autonomía por encima del 30\% como base para detonar el factor determinante de innovación con un alcance de al menos el $40 \%$ en el total de las carreras evaluadas, lo anterior se puede reflejar en la figura 5 .

\section{Figura 5}

Relación entre Autoeficacia e Innovación

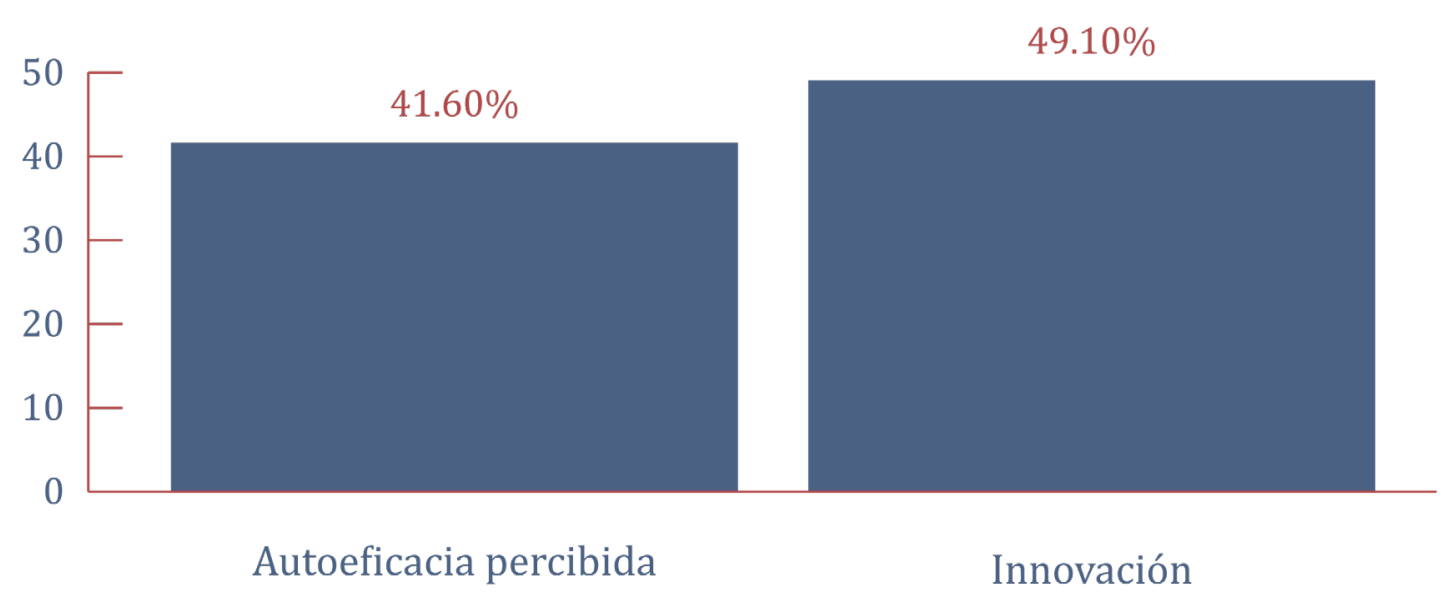

Nota: Elaboración propia. 
Asimismo se diagnóstica el factor determinante de actitud hacia el emprendimiento con mayor preponderancia en el desarrollo de las carreras de Ingeniería Industrial y Gestión Empresarial, presentando una alineación lógica-curricular desde la naturaleza de contenidos en su formación profesional, no obstante en las carreras de Bioquímica, Informática, Electromecánica y Sistemas Automotrices, la actitud hacia el emprendimiento contrasta con los valores alcanzados de la propensión al riesgo, ya que los porcentajes en este último están relacionados con el desarrollo de habilidades físico-matemáticas y el desarrollo de prácticas y materiales en laboratorios funcionales por área de especialidad. Debido a lo anterior, es importante la creación de estrategias y actividades complementarias o extra-clase que permitan el desarrollo y exponenciación de capacidades transversales en el total de nuestros alumnos, formando equipos multidisciplinarios para crear emprendimientos con impacto social o de base tecnológica, incluso de responsabilidad social como impulsores del perfil integral emprendedor.

En la figura 6 se muestran los factores de mayor preponderancia en los encuestados, destacando la innovación, la propensión al riesgo y la actitud hacia el emprendimiento.

\section{Figura 6}

Factores determinantes de mayor presencia en los encuestados

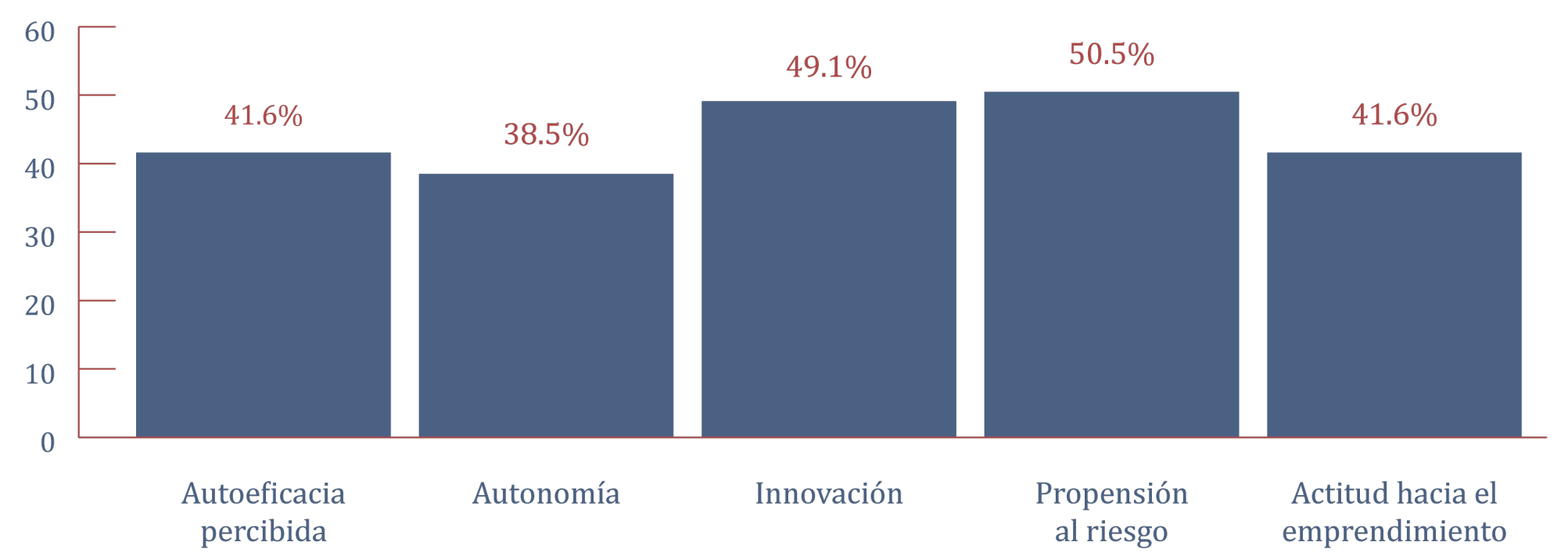

Nota: Elaboración propia.

El efecto positivo que muestran los índices de los estudiantes encuestados en relación con la autosuficiencia percibida, para al menos el 85\% de las carreras involucradas, lo sitúa como un factor determinante en el desarrollo de mecanismos de vinculación que permitan, a partir de esfuerzos institucionales, apoyar a los estudiantes en el desarrollo 
de prácticas profesionales, participación en concursos, movilidad internacional, y desarrollo de proyectos de investigación y emprendimiento, desde las alternativas propias del TecNM hasta su coparticipación con organismos, incubadoras, centros de investigación, e instituciones de educación superior (IES) del Estado de Guanajuato y del ecosistema emprendedor de México.

\section{Conclusiones}

Entre los retos más urgentes y prioritarios que enfrenta el ITSPR en materia de emprendimiento es el fomento de una cultura de trabajo colaborativa para la solución de retos, que detone la formación emprendedora de los estudiantes y el trabajo vinculado con los docentes. Dado que es necesario crear los contextos idóneos de trabajo entre docente-estudiante, se requiere implementar diversas estrategias en cada uno de los cursos, dotando a los docentes de herramientas para establecer con los estudiantes una interacción de trabajo continuo.

Los hallazgos del estudio muestran un avance significativo en el desarrollo de los estudiantes, es decir, poseen las cualidades mínimas idóneas para comenzar a generar iniciativas de emprendimiento en las primeras etapas, las cuales deberán fortalecerse para incrementar su capacidad y mostrarse en diversos escenarios que contribuyan al logro de cada una de las licenciaturas. Es pertinente señalar que en los planes académicos de cada Ingeniería se sugiere fortalecer las materias ligadas a la formación de emprendedores y la gestión de proyectos; asimismo, integrar nuevos enfoques que ayuden a los estudiantes a colaborar y trabajar de manera dinámica a través de proyectos reales. El nuevo enfoque en los cursos tiene como objetivo que cada integrante logre tener una visión orientada a la búsqueda del autoempleo a través del emprendimiento.

Uno de los aspectos trascendentes del estudio se refiere a las cualidades preponderantes en los estudiantes encuestados y, en ese sentido, es pertinente señalar que la eficacia percibida, la innovación y la actitud hacia el emprendimiento son las que se presentan en un porcentaje más alto, aunque el resto de las cualidades también juegan un rol relevante dentro del perfil emprendedor. Las cualidades antes mencionadas son un aspecto medular que, de alguna forma, pueden definir el perfil de los estudiantes de cada una de las Ingenierías desde el momento del ingreso hasta su egreso.

Actualmente, el ITSPR cuenta con dos programas institucionales relacionados con el emprendimiento; el primero de ellos es el Modelo de Talento Emprendedor, promovido por el Tecnológico Nacional de México y cuyo objetivo es fomentar una actitud de 
emprendimiento e identificar emprendedores con talento, este programa busca promover el emprendimiento a través de talleres, pláticas y diversas actividades enfocadas a impulsar la creatividad e innovación; este taller se complementa con la etapa local del Evento Nacional Estudiantil de Innovación Tecnológica, donde los estudiantes dan a conocer sus emprendimientos y prototipos; además, existen otras ferias y concursos externos que detonan también la participación.

El segundo es un programa estatal, PRACTICUM, que tiene como objetivo identificar emprendedores en etapas tempranas para generar iniciativas de emprendimiento y formar empresas de base tecnológica.

La postura de ambos programas es de suma relevancia, de tal manera que se acopla en gran medida con las cualidades que muestran los estudiantes encuestados, y satisface las necesidades a través de las iniciativas de emprendimiento.

De lo anterior, se derivan sugerencias que pueden fortalecer los planes académicos, por ejemplo, desarrollar un proyecto de actualización del currículo de cada una de las Ingenierías, enfocado en competencias transversales, como lo es la actitud hacia el emprendimiento, el desarrollo de habilidades de investigación, el desarrollo de proyectos con base tecnológica, el uso de tecnologías de la información y la comunicación (TIC) y el fomento de la responsabilidad social, iniciando con un proceso de detección formalizado a partir del ingreso a primer semestre, con un calendario de actividades y propuestas de continuidad técnica e integral para cada programa de estudio, incluyendo talleres, cursos, solución de retos, convocatorias a concursos internos y externos, construcción de proyectos de manera colaborativa con estudiantes de otras universidades nacionales o extranjeras, asimismo actividades profesionales involucrando innovación con impacto social, que sean estratégicamente favorables para los estudiantes a partir del semestre que cursan, considerando los conocimientos previos, así como las condiciones propias de su edad, género y comunidad a la que pertenecen.

También es importante fortalecer el desarrollo conductual de las actitudes que se requieren en el perfil emprendedor, lo cual permitiría forjar en los estudiantes una visión de emprendedores.

Otro aspecto relevante es el caso de los estudiantes de reciente ingreso, quienes poseen ciertas actitudes emprendedoras, las cuales es importante conservar e incluso fortalecer durante el desarrollo de los primeros semestres. En estos semestres se debe promover el emprendimiento, la colaboración para el desarrollo de proyectos y la generación de soluciones a través de cursos. 
El estudio pretende aportar una alternativa que pueda ser tomada como referencia para otras instituciones que actualmente estén interesadas en fomentar acciones en materia de emprendimiento en su comunidad estudiantil o fortalecer sus esquemas de trabajo.

Por otro lado, el estudio busca impulsar una alternativa para que los programas de ingeniería en determinado momento se reconviertan, y adopten una postura más apegada a la generación de proyectos, pero con un perfil de productos, detectando previamente una necesidad real.

Finalmente, es necesario fortalecer la actitud hacia el emprendimiento desde los programas de vinculación y movilidad del ITSPR, en forma local y global, con el objetivo de proporcionar las herramientas necesarias para forjar esa vocación esperada en la comunidad tecnológica.

\section{Referencias}

Afuah, A., \& Tucci, C. (2002). Internet Business Models and Strategies. McGraw-Hill.

Álvarez, L. C., \& López, P. L. (2010). Modelos de gestión del conocimiento. XII Asamblea General de ALAFEC. Lima, Perú. http://www.alafec.unam.mx/docs/asambleas/xii/ ponencias/administracion/ADMON4.PDF

Bandura, A. (1977). Self-efficacy: Toward a Unifying Theory of Behavioral Change. Psychological Review, 84(2), 191-215.

Blank, S., \& Dorf, B. (2013). El Manual del Emprendedor. Gestión 2000.

Covin, J. G. \& Slevin, D. P. (1989). Strategic management of small firms in hostile and benign environments. Strategic Management Journal, 10, 75-87.

Cromie, S. (2000). Assessing entrepreneurial inclinations: Some approaches and empirical evidence. European Journal of Work and Organizational Psychology, 9(1), 7-30.

Dirección General de Educación Superior Tecnológica (DGEST). (2012). Modelo Educativo para el Siglo XXI: Formación y desarrollo de competencias profesionales. DGEST.

Dussauge, M. I. (2013). Cross-National Policy Learning and and administrative reforms: the making of 'management for results' policies in Chile and Mexico (1990-2010) (PhD thesis). The London School of Economic and Political Science (LSE).

Filion, L. J. (2003). Emprendedores y propietarios dirigentes de pequeña y mediana empresa (PYME). Revista de Administración de Empresas, 34(2), 5-28.

Gee, S. (1981). Technology transfer, innovation and international competitiveness. Wiley. 
Igwe, P. A., Odunukan, K., Rahman, M., Rugara, D. G., \& Ochinanwata, C. (2020). How entrepreneurship ecosystem influences the development of frugal innovation and informal entrepreneurship. Thunderbird International Business Review, 62(5), 475488.

Instituto Tecnológico Superior de Purísima del Rincón (ITSPR). (2019). Estudio de Factibilidad de la Carrera de Ingeniería en Gestión Empresarial. Reporte Técnico. Subdirección de Planeación y Vinculación.

Instituto Nacional de Estadística y Geografía (INEGI) (2020). Comunicado de Prensa Número 617/20. El INEGI presenta resultados de la segunda edición del ECOVID-IEy del estudio sobre la demografía de los negocios 2020. https://inegi.org.mx/contenidos/ saladeprensa/boletines/2020/OtrTemEcon/ECOVID-IE_DEMOGNEG.pdf

Llorens, B. (2010). Una perspectiva al Concepto de Modelo de Negocios. América Economía. https://mba.americaeconomia.com/sites/mba.americaeconomia.com/files/ paperventajacompetitiva.pdf

López, F. J. M., Ortiz, P. A., \& Torres, L. G. G. (2018). Emprendimiento como estrategia para la formación de líderes en Institutos Tecnológicos, un caso de éxito. ANFEI Digital, (8), 1-6. https://www.anfei.mx/revista/index.php/revista/article/viewFile/426/1073 Magretta, J. (2002). Why Business Model Matter. Harvard Business Review. https://hbr. org/2002/05/why-business-models-matter

Mason, C., \& Brown, R. (2014). Entrepreneurial Ecosystems and Growth Oriented Entrepreneurship. https://www.oecd.org/cfe/leed/Entrepreneurial-ecosystems. pdf

Montufar, A. (2018). Análisis de perfiles de actitudes relacionadas con el emprendimiento (Trabajo de Maestría). Universidad Nacional Autónoma de México, México.

Motoyama, Y., \& Knowlton, K. (2016). Examining the Connections within the Startup Ecosystem: A Case Study of St. Louis. Entrepreneurship Research Journal, 7(1). https://doi.org/10.1515/erj-2016-0011

Nederlands Instituut voor Kennisintensief OndernemerSchap (NIKOS). (2004). Progress Report 2001-2004. University of Twente.

Organización de las Naciones Unidas para la Educación, la Ciencia y la Cultura (UNESCO). (2017). Educación para los objetivos de desarrollo sostenible: objetivos de aprendizaje. UNESCO. https://unesdoc.unesco.org/ark:/48223/pf0000252423/ PDF/252423spa.pdf.multi

Osterwalder,A.(2009).BusinessModelCanvas.http://www.alexosterwalder.com/index.html 
Olutuase, S. O., Brijlal, P., Yan, B., \& Ologundudu, E. (2018). Entrepreneurial Orientation and Intention: Impact of Entrepreneurial Ecosystem Factors. Journal of Entrepreneurship Education, 21(3), 1-14. https://www.abacademies.org/articles/Entrepreneurialorientation-and-intention-1528-2651-21-3-185.pdf

Organización para la Cooperación y el Desarrollo Económicos (OCDE). (2016). Startup América Latina: Promoviendo la innovación en la región. OCDE.

Prahalad, C. K., \& Hammond, A. (2002). Serving the world's poor, profitably. Harvard Business Review, 80(9),48-57.

Piatier A (1987). Les Innovations Transsectorielles Transformation Des enterprises. Conferencia sobre las regiones, la innovación y la tecnología. ESADE.

Radjou, N., \& Prabhu, J. (2014). What frugal innovators do? Harvard Business Review. https://hbr.org/2014/12/what-frugal-innovators-do

Shane, S., \& Venkataraman, S. (2000). The promise of entrepreneurship as a field of research. Academy of Management Review, 26(1), 13-17.

Schneewind, J. B. (1998). The Invention of Autonomy. New York: Cambridge University Press.

Tecnológico Nacional de México (TecNM). (s.f.). Modelo Talento Emprendedor. https:// mooc.tecnm.mx/courses/course-v1:TecNM+MTE-001+2020_T2/about

Tecnológico Nacional de México (TECNM). (2014). Proyectos integradores para la formación y desarrollo de competencias profesionales del Tecnológico Nacional de México. TECNM. http://tecnm.mx/images/areas/docencia01/Libre_para_ descarga/Proyectos_Integradores_2_ed/Proyectos_Integradores_2da_edicion.pdf

Tecnológico Nacional de México (TecNM). (2017). Evaluación del Modelo Educativo del Siglo XXI. Formación y Desarrollo de Competencias Profesionales (Documento de Consulta). Instituto Tecnológico de Tepic.

Vecchio, R. P. (2003). Entrepreneurship and leadership: common trends and common threads. Human Resource Management Review, 13, 303-327.

Williams, N., \& Vorley, T. (2015). Institutional asymmetry: How formal and informal institutions affect entrepreneurship in Bulgaria. International Small Business Journal, 33(8), 840-861.

Zott, C., \& Amit, R. (2009). Business Model Design: An Activity System Perspective. Long Range Planning, 43, 216-226. https://faculty.wharton.upenn.edu/wp-content/ uploads/2012/05/businessModelDesign_Amitzott_LRP2010.pdf 


\section{Capítulo 3}

\section{Perfil emprendedor en estudiantes universitario}

Laura Elena Zárate Negrete, Ma. Eugenia Sánchez Ramos

y Lizeth Alejandra Contreras Lemus 


\section{Capítulo 3}

\section{Perfil emprendedor en estudiantes universitarios}

Laura Elena Zárate Negrete, Ma. Eugenia Sánchez Ramos

y Lizeth Alejandra Contreras Lemus

En la actualidad, el emprendimiento ha tomado gran relevancia, no solo por ser una alternativa para reforzar la economía sino también porque ofrece la posibilidad de generar empleos y disminuir la pobreza. En este sentido, en México es imperante reforzar las actitudes emprendedoras en los estudiantes, con la finalidad de impulsar el desarrollo de empresas que mejoren la calidad de vida de la sociedad. Al respecto, de acuerdo con el Instituto Nacional de Estadística y Geografía (INEGI, 2014), la población mexicana está compuesta por un $26.3 \%$ de jóvenes, los cuales poseen el mayor nivel de desempleo en el país. Uno de los estados más afectados por esta situación es el estado de Guanajuato, lo cual repercute en las decisiones que las instituciones de educación superior deben tomar sobre sus planes académicos, puesto que la mayor parte de estos jóvenes desocupados son universitarios.

En un reporte realizado por el Instituto Mexicano para la Competitividad (IMCO, 2009), se puntualiza que en México los emprendedores y las MIPYMES generan el 52\% del PIB y crean el 72\% de los empleos, dando así, una importancia exorbitante a los emprendedores; por lo tanto, es necesario desarrollar actitudes y habilidades como la inteligencia de mercado y la valoración empresarial y, por otro lado, en las instituciones educativas fomentar la opción del trabajo por cuenta propia. 
De acuerdo con la Encuesta Nacional de Ocupación y Empleo (ENOE):

la población emprendedora en México comprende 5 mil 883 personas, de las cuales 5 mil 331 son adultos de 30 a 59 años y 522 jóvenes, cuya edad está entre los 18 a 29 años con representatividad a nivel nacional, mismos que personifican a 1, 450,324 adultos y 148, 646 jóvenes después de haber aplicado el factor de expansión. (INEGI, 2016 citado en Canales et al., 2017)

Acorde a lo anterior, la población juvenil en México no logra tener los medios para ser partícipes en proyectos emprendedores, esto se debe a que, en muchas ocasiones, no cuentan con la educación correspondiente para su desarrollo o con el apoyo económico necesario para realizar las inversiones. Además, la mayoría de los jóvenes desconocen los programas públicos y privados que apoyan la capacidad emprendedora.

Al realizar un análisis del plan académico de la División de Ciencias EconómicoAdministrativas (DCEA) de la Universidad de Guanajuato (UG), se encontró que a pesar de que en su estructura existen materias relacionadas con el buen control económico, solo dan un soporte para el control financiero de empresas u organismos ya establecidos, por lo que sería conveniente agregar Unidades de Aprendizaje (UDAS) enfocadas en desarrollar actitudes emprendedoras, lo cual permitiría al alumno crear proyectos de alto impacto económico y social.

Una orientación emprendedora (OE) ayudaría al alumno a tener una visión más amplia de las acciones que debe realizar durante el proceso de implementación de un emprendimiento, cómo hacerlo y cómo hacer frente a las problemáticas que se presenten. Sin embargo, por el momento, la UG no otorga esta orientación a sus alumnos.

Cabe mencionar que la orientación emprendedora es un área emergente de investigación que analiza la innovación, el riesgo, la proactividad, la autonomía y la agresividad competitiva (Arzubiaga et al., 2012), por lo que se trata de un proceso de adopción de decisiones que posibilitan la actividad emprendedora.

Por su parte, Covin y Slevin (1989, citados en Arzubiaga et al., 2012) afirmaron que:

la orientación emprendedora de una empresa se demuestra por el grado en que la alta dirección está dispuesta a asumir los riesgos relacionados con la empresa [...], para favorecer el cambio y la innovación con el fin de obtener una ventaja competitiva para su empresa [...], y competir agresivamente con otras firmas. (p.59) 
La Universidad de Guanajuato ha comenzado a implementar estrategias de programas de emprendimiento cuyo objetivo es lograr que el alumno se introduzca en esta práctica y realice proyectos de emprendimiento que permita autoemplearse. Para lograrlo, en 2009, se adoptó el Programa Institucional de Emprendedores de la Universidad de Guanajuato (PIEUG), sin embargo, ha sido difícil obtener referencias sobre su éxito (UG, 2014).

\section{Emprendimiento}

El emprendimiento suele estar relacionado con un estado de alerta, a partir del cual un individuo genera una idea de negocio para dar respuesta a una problemática económica, como el desempleo o la falta de oportunidades laborales. Por ello, se considera que es una de las características que determina el crecimiento, la transformación y el desarrollo de nuevos sectores económicos de una región o un país.

El impulso emprendedor se ve afectado por factores externos como el tipo de desarrollo económico de un país, sus actividades y características, las costumbres sociales, o bien, por factores internos relacionados con las características del emprendedor, como la aptitud para innovar y la disposición para asumir riesgos.

De acuerdo con Drucker (1985), el emprendimiento se caracteriza por realizar una maximización sobre las oportunidades existentes, es decir, se centra en la obtención de la efectividad y no de la eficiencia en la esencia del trabajo. Por su parte, Timmons (1997) refiere al emprendimiento como la toma de acciones humanas y creativas, con las cuales se pretende construir algo de valor utilizando pocos recursos.

Con el emprendimiento se persigue una oportunidad e idea innovadora, que se encuentra más allá de los recursos que la sociedad actual puede proveer, obligando a una persona a buscar la manera de obtenerlos (Stevenson, 1990). En este sentido, se emprende con el fin de cubrir las necesidades que se encuentran en un entorno social, creando acciones o ideas innovadoras que ofrezcan una solución.

El emprendimiento es una de las características que determinan el crecimiento, la transformación y el desarrollo de nuevos sectores económicos de una región o un país, por lo que una o varias personas se vuelven el pilar durante la creación e implementación de dichas ideas de emprendimiento. Así, existen personas que cuentan con ciertas particularidades, que les permiten ser más exitosas que otras (Montoya et al., 2009).

\section{Definición de emprendedor}

La comprensión del término emprendedor permite entender el sentido y relación con la economía; a este respecto Hidalgo (2014) enfatiza que: 
La palabra emprendedor deriva de la voz francesa "entrepreneur" que aparece a principios del siglo XVI para designar a los hombres relacionados con las expediciones militares. A principios del siglo XVIII los franceses extendieron el significado del término a otros aventureros como los constructores de puentes, caminos y los arquitectos. En sentido económico fue definida por primera vez por un escritor francés, Richard Cantillón (1755) como el proceso de enfrentar la incertidumbre. (p.47)

Los emprendedores son aquellas personas con una enorme dosis de creatividad e innovación, capaces de detectar problemáticas en su entorno y brindar soluciones, asumir riesgos y actuar frente a situaciones inesperadas, y adaptarse para afrontar retos.

De acuerdo con Hidalgo (2014), los emprendedores cuentan con ciertas características que los definen y que los diferencian de los gerentes típicos: asumen riesgos, están dispuesto a invertir todos sus recursos en una idea o acción innovadora, tiene una visión clara sobre lo que buscan hacer y del nivel de riesgo que supone.

Por lo tanto, una persona emprendedora es aquella que cuenta con la capacidad de convertir, mejorar o adaptar un producto o servicio, ya que puede identificar y desarrollar una idea innovadora y destacarla sobre otras.

Según Shaver (2004), un emprendedor cuenta con ciertas características psicológicas, que se manifiestan dentro de su personalidad o durante el desarrollo de procesos cognitivos, que se activan por las diferentes circunstancias a las que un sujeto se encuentra expuesto en su entorno. Mientras que para Miner (1997), la mente o pensamiento de un emprendedor está integrada por un sinfín de posibilidades y cuenta con la motivación necesaria para persistir hasta lograr un objetivo determinado.

\section{Actitud emprendedora}

Las actitudes de un individuo se desarrollan conforme va creciendo, de acuerdo con la experiencia o interacción con el entorno, manifestándose como un comportamiento; lo cual determinará su forma de reaccionar ante diferentes situaciones.

Existen diferentes conceptos sobre las actitudes, así como hipótesis sobre la correlación entre una situación o momento y el comportamiento de una persona al enfrentarse a ella. De acuerdo con Eagly y Chaiken (1993), una actitud es una tendencia psicológica que se expresa mediante la evaluación de una entidad u objeto concreta, con cierto grado de favorabilidad o desfavorabilidad. Mientras que para Rosenberg y Hovland (1960), es la 
conducta que tiene un sujeto al encontrarse expuesto a una situación, lo que genera una vinculación cognitiva que produce un efecto en sus acciones, sea este positivo o negativo.

Las actitudes son factores que forman parte de nuestra vida cotidiana, nuestro entorno y comportamiento (Staats, 1958), por lo que se pretende obtener evaluaciones duraderas de diversos hechos o aspectos del comportamiento social, que se van almacenando en la memoria de un sujeto, lo que permite conseguir un desarrollo emocional sobre diversos aspectos (Judd et al., 1991).

Respecto a la actitud emprendedora, en la actualidad hay una tendencia de estimulación hacia el emprendimiento, por considerarlo como una alternativa para enfrentar las diferentes crisis económicas a nivel global y como una forma de impulsar el desarrollo (Fontaines-Ruiz et al., 2016); su estudio permite predecir el comportamiento empresarial en el futuro (Villacis et al., 2018).

Según Formichella (2004), en algunos casos la educación es un factor que favorece la adquisición y desarrollo de actitudes emprendedoras en los individuos, pues existe una relación estrecha entre ambos elementos. En caso de que se implementen medidas de mejora en la educación sobre emprendimiento, es posible aumentar tanto el espíritu emprendedor de los individuos como la dotación social de cualidades emprendedoras, lo cual provocará efectos positivos, tales como la creación de empresas, el crecimiento de las empresas existentes y la generación de autoempleo.

\section{Caso de estudio}

Actualmente la División de Ciencias Económico-Administrativas (DCEA) de la Universidad de Guanajuato cuenta con siete programas educativos de licenciatura:

1. Licenciatura en Relaciones Industriales (LRI).

2. Licenciatura en Contador Público (LCP).

3. Licenciatura en Administración de la Calidad y Productividad (LACP).

4. Licenciatura en Comercio Internacional (LCI).

5. Licenciatura en Administración de Recursos Turísticos (LART).

6. Licenciatura en Economía (LE).

7. Licenciatura en Sistemas de Información Administrativa (LSIA).

Con base en el semestre de agosto-diciembre del año 2018, la DCEA cuenta con aproximadamente 2,788 alumnos del nuevo plan y 168 alumnos que siguen en el plan de 1999, dando un total de 2,956 alumnos; cabe destacar que esta cifra incluye todas las carreras y semestres. 
En 2008, a partir de la entrada en vigor de la Ley Orgánica de la Universidad de Guanajuato, se comenzó con una serie de actualizaciones que implicó la modificación de su estructura organizacional, la formulación de su Plan de Desarrollo Institucional 20102020 (PLADI), y la configuración del correspondiente Modelo Educativo; este último, aprobado en mayo del 2011 por el Consejo General Universitario junto con sus Modelos Académicos (UG, 2016).

Con este Modelo Educativo, la Institución asumió los siguientes objetivos:

- Conferir unidad y sentido a sus funciones sustantivas;

- Explicitar los valores y principios que orientan su labor educativa;

- Proporcionar las líneas generales de los diversos enfoques pedagógicos que adopten los programas educativos;

- Otorgar un perfil de identidad a la comunidad de la Universidad de Guanajuato, por medio de los programas educativos y actividades de formación; y

- Coadyuvar a la planeación estratégica institucional. (UG, 2016, p.6)

En la figura 1 se presenta el Modelo Educativo derivado del PLADI 2010-2020, con el cual existe una apertura a diferentes posturas pedagógicas y la Universidad de Guanajuato innova en los paradigmas educativos y genera ideas nuevas.

El Modelo Educativo se estructura en tres planos: conceptual, ejecutivo y operativo.

En el plano conceptual se encuentran los elementos filosóficos, pedagógicos, sociológicos, culturales y epistemológicos que sustentan los procesos educativos en la Universidad de Guanajuato. El plano ejecutivo se realiza mediante los modelos académicos en los que se establecen los principios, líneas, políticas y orientaciones para realizar el diseño, la evaluación y el rediseño de los programas educativos que se ofrecen en la Institución así como la organización académica que hace posible la formación integral del estudiante. El plano operativo hace referencia a la concreción, en la vida de la Institución, de las aspiraciones plasmadas en el modelo, por medio de la correcta actuación e interacción, articulada y armónica, entre todos los miembros de la comunidad universitaria y el aprovechamiento responsable y pleno de sus recursos. (UG, 2016, p.14) 


\section{Figura 1}

Modelo Educativo de la Universidad de Guanajuato

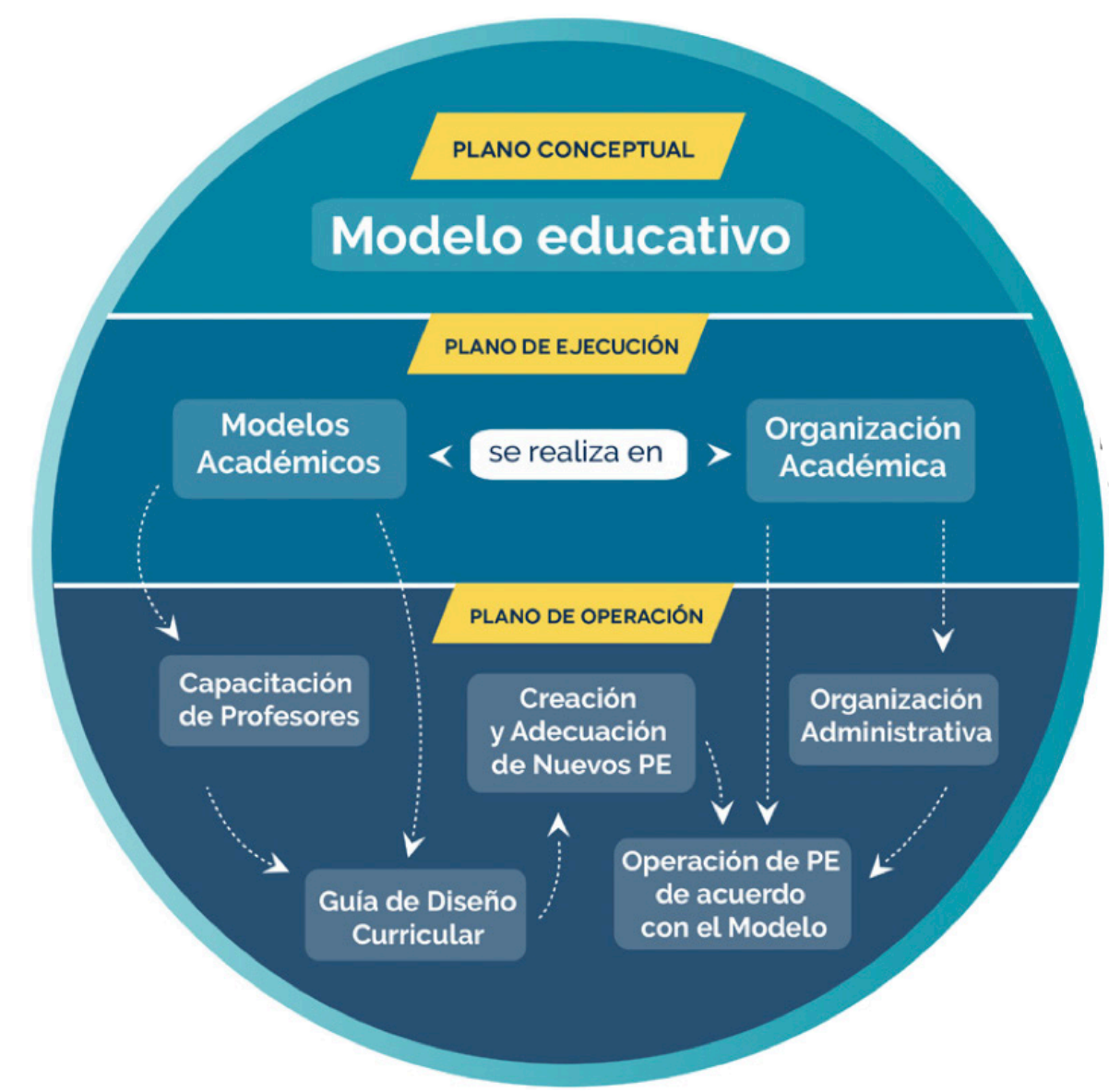

Nota: Universidad de Guanajuato (2016).

Dentro de los procesos académicos y administrativos, la UG considera el desarrollo integral y profesional del alumno como eje central, junto con los componentes asociados a ello. Además, se fortalece con otros ejes de vital importancia como la innovación, la interculturalidad e internacionalización, la flexibilidad, y la vinculación con las necesidades del entorno (figura 2).

Por su parte, "Los Modelos Académicos son la aplicación ejecutiva del Modelo Educativo, los instrumentos para la realización de sus ejes por medio de los programas educativos" (UG, 2016, p.27).

"Los programas educativos que ofrece la Universidad se evalúan periódicamente por medio de mecanismos institucionales, internos y externos, en diferentes instancias a nivel nacional e internacional, garantizando así su acreditación permanente e internacionalización" (UG, 2016, p.27).

Al realizarse una evaluación periódica se cumple con un rediseño constante, esto se realiza dependiendo su duración: el Nivel Medio Superior, al menos cada cuatro años; la Licenciatura, la Especialidad, la Maestría y el Doctorado, por lo menos cada cinco años. Cabe destacar que la evaluación curricular se realiza con la participación de académicos y estudiantes (UG, 2016). 


\section{Figura 2}

Estrategias y acciones del modelo educativo

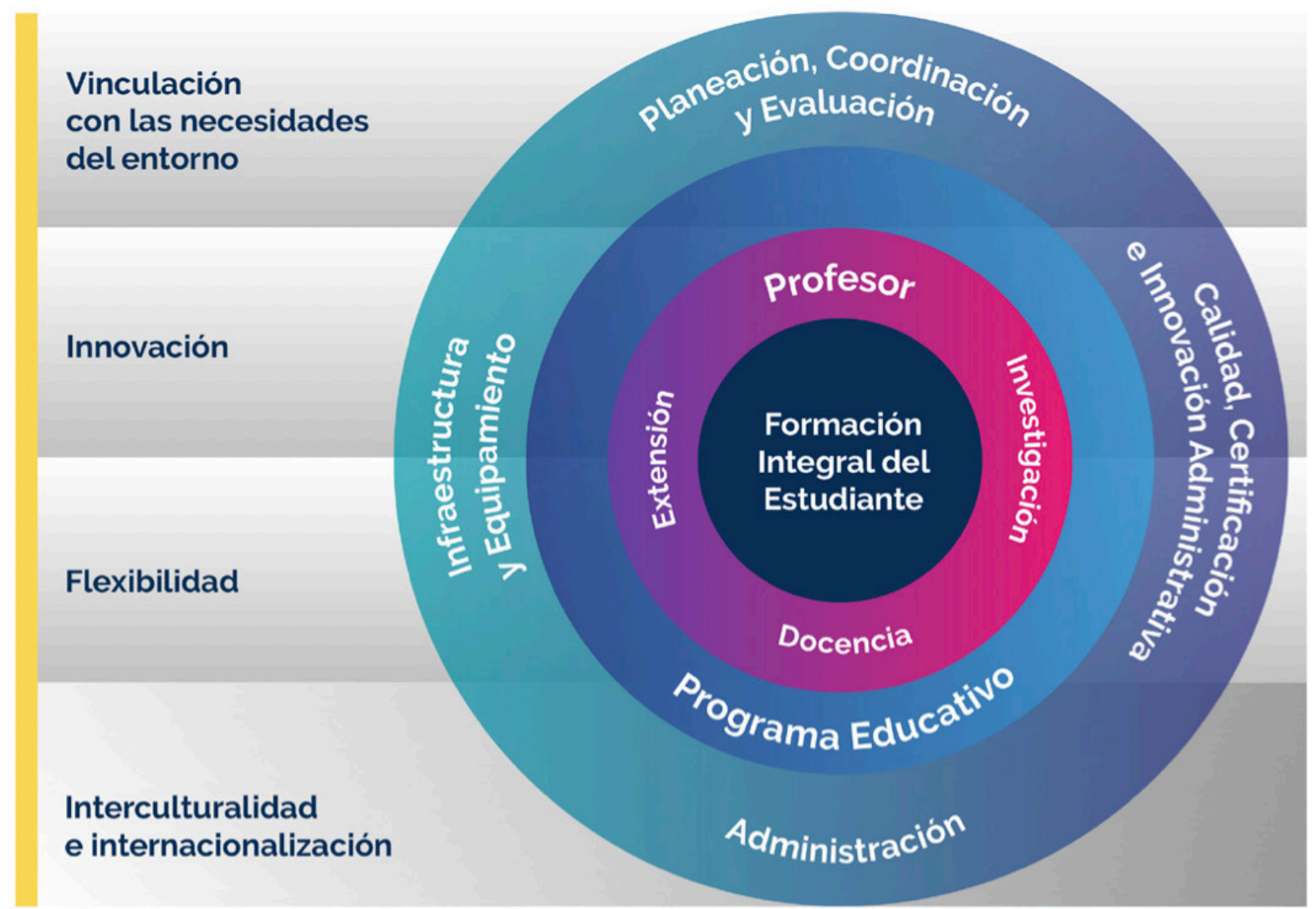

Nota: Universidad de Guanajuato (2016).

\section{Metodología}

Este estudio es una investigación cuantitativa, descriptiva y explicativa, que tiene como objetivo conocer si los estudiantes de la DCEA de la Universidad de Guanajuato cuentan con un perfil para ser emprendedor. La investigación se desarrolló a lo largo del curso escolar enero-diciembre 2019, y a través de un cuestionario (anexo 1) se evaluaron cinco variables: Autoeficacia percibida, Autonomía, Innovación, Propensión al riesgo, y Actitud hacia el emprendimiento; cada una con tres dimensiones, y cada una de estas con cinco preguntas, por lo cual suman un total de 15 ítems por variable.

\section{Aplicación y análisis de datos}

Para la obtención de datos se diseñaron y aplicaron 230 encuestas a estudiantes de la DCEA de dos programas educativos, Relaciones Industriales y Comercio Internacional. Se tomó como muestra el 30\% de la población estudiantil, excluyendo del programa de Relaciones Industriales a los alumnos de primer semestre; y del programa de Comercio Internacional a los de primero y segundo semestre. En la tabla 1 se muestra el número de alumnos encuestados en los dos programas seleccionados. 


\section{Tabla 1}

Universidades públicas y privadas que impulsan el emprendimiento

\begin{tabular}{lccccccccc}
\multicolumn{1}{c}{ Programa educativo } & $\mathbf{1}$ & $\mathbf{2}$ & $\mathbf{3}$ & $\mathbf{4}$ & $\mathbf{5}$ & $\mathbf{6}$ & $\mathbf{7}$ & $\mathbf{8}$ & Total \\
Relaciones Industriales & - & 19 & 11 & 20 & 5 & 15 & 20 & 10 & $\mathbf{1 0 0}$ \\
\hline Comercio Internacional & - & - & 63 & 22 & 11 & 19 & 8 & 7 & $\mathbf{1 3 0}$ \\
\hline Total & & & & & & & & & $\mathbf{2 3 0}$ \\
\hline
\end{tabular}

Nota: Elaboración propia con base en el 30\% del total de alumnos por carrera (2019).

Para efectos de la elaboración de la encuesta se tomó como base el instrumento que Montufar (2018). Este instrumento está enfocado en el estudio de las actitudes, por lo cual se pensó meticulosamente en los ítems correspondientes a cada variable. Cabe destacar que está diseñado para contemplar su división en los planos cognitivo, afectivo y emocional, y conductual. El instrumento original se contiene un total de 104 reactivos, los cuales representan situaciones hipotéticas, que se evalúan en cada una de las tres dimensiones de las actitudes; de modo que cada variable abarcó 21 ítems, siete para la dimensión cognitiva, siete para la dimensión afectiva/emocional, y otros siete para la dimensión comportamental; con excepción de la dimensión emocional relativa a la variable Autoeficacia percibida, con solo 6 ítems.

Los resultados obtenidos permitieron tener un conocimiento más amplio sobre las actitudes emprendedoras de los estudiantes.

\section{Resultados}

Se llevó a cabo un análisis comparativo sobre los resultados de las actitudes de emprendimiento de los alumnos de la Licenciatura de Relaciones Industriales (LRI) y la Licenciatura en Comercio Internacional (LCI), impartidas en la Universidad de Guanajuato, con el propósito de obtener un margen relativo sobre los diferentes resultados alcanzados y tener una perspectiva sobre el desempeño de estos programas.

Los resultados se analizaron de dos formas, uno a partir de la edad de los alumnos y otra a partir de los semestres que cursan. Esto con el fin de comparar el perfil de ingreso, su desarrollo durante la licenciatura y el perfil de egreso. 


\section{Hallazgos por edad y licenciatura}

La interpretación para el análisis de los resultados se sustenta en el punto medio de las opciones dos (en desacuerdo) y tres (de acuerdo) de la escala de medición. Considerando como margen positivo un 40\% en el resultado de la opción 3 (de acuerdo). Mientras que un resultado del 30\% indica que el sujeto necesita tener una mejora en su actitud, siempre y cuando estos resultados se encuentren en la respuesta dos, ya que esta es la que tiene un mayor impacto en los alumnos.

En la tabla 2 se presentan los resultados obtenidos de la aplicación del cuestionario en la Licenciatura en Relaciones Industriales.

\section{Tabla 2}

Resultados de la Licenciatura en Relaciones Industriales (LRI)

\begin{tabular}{|c|c|c|c|c|c|c|}
\hline Edad & & $\begin{array}{c}\text { Eficacia } \\
\text { percibida }\end{array}$ & Autonomía & Innovación & $\begin{array}{c}\text { Propensión } \\
\text { al riesgo }\end{array}$ & $\begin{array}{l}\text { Actitud hacia el } \\
\text { emprendimiento }\end{array}$ \\
\hline \multirow{4}{*}{$18-19$} & $\begin{array}{l}\text { Completamente } \\
\text { en desacuerdo }\end{array}$ & $10.7 \%$ & $17.3 \%$ & $11.3 \%$ & $8.0 \%$ & $16.7 \%$ \\
\hline & En desacuerdo & $22.7 \%$ & $31.3 \%$ & $20.0 \%$ & $23.3 \%$ & $20.7 \%$ \\
\hline & De acuerdo & $45.3 \%$ & $34.0 \%$ & $44.7 \%$ & $48.7 \%$ & $40.7 \%$ \\
\hline & Muy de acuerdo & $21.3 \%$ & $17.3 \%$ & $24.0 \%$ & $20.0 \%$ & $22.0 \%$ \\
\hline \multirow{4}{*}{$20-23$} & $\begin{array}{l}\text { Completamente } \\
\text { en desacuerdo }\end{array}$ & $10.4 \%$ & $20.4 \%$ & $6.7 \%$ & $4.6 \%$ & $12.5 \%$ \\
\hline & En desacuerdo & $19.8 \%$ & $32.4 \%$ & $22.2 \%$ & $24.2 \%$ & $22.3 \%$ \\
\hline & De acuerdo & $39.2 \%$ & $31.8 \%$ & $43.0 \%$ & $46.6 \%$ & $41.9 \%$ \\
\hline & Muy de acuerdo & $30.6 \%$ & $15.4 \%$ & $28.1 \%$ & $24.7 \%$ & $23.3 \%$ \\
\hline \multirow{4}{*}{$24-25$} & $\begin{array}{l}\text { Completamente } \\
\text { en desacuerdo }\end{array}$ & $10.4 \%$ & $20.4 \%$ & $6.7 \%$ & $4.6 \%$ & $12.5 \%$ \\
\hline & En desacuerdo & $19.8 \%$ & $32.4 \%$ & $22.2 \%$ & $24.2 \%$ & $22.3 \%$ \\
\hline & De acuerdo & $39.2 \%$ & $31.8 \%$ & $43.0 \%$ & $46.6 \%$ & $41.9 \%$ \\
\hline & Muy de acuerdo & $30.6 \%$ & $15.4 \%$ & $28.1 \%$ & $24.7 \%$ & $23.3 \%$ \\
\hline
\end{tabular}

Nota: Elaboración propia con base en el 30\% del total de alumnos por carrera (2019). 
Como se observa en la tabla 2, en la categoría de 18 a 19 años, se obtuvieron los siguientes resultados: en autoeficacia percibida cuentan con un $45.3 \%$, que es un porcentaje mucho más alto de lo mínimo esperado; sin embargo, en el apartado de autonomía obtuvieron $34.0 \%$, que es un porcentaje bajo. En innovación se alcanza un porcentaje de $44.7 \%$ y en propensión al riesgo $48.7 \%$, lo que indica un muy buen progreso sobre estas actitudes; y en actitud hacia el emprendimiento se generó un 40.7\%; lo anterior indica que se cuenta con un desarrollo óptimo en cuatro de cinco actitudes.

En la categoría de 20 a 23 años, se obtuvieron los siguientes resultados: en autoeficacia percibida un 39.2\% y en autonomía un 31.8\%, es decir, se encuentra por debajo del mínimo. En innovación se generó un 43.0\% y en actitud hacia el emprendimiento se obtiene un 41.9\%, cumpliendo con el porcentaje esperado; mientras que en propensión al riesgo se obtuvo un $46.6 \%$, que es un resultado alentador; se puede decir que en esta categoría se cumple con tres de cinco actitudes emprendedoras.

Finalmente, dentro de la categoría de 24 a 25 años se obtuvo el $39.2 \%$ en eficiencia percibida, es decir, le falta muy poco para obtener un buen desarrollo; en autonomía, se consiguió el 32.4\%, que es un porcentaje muy por debajo de lo esperado; en innovación se alcanzó un 43.0\%, lo que supone un resultado positivo; en lo que respecta a la propensión al riesgo, se generó un 46.6\%, que se encuentra muy por encima de lo esperado, y, por último, en actitud hacia el emprendimiento se obtuvo un $41.9 \%$. Estos porcentajes son similares a los de la categoría de 20 a 23 años, lo cual significa que no hubo una optimización dentro de sus actitudes emprendedoras.

En la tabla 3 se exponen de forma gráfica los resultados de la aplicación del instrumento en la Licenciatura en Comercio Internacional.

Como se observa en la tabla 3, en la categoría de 18 a 19 años se obtuvieron resultados por debajo de lo esperado, sobre todo en autonomía con un 31.7\% y en innovación con $37.4 \%$, sin embargo, aún tienen posibilidades de desarrollo; en actitud hacia el emprendimiento se generó un $40.8 \%$ y en autoeficacia percibida un $42.4 \%$, cumpliendo con el mínimo; mientras que en propensión al riesgo se obtuvo un $47.5 \%$, lo que indica un buen progreso. Por lo tanto, se cumplió con tres de las cinco actitudes correspondientes a un perfil emprendedor.

En la categoría de 20 a 23 años, los resultados fueron sumamente diferentes, ya que solo se cumplió con una de las cinco actitudes emprendedoras, propensión al riesgo con un resultado del 41.7\%. Mientras que en innovación se alcanzó el 39.8\% y en autoeficacia percibida se generó un $38.0 \%$, los cuales se encuentra por debajo del mínimo; los 


\section{Tabla 3}

Resultados de la Licenciatura en Comercio Internacional (LCI)

\begin{tabular}{|c|c|c|c|c|c|c|}
\hline Edad & & $\begin{array}{c}\text { Autoeficacia } \\
\text { percibida }\end{array}$ & Autonomía & Innovación & $\begin{array}{c}\text { Propensión } \\
\text { al riesgo }\end{array}$ & $\begin{array}{l}\text { Actitud hacia el } \\
\text { emprendimiento }\end{array}$ \\
\hline \multirow{4}{*}{$18-19$} & $\begin{array}{l}\text { Completamente } \\
\text { en desacuerdo }\end{array}$ & $8.5 \%$ & $19.4 \%$ & $6.5 \%$ & $6.9 \%$ & $12.9 \%$ \\
\hline & En desacuerdo & $16.6 \%$ & $26.7 \%$ & $19.8 \%$ & $16.4 \%$ & $17.0 \%$ \\
\hline & De acuerdo & $42.4 \%$ & $31.7 \%$ & $37.4 \%$ & $47.5 \%$ & $40.8 \%$ \\
\hline & Muy de acuerdo & $32.5 \%$ & $22.2 \%$ & $36.4 \%$ & $29.3 \%$ & $29.3 \%$ \\
\hline \multirow{4}{*}{$20-23$} & $\begin{array}{l}\text { Completamente } \\
\text { en desacuerdo }\end{array}$ & $8.8 \%$ & $16.0 \%$ & $5.7 \%$ & $6.4 \%$ & $11.4 \%$ \\
\hline & En desacuerdo & $20.9 \%$ & $30.5 \%$ & $20.9 \%$ & $22.4 \%$ & $22.0 \%$ \\
\hline & De acuerdo & $38.0 \%$ & $33.0 \%$ & $39.8 \%$ & $41.7 \%$ & $35.2 \%$ \\
\hline & Muy de acuerdo & $32.3 \%$ & $20.5 \%$ & $33.6 \%$ & $29.6 \%$ & $31.3 \%$ \\
\hline \multirow{4}{*}{$24-25$} & $\begin{array}{l}\text { Completamente } \\
\text { en desacuerdo }\end{array}$ & $5.0 \%$ & $11.7 \%$ & $5.8 \%$ & $7.5 \%$ & $15.0 \%$ \\
\hline & En desacuerdo & $21.7 \%$ & $27.5 \%$ & $18.3 \%$ & $17.5 \%$ & $11.7 \%$ \\
\hline & De acuerdo & $36.7 \%$ & $35.8 \%$ & $35.8 \%$ & $44.2 \%$ & $35.8 \%$ \\
\hline & Muy de acuerdo & $36.7 \%$ & $25.0 \%$ & $40.0 \%$ & $30.8 \%$ & $37.5 \%$ \\
\hline
\end{tabular}

Nota: Elaboración propia con base en el 30\% del total de alumnos por carrera (2019).

porcentajes más bajos se presentaron en actitud hacia el emprendimiento con un 35.2\% y en autonomía un 33.0\%.

En la categoría de 24 a 25 años, solo se cumplió con una de las cinco variables, propensión al riesgo con un 44.2\%. Mientras que en innovación se obtuvo un 39.8\%, en autoeficacia percibida un $36.7 \%$, en autonomía un $35.8 \%$ y en actitud hacia el emprendimiento un $35.2 \%$, porcentajes por debajo de lo esperado.

$\mathrm{Al}$ realizarse una comparación de los resultados obtenidos en ambas licenciaturas, se puede observar que la LRI cuenta con un mejor desarrollo de actitudes emprendedoras que los estudiantes de la LCI; sin embargo, en ambas destaca la falta de autonomía, pues ninguna obtuvo un porcentaje relevante en esta variable. 
Respecto a la comparación entre licenciaturas por edades, dentro de la categoría de 18 a 19 años, la LRI concentra una mayor cantidad de actitudes emprendedoras que la LCI. Sin embargo, los porcentajes obtenidos no tienen una gran diferencia y la variable con más área de oportunidad es la de autonomía. Por su parte, los resultados de los alumnos en la categoría de 20 a 23 años, en ambos programas no fueron alentadores, se asume que conforme se avanza en sus estudios, las actitudes emprendedoras van decreciendo. La variable menos desarrollada en ambas licenciaturas es autonomía.

En la categoría de 24 a 25 años, la LRI cumplió con tres de cinco variables y al LCI solo con una. Estos resultados son contrarios al argumento que supone que deberían tener un perfil de emprendedor completo debido al término de su formación.

\section{Hallazgos por semestre y licenciatura}

Para continuar con el estudio, también se evaluaron las variables de acuerdo con el semestre en cada una de las licenciaturas seleccionadas. Se tomó como resultado positivo el cumplimiento mínimo del $40 \%$ en la opción 3 (de acuerdo); si el resultado es inferior se toma como resultado negativo.

Si los alumnos de los diferentes semestres cumplen por lo menos con tres de las cinco variables, será un resultado prometedor; mientras que si cumple con menos de tres se considera desfavorable.

En la tabla 4 se presentan los resultados por semestre de la Licenciatura en Relaciones Industriales.

Respecto a las evaluaciones realizadas, se considera que los alumnos de primero y segundo semestre de la LRI cuentan con tres de las cinco variables correspondientes al perfil de un emprendedor, innovación con un 45.3\%, propensión al riesgo con un 49.5\% y actitud hacia el emprendimiento con un 47.0\%. Estas variables representan más del mínimo esperado, por lo cual es un resultado positivo, y se cuenta con un buen desarrollo de estas. Las variables con las cuales no cuentan el alumnado evaluado son: autoeficacia percibida con el $37.5 \%$ y autonomía con $32.6 \%$, porcentajes que se encuentran por debajo de lo mínimo esperado.

Los alumnos de tercero y cuarto semestre obtuvieron tres variables de cinco, autoeficacia percibida con $42.1 \%$, propensión al riesgo con un $46.4 \%$, y actitud hacia el emprendimiento con $40.3 \%$. Mientras que se observa carencia en dos variables, pues en autonomía se obtuvo un $28.5 \%$ y en innovación un 37.9\%. 


\section{Tabla 4}

Resultados por semestre de la Licenciatura en Relaciones Industriales (LRI)

\begin{tabular}{|c|c|c|c|c|c|c|}
\hline Semestre & & $\begin{array}{c}\text { Autoeficacia } \\
\text { percibida }\end{array}$ & Autonomía & Innovación & $\begin{array}{c}\text { Propensión } \\
\text { al riesgo }\end{array}$ & $\begin{array}{l}\text { Actitud hacia el } \\
\text { emprendimiento }\end{array}$ \\
\hline \multirow{4}{*}{$1-2$} & $\begin{array}{l}\text { Completamente } \\
\text { en desacuerdo }\end{array}$ & $12.6 \%$ & $20.7 \%$ & $9.1 \%$ & $7.0 \%$ & $13.0 \%$ \\
\hline & En desacuerdo & $17.9 \%$ & $31.2 \%$ & $17.2 \%$ & $16.5 \%$ & $20.7 \%$ \\
\hline & De acuerdo & $37.5 \%$ & $32.6 \%$ & $45.3 \%$ & $49.5 \%$ & $47.0 \%$ \\
\hline & Muy de acuerdo & $31.9 \%$ & $15.4 \%$ & $28.4 \%$ & $27.0 \%$ & $19.3 \%$ \\
\hline \multirow{4}{*}{$3-4$} & $\begin{array}{l}\text { Completamente } \\
\text { en desacuerdo }\end{array}$ & $9.1 \%$ & $20.3 \%$ & $9.7 \%$ & $3.0 \%$ & $11.2 \%$ \\
\hline & En desacuerdo & $18.2 \%$ & $27.0 \%$ & $19.1 \%$ & $26.7 \%$ & $22.4 \%$ \\
\hline & De acuerdo & $42.1 \%$ & $28.5 \%$ & $37.9 \%$ & $46.4 \%$ & $40.3 \%$ \\
\hline & Muy de acuerdo & $30.6 \%$ & $24.2 \%$ & $33.3 \%$ & $23.9 \%$ & $26.1 \%$ \\
\hline \multirow{4}{*}{$5-6$} & $\begin{array}{l}\text { Completamente } \\
\text { en desacuerdo }\end{array}$ & $10.9 \%$ & $16.5 \%$ & $6.0 \%$ & $4.9 \%$ & $10.5 \%$ \\
\hline & En desacuerdo & $21.4 \%$ & $37.9 \%$ & $21.1 \%$ & $22.1 \%$ & $23.5 \%$ \\
\hline & De acuerdo & $40.4 \%$ & $35.4 \%$ & $41.4 \%$ & $40.7 \%$ & $40.4 \%$ \\
\hline & Muy de acuerdo & $27.4 \%$ & $10.2 \%$ & $31.6 \%$ & $32.3 \%$ & $25.6 \%$ \\
\hline \multirow{4}{*}{$7-8$} & $\begin{array}{l}\text { Completamente } \\
\text { en desacuerdo }\end{array}$ & $10.5 \%$ & $21.9 \%$ & $4.5 \%$ & $5.2 \%$ & $15.7 \%$ \\
\hline & En desacuerdo & $21.9 \%$ & $31.7 \%$ & $27.1 \%$ & $25.7 \%$ & $19.0 \%$ \\
\hline & De acuerdo & $36.0 \%$ & $31.4 \%$ & $42.6 \%$ & $45.2 \%$ & $37.9 \%$ \\
\hline & Muy de acuerdo & $31.7 \%$ & $15.0 \%$ & $25.7 \%$ & $23.8 \%$ & $27.4 \%$ \\
\hline
\end{tabular}

Nota: Elaboración propia con base en el 30\% del total de alumnos por carrera (2019).

Por otra parte, los alumnos más destacados son los que pertenecen a la quinto y sexto semestre, ya que cuentan con cuatro de cinco actitudes emprendedoras: autoeficacia percibida con $40.4 \%$, innovación con $41.1 \%$, propensión al riesgo con $40.7 \%$, y actitud hacia el emprendimiento con 47.0\%. Mientras que sus resultados en autonomía son bajos con 37.9\%; sin embargo, se asume que son los alumnos que cumplen con las actitudes esperadas y con los mejores resultados de esta categoría y carrera. 
Por último, tenemos a los alumnos de séptimo y octavo semestre, los cuales cumplen con solo dos de las variables esperadas, innovación con $42.6 \%$ y propensión al riesgo con $45.2 \%$. Las variables que tuvieron un resultado negativo fueron: autoeficacia percibida con $36.0 \%$, autonomía con $31.4 \%$ y actitud hacia el emprendimiento $37.9 \%$; lo cual es un resultado negativo, pues revela una disminución de las actitudes emprendedoras cuando los alumnos están por culminar sus estudios universitarios.

En la tabla 5 se muestran los resultados por semestre de la Licenciatura en Comercio Internacional.

\section{Tabla 5}

Resultados por semestre de la Licenciatura en Comercio Internacional (LCI)

\begin{tabular}{|c|c|c|c|c|c|c|}
\hline Semestre & & $\begin{array}{l}\text { Eficiencia } \\
\text { percibida }\end{array}$ & Autonomía & Innovación & $\begin{array}{l}\text { Propensión } \\
\text { al riesgo }\end{array}$ & $\begin{array}{l}\text { Actitud hacia el } \\
\text { emprendimiento }\end{array}$ \\
\hline \multirow{4}{*}{$1-2$} & $\begin{array}{l}\text { Completamente } \\
\text { en desacuerdo }\end{array}$ & $4.4 \%$ & $5.6 \%$ & $1.1 \%$ & $3.3 \%$ & $7.8 \%$ \\
\hline & En desacuerdo & $15.6 \%$ & $18.9 \%$ & $30.0 \%$ & $23.3 \%$ & $18.9 \%$ \\
\hline & De acuerdo & $46.7 \%$ & $53.3 \%$ & $47.8 \%$ & $38.9 \%$ & $42.2 \%$ \\
\hline & Muy de acuerdo & $33.3 \%$ & $22.2 \%$ & $21.1 \%$ & $34.4 \%$ & $31.1 \%$ \\
\hline \multirow{4}{*}{$3-4$} & $\begin{array}{l}\text { Completamente } \\
\text { en desacuerdo }\end{array}$ & $8.6 \%$ & $17.9 \%$ & $6.5 \%$ & $7.0 \%$ & $13.0 \%$ \\
\hline & En desacuerdo & $19.6 \%$ & $29.9 \%$ & $20.1 \%$ & $19.6 \%$ & $19.2 \%$ \\
\hline & De acuerdo & $38.5 \%$ & $30.5 \%$ & $37.2 \%$ & $42.6 \%$ & $35.1 \%$ \\
\hline & Muy de acuerdo & $33.3 \%$ & $21.7 \%$ & $36.2 \%$ & $30.8 \%$ & $32.6 \%$ \\
\hline \multirow{4}{*}{$5-6$} & $\begin{array}{l}\text { Completamente } \\
\text { en desacuerdo }\end{array}$ & $7.5 \%$ & $11.8 \%$ & $3.9 \%$ & $7.8 \%$ & $12.5 \%$ \\
\hline & En desacuerdo & $22.0 \%$ & $31.4 \%$ & $23.1 \%$ & $22.0 \%$ & $25.5 \%$ \\
\hline & De acuerdo & $38.8 \%$ & $33.7 \%$ & $46.3 \%$ & $45.5 \%$ & $39.6 \%$ \\
\hline & Muy de acuerdo & $31.8 \%$ & $23.1 \%$ & $26.7 \%$ & $24.7 \%$ & $22.4 \%$ \\
\hline \multirow{4}{*}{$7-8$} & $\begin{array}{l}\text { Completamente } \\
\text { en desacuerdo }\end{array}$ & $8.9 \%$ & $15.6 \%$ & $5.7 \%$ & $3.8 \%$ & $6.7 \%$ \\
\hline & En desacuerdo & $21.3 \%$ & $27.0 \%$ & $16.5 \%$ & $24.1 \%$ & $21.9 \%$ \\
\hline & De acuerdo & $41.6 \%$ & $40.3 \%$ & $42.2 \%$ & $47.3 \%$ & $41.3 \%$ \\
\hline & Muy de acuerdo & $28.3 \%$ & $17.1 \%$ & $35.6 \%$ & $24.8 \%$ & $30.2 \%$ \\
\hline
\end{tabular}

Nota: Elaboración propia con base en el 30\% del total de alumnos por carrera (2019). 
Los alumnos de primero y segundo semestre, cuentan con resultados sumamente favorables, ya que poseen cuatro de cinco actitudes emprendedoras, obteniendo un porcentaje de $46.7 \%$ en autoeficacia percibida, en autonomía 53.3\%, en innovación $47.8 \%$ y en actitud hacia el emprendimiento $42.2 \%$. Estos valores sobrepasan del mínimo, esta categoría es la única que hasta ahora ha obtenido un puntaje alto en la variable de autonomía. En propensión al riesgo cuenta con 38.9\%, sin embargo, son resultados muy prometedores.

Ahora bien, los alumnos de tercero y cuarto semestre son desalentadores, ya que sus resultados fueron negativos en cuatro de las cinco variables; en autoeficacia percibida se obtuvo 38.5\%, en autonomía 30.5\%, en innovación 37.2\% y en actitud hacia el emprendimiento $35.1 \%$. La única variable con resultado positivo fue propensión al riesgo con $42.6 \%$.

Los alumnos de quinto y sexto semestre están aún por debajo de lo esperado, ya que solo cuentan con dos actitudes emprendedoras, innovación con $46.3 \%$ y propensión al riesgo $45.5 \%$, por lo que en general son resultados negativos. En autoeficacia percibida cuenta con $38.8 \%$, en autonomía $33.7 \%$, y en actitud hacia el emprendimiento $39.6 \%$, lo que genera desaliento, ya que son alumnos que se encuentran a mitad de su desarrollo académico y no han logrado un perfil emprendedor.

Por su parte, los alumnos de séptimo y octavo semestre tienen resultados importantes, ya que cuentan con cinco de cinco actitudes necesarias para ser emprendedores, y si saben explotarlas tendrán resultados óptimos.

Finalmente, al realizar un comparativo de estas dos licenciaturas se puede observar que la LRI tiene un mejor desempeño dentro de los semestres medios, ya que es cuando más desarrollo obtienen los alumnos dentro de las actitudes emprendedoras; sin embargo, también los alumnos de primero y segundo semestre cuentan con un perfil emprendedor que requiere refuerzo en las habilidades.

En el caso de LCI en los semestres medios tienen un desempeño muy bajo y necesitan tener un mejor perfeccionamiento de las actitudes emprendedoras; sin embargo, los alumnos de esta licenciatura, al iniciar sus estudios cuentan con un buen nivel de emprendimiento, y al culminarlos presentan el mismo escenario. Los resultados refieren que son sumamente eficientes y eficaces en su desarrollo, ya que consiguen egresar con un perfil completo. No obstante, cada una de estas licenciaturas obtiene un desempeño diferente en los semestres evaluados, por lo que ambas deben de perfeccionar su plan de estudios, para que todos los semestres logren destacar como emprendedores. 


\section{Conclusiones}

En México ha sido una constante el interés por el estudio del emprendimiento, considerado como un motor de innovación, competitividad y crecimiento; pero también como una vía para subsanar la escasez de empleo.

El desarrollo de actitudes emprendedoras es una prioridad para enfrentar la crisis económica, derivada del colapso de los mercados y del cierre de MIPYMES, las cuales representan el 99\% del total de las empresas del país (INEGI, 2019), y son la base de la economía mexicana.

En este sentido, la universidad debe ser consciente de los cambios que está viviendo el país e impulsar el emprendimiento. De tal forma que los egresados no tengan como visión ser empleados, sino que a través de una formación integral se conviertan en empleadores.

Respecto a los resultados del estudio presentado, el análisis comparativo de las dos licenciaturas establece diferencias significativas que pueden ser atribuibles al perfil de los docentes y al perfil de egreso de cada licenciatura. Por lo tanto, deben implementarse acciones para desarrollar las actitudes emprendedoras como parte de la formación del estudiante, no solo como un programa, sino como un proceso capaz de motivar y desarrollar competencias en los estudiantes, e impulsar el emprendimiento, la formación de empresarios y la creación de empresas.

Ahora bien, para ser una universidad emprendedora, se debe aceptar el cambio hacia una universidad abierta a la sociedad, con un modelo híbrido que incluya la enseñanza y la investigación aplicada vinculada con el sector productivo. Una universidad emprendedora busca satisfacer las necesidades de la sociedad y esto significa cambiar de paradigma; por lo tanto, la universidad debe vincularse con empresarios y gobierno para lograr un círculo virtuoso, pues hoy más que nunca, las regiones tienen el reto de consolidar su propio crecimiento y desarrollo económico a través de la generación de empleo.

\section{Referencias}

Arzubiaga, U., Iturralde, T., \& Maseda, A. (2012). La medición de la Orientación Emprendedora en las empresas familiares: una revisión crítica de la literatura. Revista de Empresa Familiar, 2(2), 57-71.

Canales, R. A., Román, Y. G., \& Ovando, W. (2017). Emprendimiento de la población joven en México. Una perspectiva crítica. Entreciencias: diálogos en la Sociedad del Conocimiento, 5(12). https://www.redalyc.org/jatsRepo/4576/457650040001/ html/index.html\#redalyc_457650040001_ref24 
Drucker, P. (1985). Innovation and Entrepreneurship. Harper and Row.

Eagly, A. H., \& Chaiken, S. (1993). The psychology of attitudes. Harcourt Brace Jovanovich College Publishers.

Fontaines-Ruiz, T., Palomo, M., Velásquez, M.V., \&Aguirre, M. (2016). Actitud emprendedora: ¿Qué es? ¿De qué se compone? Ágora de heterodoxies, 2(3), 19-36.

Formichella, M. (2004). El concepto de emprendimiento y su relación con la educación, el empleo y el desarrollo local. https://www.t-educa.cl/descargas/pdfs_portal/ emprendimiento/emprendydesarrollolocal.pdf

Hidalgo, L. (2014). La cultura del emprendimiento y su formación. Revista Alternativas $U C S G, 15(1), 46-50$.

Instituto Nacional de Estadística y Geografía (INEGI). (2014). Encuesta Nacional de Ocupación y Empleo (ENOE).

Instituto Nacional de Estadística y Geografía (INEGI). (2019). Datos. Empresas y establecimientos. https://www.inegi.org.mx/datos/.

Instituto Mexicano para la Competitividad (IMCO). (2009). Desarrollando las PYMES que requiere México. https://imco.org.mx/pymes_que_requiere_mexico_2009/

Judd, C. M., Drake, R. A., Downing, J. W., \& Krosnick, J. A. (1991). Some dynamic properties of attitude structures: Context-induced response facilitation and polarization.Journal of Personality and Social Psychology, 60(2), 193-202. https://doi.org/10.1037/00223514.60.2.193

Miner, J. (1997). A psychological typology of successful entrepreneurs. Quorom Books.

Montoya, J., Correa, G., \& Mejía, L. (2009). Emprendimiento: visiones desde las teorías del comportamiento humano. Revista Escuela de Administración de Negocios, 66, 153168. https://www.redalyc.org/pdf/206/20620269008.pdf

Montufar, A. (2018). Análisis de perfiles de actitudes relacionadas con el emprendimiento (Trabajo de Maestría). Universidad Nacional Autónoma de México, México.

Rosenberg, J., \& Hovland, I. (1960). Cognitive, affective and behavioral components of attitudes', Attitude organization and change. Yale University Press.

Shaver, K. (2004). Overview: The cognitive characteristics of the entrepreneur. In W. Gartner, K. Shaver, N. Carter, \& P. Reynolds (Eds.), Handbook of entrepreneurial dynamics (pp. 131-137). Sage Publications.

Staats, A. W., \& Staats, C. K. (1958). Attitudes established by classical conditioning. Journal of Abnormal and Social Psychology, 57, 37-40. 
Stevenson, H., \& Jarillo, J. (1990). A Paradigm of Entrepreneurship: Entrepreneurial Management. Strategic Management Journal,11,17-27.

Timmons, J. A. (1997). Opportunity Recognition. In W. D. Bygrave, \& A. Zacharakis (Eds.), The Portable MBA in Entrepreneurship. Wiley.

Universidad de Guanajuato (UG). (2014). Programa de emprendedores. https://www.ugto. $\mathrm{mx} / 161$-programas-y-servicios-de-vinculacion/573-programa-de-emprendedores Universidad de Guanajuato (UG). (2016). Modelo Educativo de la Universidad de Guanajuato y sus Modelos Académicos. https://www.ugto.mx/profesores/modelo-educativo Villacis, J. F., Méndez, J. C., \& Méndez, M. A. (2018). Actitud emprendedora: motor de liderazgo e innovación. Revista Contribuciones a la Economía. https://www.eumed. net/rev/ce/2018/1/actitud-emprendedora.html 


\section{Anexo 1}

\section{Cuestionario}

A continuación, hallará algunos enunciados que establecen situaciones reales o hipotéticas.

Marque con una X solo una de las cuatro opciones por cada enunciado, aquella que usted considere como la indicada.

No existen respuestas correctas o incorrectas, estas solo reflejan su opinión.

Si no puede contestar una pregunta o si la pregunta no tiene sentido para usted, pregunte a la persona que le estregó este cuestionario.

Sus respuestas serán anónimas y absolutamente confidenciales. En ningún momento se le pide su nombre.

Edad: Sexo: Carrera:

Claves: 4: Muy de acuerdo 3: De acuerdo 2: En desacuerdo 1: Completamente en desacuerdo.

\begin{tabular}{|c|c|c|c|c|}
\hline & Ítems & 1 & 2 & 3 \\
\hline 1 & Creo que puedo proponerme metas y conseguirlas. & & & \\
\hline 2 & "Si no vas a hacer bien algo, mejor no lo hagas" es una frase que me define. & & & \\
\hline 3 & Tarde o temprano alcanzare las metas que me he propuesto. & & & \\
\hline 4 & $\begin{array}{l}\text { Creo que las únicas tareas que deben completarse son aquellas que requieren poco } \\
\text { esfuerzo. }\end{array}$ & & & \\
\hline 5 & Creo firmemente que, si alguien se propone hacer algo, debe terminarlo. & & & \\
\hline 6 & Me gusta iniciar proyectos y terminarlos. & & & \\
\hline 7 & Si finalizo algo, es más bien por temor a las consecuencias de no haberlo acabado. & & & \\
\hline 8 & Prefiero entregar o finalizar mis tareas antes del pazo establecido. & & & \\
\hline 9 & Conseguir los resultados en tiempo y forma es algo que me motiva demasiado. & & & \\
\hline 10 & Las acciones que llevo a cabo cumplen los objetivos que me había propuesto. & & & \\
\hline 11 & Hago aportaciones cuando tengo la oportunidad de hacerlo. & & & \\
\hline 12 & $\begin{array}{l}\text { Si voy a emprender alguna acción, es porque voy a terminarla, y no a dejarla a } \\
\text { medias. }\end{array}$ & & & \\
\hline 13 & $\begin{array}{l}\text { A los primeros intentos de completar una tarea, si no lo consigo, comienzo mejor } \\
\text { con otra actividad. }\end{array}$ & & & \\
\hline 14 & Las acciones que llevo a cabo tienen por objetivo ser el mejor en mis intereses. & & & \\
\hline 15 & Soy mejor resolviendo problemas solo que en equipo. & & & \\
\hline 16 & $\begin{array}{l}\text { Considero que la autonomía en el trabajo o en el estudio es de vital importancia } \\
\text { para cumplir con los objetivos. }\end{array}$ & & & \\
\hline 17 & $\begin{array}{l}\text { Creo que es mejor no estar en posición de tomar decisiones, ya que así uno evita } \\
\text { equivocarse. }\end{array}$ & & & \\
\hline
\end{tabular}




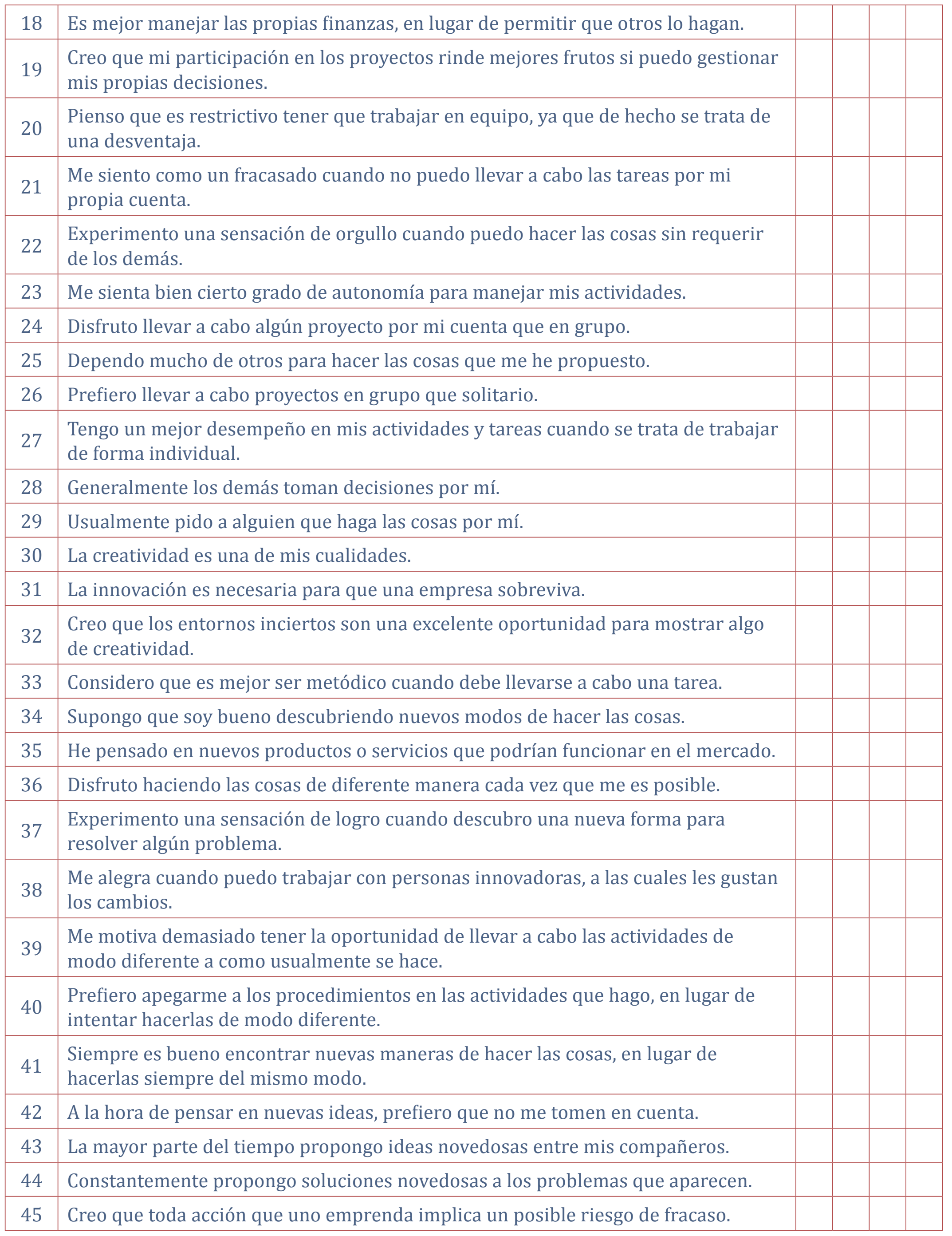




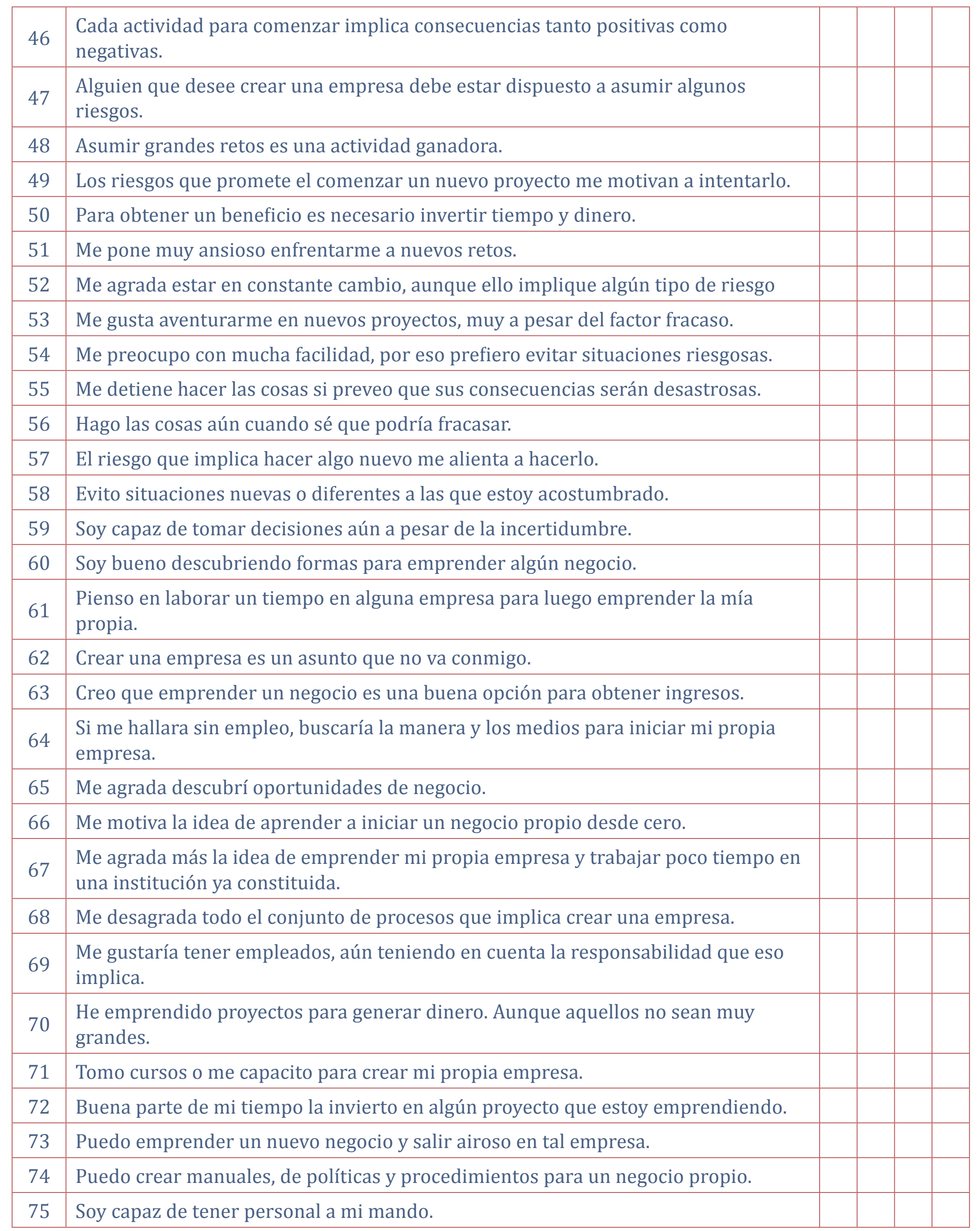




\section{Acerca de los autores}

\section{Adriana Fragoso Mora}

Maestra en Administración por la Universidad de Guanajuato; Doctorante del Programa de Posgrado en Administración y Estudios Organizacionales de la Universidad de La Salle Bajío; Profesora en Instituciones Públicas y Privadas de Educación Superior desde el 2009. Docente con reconocimiento al Perfil Prodep Deseable (SEP) dentro de la Academia de Ingeniería en Gestión Empresarial. Responsable del Cuerpo Académico Gestión y Competitividad Empresarial en el Instituto Tecnológico de Purísima del Rincón. Líneas de investigación: Competitividad Empresarial con proyectos de Emprendimiento y Gestión de Nuevos Negocios, Empleabilidad a partir de Inteligencia Artificial, Gestión Estratégica del Talento Humano, Evaluación al Desempeño Gerencial mediante KPI's estratégicos. Aplicación de Normas Oficiales Mexicanas en el Sector Empresarial, Gubernamental e Instituciones de Educación Superior. Miembro de la Red de Estudios Latinoamericanos en Administración y Negocios (RELAYN).

Correo electrónico: adriana.fm@purisima.tecnm.mx

\section{Ma. Eugenia Sánchez Ramos}

Diseñadora Gráfica de profesión, Maestra en Artes Visuales por la Universidad Nacional Autónoma de México. Doctora en Arquitectura, Diseño y Urbanismo por la Universidad Autónoma del Estado de Morelos. Profesora de Tiempo Completo en la División de Ciencias Económico Administrativas, Departamento de Estudios Organizacionales, Universidad de Guanajuato. Docente con reconocimiento al Perfil Prodep Deseable (SEP). Líder del Cuerpo Académico Consolidado Diseño y Cultura desde 2019. Consultora Experta en Sector Empresarial, Gubernamental e Instituciones de Educación Superior. Líneas de investigación: Emprendimiento universitario, Género y Trabajo, Ergonomía y Estudios de Divulgación Científica.

Correo electrónico: sanchez.me@ugto.mx 


\section{Tomás Oliva Ramos}

Ingeniero Ambiental por la Universidad de Guanajuato y Maestro en Ingeniería Administrativa y Calidad por la Universidad de La Salle Bajío. Docente con reconocimiento al Perfil Prodep Deseable (SEP) dentro de la Academia de Ingeniería en Gestión y Empresarial. Miembro del Cuerpo Académico Gestión y Competitividad Empresarial en el Instituto Tecnológico de Purísima del Rincón. Catedrático de cursos de Estadística y Planes de Negocio. Mentor del programa de emprendimiento en la Academia de Ingeniería en Gestión Empresarial del Instituto Tecnológico Superior de Purísima del Rincón desde el 2018. Coautor del libro Arduino y Android: Proyectos wearable para smart watches, smart tv y dispositivos móviles (2019). Más de 5 años de experiencia en la gestión de invenciones ante el Instituto Mexicano de la Propiedad Industrial. Desde 2018, colabora como revisor de contenidos técnicos de libros tecnológicos.

Correo electrónico: tomas.or@purisima.tecnm.mx

\section{Laura Elena Zárate Negrete}

Licenciada en Relaciones Industriales y Maestra en Desarrollo Organizacional y Administración de Personal por la Universidad de Guanajuato, Doctora en Desarrollo Humano. Profesora de Tiempo Completo División de Ciencias Económico Administrativas, Departamento de Estudios Organizacionales, Universidad de Guanajuato. Docente con reconocimiento al Perfil Prodep Deseable (SEP). Miembro del Cuerpo Académico Consolidado Diseño y Cultura. Líneas de investigación: Emprendimiento universitario, Género y Trabajo. Miembro del Sistema Nacional de Investigadores SNI desde 2020. Consultora Experta en Sector Empresarial, Gubernamental e Instituciones de Educación Superior. Correo electrónico: lezarate@ugto. 


\section{Rosalba Pérez Márquez}

Contadora Pública por la Universidad de León y Maestra en Finanzas Corporativas por la Universidad de La Salle Bajío; Docente de Tiempo Completo de la Academia de Ingeniería en Gestión y Empresarial. Miembro del Cuerpo Académico Gestión y Competitividad Empresarial en el Instituto Tecnológico de Purísima del Rincón. Línea de investigación: Gestión y Competitividad Empresarial con proyectos de Vinculación, Análisis Financiero en las MiPymes y proyectos Tecnológicos. Socia del Colegio de Contadores Públicos de León (CCPL) y del Colegio de Contadores Públicos de San Francisco del Rincón (CCPSF). Correo electrónico: rosalba.pm@purisima.tecnm.mx

\section{Alba Edith Elías Chávez}

Licenciada en Ciencias y Técnicas de la comunicación y Maestra en Mercadotecnia por la Universidad del Valle de Atemajac. Maestra en Innovación de Negocios, Servicios y Experiencias por la ICON University. Docente en la Academia de Ingeniería en Gestión Empresarial. Mentora de Emprendimiento y Emprendedora de Start up en el ámbito de la tecnología. Con experiencia en E-Commerce, Marketing Digital y Publicidad. Experta en análisis de mercado, previsión y valoración de necesidades del cliente, estrategias de marketing, detección y monetización de necesidades del consumidor y desarrollo de nuevos mercados.

Correo electrónico: alba.ec@purisima.tecnm.mx 
Qartuppi, S. de R.L. de C.V. está inscrita de forma definitiva

en el Registro Nacional de Instituciones y Empresas Científicas y Tecnológicas (RENIECYT) con el número 1600052.

Qartuppi, S. de R.L. de C.V. es miembro activo

de la Cámara Nacional de la Industria Editorial Mexicana (CANIEM)

con número de registro 3751 .

Actitud emprendedora

en Instituciones de Educación Superior de Guanajuato

Esta obra se terminó de producir en mayo de 2021.

Su edición y diseño estuvieron a cargo de:

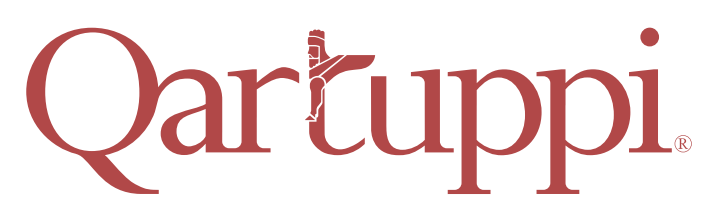

Qartuppi, S. de R.L. de C.V.

http://www.qartuppi.com 


\section{(c) (i) (2)}

Esta obra se edita bajo una Licencia Creative Commons

Atribución-NoComercial-CompartirIgual 4.0 Internacional. 
El emprendimiento es necesario para el crecimiento económico y, por lo tanto, representa un pilar que requiere impulso y fortalecimiento de competencias tanto en la educación como en las organizaciones. Esta publicación expone experiencias en la industria y en instituciones educativas, las cuales se orientan a compartir estrategias para el desarrollo del perfil emprendedor en diversos sectores sociales; por otro lado, con base en los resultados obtenidos de las investigaciones establece la relación e importancia del apoyo gubernamental y las instancias privadas, así como de la cooperación social en la proliferación y permanencia de las empresas.

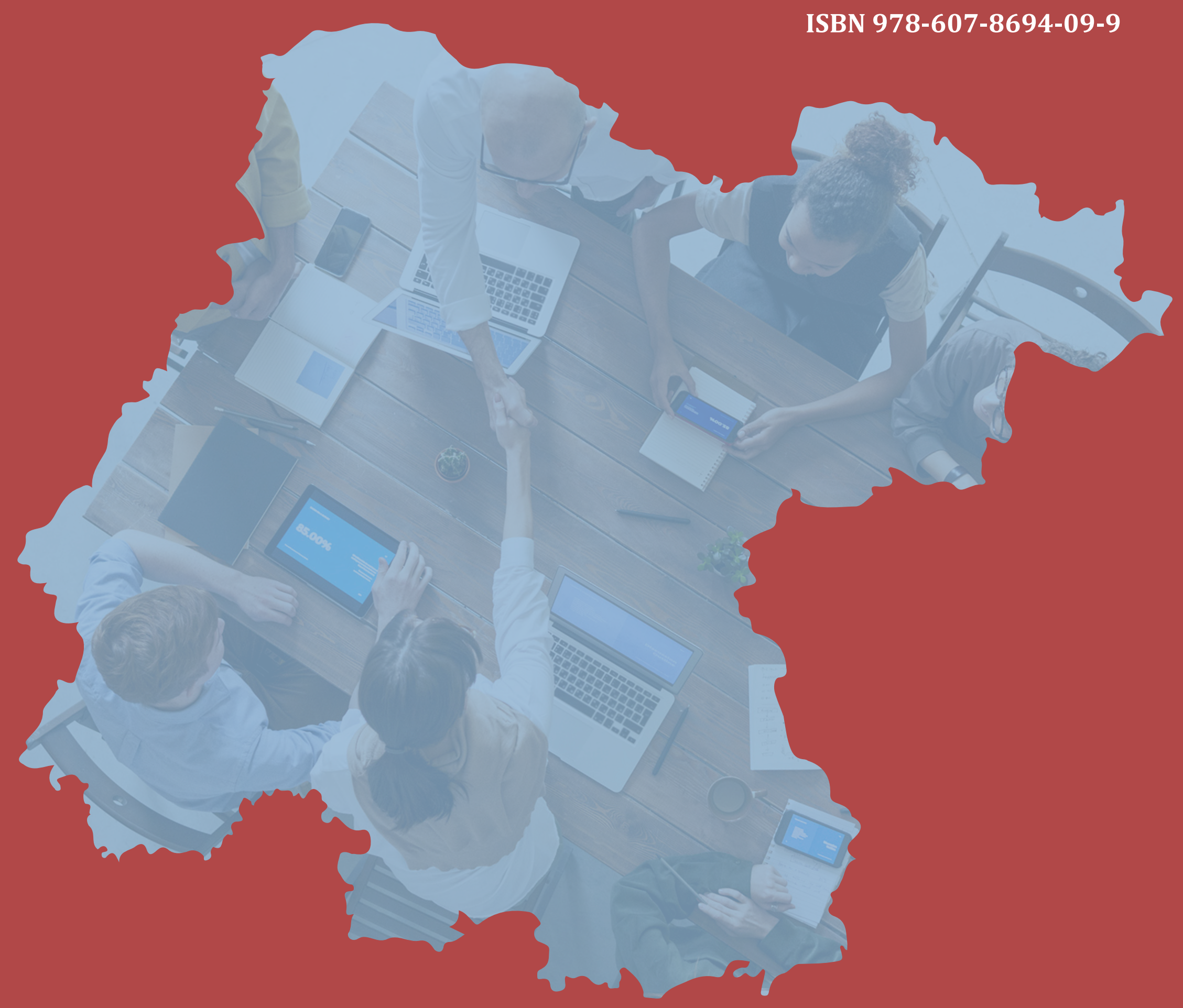

\section{Qartuppi}

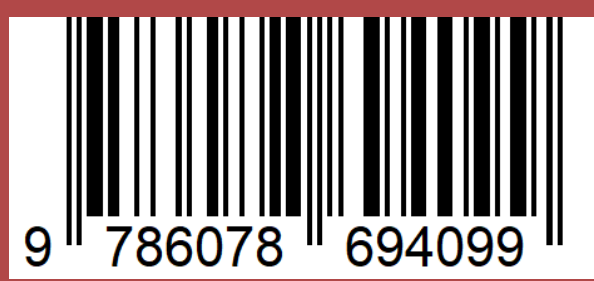

